Human Evolution

Elsevier Editorial System(tm) for Journal of

Manuscript Draft

Manuscript Number: HUMEV-E-17-00531R2

Title: Oldowan technological behaviour at HWK EE (Olduvai Gorge, Tanzania

Article Type: SI: Oldowan-Acheulean

Keywords: Early Pleistocene; Early Stone Age; lithic technology; knapping skill; stone tool reduction sequence; Acheulean origins

Corresponding Author: Professor Ignacio de la Torre, PhD

Corresponding Author's Institution: University College London

First Author: Ignacio de la Torre, PhD

Order of Authors: Ignacio de la Torre, PhD; Rafael Mora, PhD

Abstract: HWK EE (Olduvai Gorge, Tanzania) is a late Oldowan site dated to $\sim 1.7 \mathrm{Ma}$ that contains a large fossil and lithic assemblage. This paper reports on the technology of the recently excavated stone tool collection, over 18,000 pieces. Our results indicate that reduction sequences were generally short, flaking productivity was low, and knapping methods were largely simple and expedient, lacking the technical skills observed in other Oldowan assemblages. Conspicuous differences are observed in the chaînes opératoires of the three main raw materials used at HWK EE: the quartzite reduction sequence can be reconstructed in full at the site, most of the lava detached pieces are missing, and there is a preferential use of chert for retouched tools. This portrays a composite picture, where knapping expediency and low productivity are accompanied by raw material selectivity and consistent presence of retouched artefacts. Coexistence of these features in the same assemblage leads us to question the monolithic structure of the Oldowan techno-complex, and highlights the kaleidoscopic nature of technological strategies at olduvai immediately before the earliest Acheulean handaxes appear in the sequence. 


\title{
Oldowan technological behaviour at HWK EE (Olduvai Gorge, Tanzania)
}

\author{
Ignacio de la Torre ${ }^{1 *} \&$ Rafael Mora ${ }^{2}$
}

${ }^{1}$ Institute of Archaeology, University College London, 31-34 Gordon Square, WC1H OPY London, United Kingdom

${ }^{2}$ Centre d'Estudis del Patrimoni Arqueologic de la Prehistoria, Facultat de Lletres, Universitat Autonoma de Barcelona, 08193 Bellaterra, Spain

* Corresponding author: i.torre@ucl.ac.uk

\begin{abstract}
HWK EE (Olduvai Gorge, Tanzania) is a late Oldowan site dated to 1.7 Ma that contains a large fossil and lithic assemblage. This paper reports on the technology of the recently excavated stone tool collection, over 18,000 pieces. Our results indicate that reduction sequences were generally short, flaking productivity was low, and knapping methods were largely simple and expedient, lacking the technical skills observed in other Oldowan assemblages. Conspicuous differences are observed in the chaînes opératoires of the three main raw materials used at HWK EE: the quartzite reduction sequence can be reconstructed in full at the site, most of the lava detached pieces are missing, and there is a preferential use of chert for retouched tools. This portrays a composite picture, where knapping expediency and low productivity are accompanied by raw material selectivity and consistent presence of retouched artefacts. Coexistence of these features in the same assemblage leads us to question the monolithic structure of the Oldowan techno-complex, and highlights the kaleidoscopic nature of technological strategies at Olduvai immediately before the earliest Acheulean handaxes appear in the sequence.
\end{abstract}

Keywords: Early Pleistocene; Early Stone Age; lithic technology; knapping skill; stone tool reduction sequence; Acheulean origins 


\section{Introduction}

Recent years have witnessed considerable progress in our understanding of Oldowan technology in eastern Africa, with a growing number of studies on skill (Delagnes and Roche, 2005; Stout et al, 2010; de la Torre, 2004; Toth and Schick, 2009; Semaw, 2000; Barsky et al., 2011), raw material procurement and economy (Rogers et al., 1994; Stout et al., 2005; Braun et al., 2008, 2009; Blumenschine et al., 2008, 2012; Harmand, 2009; Goldman-Neuman and Hovers, 2012; Reti, 2016), diachronic trends (Kimura, 1999; 2002; de la Torre and Mora, 2005), and even stone-tool function (Lemorini et al., 2014). Most of these studies agree on the existence of a certain level of technological complexity during the Oldowan, which is thought now to have included awareness of the differential quality of raw materials, rock type selectivity, (some degree of) procurement planning, adaptability (to landscape variations, raw material distance and particularities of each raw material), technical know-how and relatively efficient flaking skills.

While the onset of the Oldowan sensu stricto is well established at 2.6 Ma (Semaw et al., 2003) in eastern Africa, less agreement exists on the extent that technological variability may be embedded in this techno-complex (e.g., Delagnes and Roche, 2005; Rogers and Semaw, 2009; Stout et al., 2010) and, particularly, when it ended/was replaced by the Acheulean. This latter issue has been debated since Mary Leakey's (1971) seminal work at Olduvai Gorge and her identification of evolving stages within the Oldowan (see recent reviews by de la Torre and Mora, 2005, 2014; Semaw et al., 2009; Proffitt, 2018). While so-called Developed Oldowan assemblages are still reported elsewhere (Texier et al., 2006; Braun et al., 2008b), the abundance of assemblages spanning the Oldowan-Acheulean boundary in Bed II makes Olduvai highly relevant for the study of late Oldowan technology in eastern Africa.

Here we present the assemblage from HWK EE, one of the Olduvai sites that may contribute to the discussion surrounding the end of the Oldowan in eastern Africa. Located in the southeast of the Junction Area at Olduvai Gorge (see Figure 1A), HWK EE was originally excavated by Mary Leakey in the early 1970s, but she never published the assemblage. In 2008, the Olduvai Geochronology Archaeology Project (OGAP) commenced analysis of the large collection unearthed by Leakey (see details in Pante and de la Torre, 2018), and between 2009 and 2014 OGAP conducted intensive fieldwork at the site.

The HWK EE archaeological assemblage is positioned in the stratigraphic transition from Lower to Middle Bed II (de la Torre et al., 2018) and, according to recent chrono-stratigraphic correlations (McHenry and Stanistreet, 2018; Stanistreet et al., 2018), precedes the appearance of the earliest handaxes at Olduvai. OGAP excavations at HWK EE have revealed a substantial fossil and lithic assemblage which, as far as the stone tool collection is concerned, is one of the largest at Olduvai (and elsewhere in the world) for the time period under study, 1.7 Ma. An account of the archaeostratigraphy, paleoenvironments and site formation processes of HWK EE is presented elsewhere (de la Torre et al., 2018), and accompanying papers report on the zooarchaeology (Pante et al., 2018) and mammalian paleoecology (Rivals et al., 2018) of the site.

This paper will focus on the stone tool assemblage excavated by OGAP, with particular emphasis on the technological aspects of the collection. Given the existence of several archaeological units, the remarkably large size and good preservation of the lithic assemblage, and its stratigraphic position just before the appearance of handaxes in the Olduvai sequence, HWK EE presents an excellent opportunity to contribute to several aspects currently under discussion in Oldowan research. Are 
there temporal patterns in the technology across the main stratigraphic intervals of the site? Is there a differential management of artefacts according to raw materials? Are reduction sequences complete at the site or can transport of particular elements of the chaine opératoire be inferred? What technical skills are involved in core flaking and tool production? Is HWK EE technology identical to that of the classic Oldowan sites, or are there divergences that qualify its differentiation? These are among the main research questions addressed in this paper, which aims to make the remarkably large and well-preserved assemblage of HWK EE a reference point at Olduvai and elsewhere for the understanding of hominin technological strategies during late Oldowan times in eastern Africa.

\section{Materials and methods}

\section{Materials}

OGAP excavations at HWK EE recovered 22,446 lithics, of which 4339 were classified as unmodified. The lithic assemblage was excavated from four trenches: T1-Main Trench (Figure 1C), which is adjacent to the trench excavated by Mary Leakey in the 1970s, and T27, T28 and T29, which are smaller satellite trenches dug to the west of the Leakey trench (see Figure 1B). Details on the archaeo-stratigraphy and site contexts of HWK EE are presented in an accompanying paper by de la Torre et al. (2018), which also discusses the unmodified lithics, taphonomic aspects and size patterns of stone tools and fossils. Other relevant aspects of the HWK EE lithic collection, such as raw materials (McHenry and de la Torre, 2018), battered tools (Arroyo and de la Torre, 2018), as well as the Leakey collection (Pante and de la Torre, 2018), are also presented separately.

The current paper focuses on the technological aspects of the OGAP stone tool collection, which amounts to 18,107 artefacts weighing $456.3 \mathrm{~kg}$. The assemblage was collected from twenty-five distinct archaeological units across the four excavated trenches, grouped in Table 1 according to the main stratigraphic interval to which they belong; from the bottom up, such intervals are termed Lemuta, Lower Augitic Sandstone (LAS) and Tuff IIB (Figure 1D). Details on the trench-to-trench stratigraphic correlation of archaeological units and intervals are discussed by de la Torre et al. (2018), and the chrono-stratigraphic position of the sedimentary sequence is presented elsewhere (McHenry and Stanistreet, 2018; Stanistreet et al., 2018). In this paper, comparisons will use the stratigraphic interval as the unit of analysis, with emphasis on the two main intervals, namely Lemuta ( $n=5954$ artefacts; $87.5 \mathrm{~kg}$ ) and LAS ( $n=11,880 ; 346.9 \mathrm{~kg}$; see Table 1). We chose the stratigraphic interval -rather than the archaeological level- as the unit of analysis to: (1) make our study comparable to that of the HWK EE assemblage excavated by M. Leakey, where she did not distinguish archaeological levels and recorded all material according to their position into two separate stratigraphic intervals (see details in Pante and de la Torre, 2018); (2) overcome taphonomic limitations in the definition of archaeological levels, which in HWK EE have been shown to respond to palimpsests where some inter-level admixture occurs (de la Torre et al., 2018); (3) apply to the lithic assemblage the same scale of analysis as do the zooarchaeological (Pante et al., 2018) and the isotope and use-wear (Rivals et al., 2018) studies of the HWK EE collection, so that a consistent view of behavioural and paleoecological data is presented.

\section{Methods}

All artefacts $(n=18,107)$ were measured and weighed, and ascribed to a raw material group and technological category. Artefacts were measured with callipers according to the maximal length, independent of the technological axis. Raw material classification follows geochemical and petrographic identifications by McHenry and de la Torre (2018). Our analysis includes both the petrological identification of each individual raw material (e.g., phonolite, trachyte-trachyandesite, 
basalt, quartzite, pegmatite), and more general groups (e.g., lava, metamorphic) to facilitate comparisons. Experimental flaking of local rocks informed our characterization of raw materials and knapping methods documented at HWK EE. The technological analysis presented here was based on the macroscopic features of artefacts, while microscopic aspects are discussed elsewhere (Arroyo and de la Torre, 2018).

General technological groups were classified according to Isaac et al.'s (1997) distinction between detached, flaked and pounded artefacts. The analysis of detached artefacts followed criteria established by Toth (1982) and Mora et al. (1991), although directionality and counts of dorsal scars were not considered due to ambiguity of some technological features on HWK EE flakes (see methodological discussion in Proffitt and de la Torre, 2014). Cutting edges (considering as such those that visually presented a sharp edge) of all flakes and flake fragments were measured with a diameter tape. Flaked artefacts include cores, retouched artefacts and split cobbles. Analysis of core knapping schemes is based on the interaction between flaking surfaces, angles and directionality, as detailed in de la Torre (2011), and expanded in Figure 2.

Retouched tools were analysed following a simplified version of Laplace's (1972) proposal. Given the taphonomic problems associated with the creation of "pseudo-retouch" (i.e., unintentional chipping of edges produced by use, trampling, sediment pressure or fluvial disturbance), which have been observed in other Olduvai assemblages (de la Torre and Mora, 2005), we followed a conservative approach in the identification of retouched artefacts. It is therefore possible that frequencies of retouched tools, especially chert, are slightly underreported in the results presented below.

Analysis of pounded tools follows typological and technological criteria defined by Leakey (1971), Chavaillon (1979) and Mora and de la Torre (2005). Here we summarily introduce their technological features, while more detailed aspects and a microscopic study of HWK EE pounded tools is presented elsewhere (Arroyo and de la Torre, 2018).

Results are presented by main technological categories, and compare the three stratigraphic intervals (Lemuta, LAS and Tuff IIB) and main raw material groups (lavas, metamorphic rocks and chert). Statistical comparisons of non-parametric data included the Pearson's chi-squared test, Fisher's exact test, and correspondence factor analysis.

\section{Results}

\section{Assemblage composition}

The HWK EE stone tool collection is numerically dominated by detached pieces ( $n=16,535)$, which constitute $91.2 \%$ of the entire assemblage (Table 2). There is a slight variation in the relative frequencies per interval, with the highest percentage of detached pieces in Lemuta, followed by LAS and Tuff IIB (see frequencies in Table 2 and Figure 3A). Most detached pieces are metamorphic $(n=15,625)$, essentially quartzite (see Table 3 and Figure 3B).

Trends in number of artefacts are not matched by the actual contribution of each technological group to the total number of kilograms used by hominins at the site. Weighing over $292 \mathrm{~kg}$, flaked artefacts make the largest contribution to the sample (64.1\%), followed by pounded tools (over 107 $\mathrm{kg}$; 23.6\%) (Table 2). While a lower contribution of detached pieces to the overall weight would always be expected, mass patterns highlight an acute overrepresentation of lava flaked artefacts. As shown in Table 3, the overall weight contribution of flaked lavas $(198.6 \mathrm{~kg})$ is more than twice that of flaked metamorphic rocks $(92.5 \mathrm{~kg})$. This contrasts starkly not only with trends in the number of detached pieces (see above), but also with their overall weight contribution per rock type (41.2 kg of 
detached metamorphics versus $14.1 \mathrm{~kg}$ of detached lavas) (Table 3). Given that most flaked artefacts are cores (i.e. the source of detached pieces), the overabundance of lava versus metamorphic cores is further intensified when added to the severe deficit of lava versus metamorphic detached pieces (Figure 3D). In addition, weight patterns exacerbate the predominance of the LAS assemblage (with nearly $347 \mathrm{~kg}$ ) over the Lemuta $(87.5 \mathrm{~kg}$ ) and Tuff IIB (21.9 kg) intervals (Table 2$)$.

Chi-squared results of artefact categories per interval strongly support differences between the stratigraphic assemblages $\left(X^{2}(28)=1415.51, p<0.0001\right)$. Overall, stratigraphic interval patterns show a decrease in detached fragments from Lemuta to Tuff IIB, accompanied by a reverse trend in relative frequencies of cores and whole flakes, which are progressively more abundant (Figure $3 \mathrm{~A}$ ). Correspondence factor analysis (CFA) highlights an association of small detached pieces and fragmented retouched tools in the Lemuta interval, a relatively higher frequency of subspheroids and other pounded artefacts in the Tuff IIB interval, and of most of the other technological categories in LAS (Figure 3E). With refence to raw material patterns, the Chi-square test suggests a strong association between particular rock types and technological categories $\left(X^{2}(28)=6995.24, p\right.$ $<0.0001$ ), and Figure 3F supports the predominance of lava cores. Lava is also associated with most battered tools apart from anvils and subspheroids. These latter two are linked to metamorphic rocks, alongside most other categories apart from retouched tools (which are more strongly associated with chert; see Figure 3F).

\section{Detached pieces}

Shatter under $20 \mathrm{~mm}$ is the most abundant category (61.4\% of the whole HWK EE collection) within the group of detached pieces (Table 2). Size patterns and taphonomic signatures of lithic debris at HWK EE have been discussed in detail elsewhere (de la Torre et al., 2018), so here we focus on the technological implications. The number of lava fragments smaller than $20 \mathrm{~mm}$ is negligible $(n=66)$, particularly when compared to metamorphic fragments ( $n=15,625$; Table 3$)$. The chert sample is also very small $(n=106)$ but is more proportional to the marginal role of chert across all other categories apart from retouched tools.

Metamorphic rocks also dominate shatter larger than $20 \mathrm{~mm}$ and flake fragment categories, and representation of lavas is again negligible (see counts in Table 3). Quartzite shatter at HWK EE is often atypical of conchoidal fracture, being characterised instead by a lack of sharp edges and a 'chunky', cuboidal shape (Figure 4B). The absence of cutting edges could partially be explained by taphonomic factors given that, as discussed elsewhere (de la Torre et al., 2018), post-depositional fracturing is observed in part of the HWK EE assemblage (see also Figure 4A). However, there are also abundant pieces which are fresh and yet present such cuboidal morphology. These cuboids are common among debris under $20 \mathrm{~mm}$ as well, which initially could lead one to link such morphologies with the original shape of individual quartz crystals. However, such 'chunky' fragments are often larger than any quartz crystals forming quartzite aggregates, and hence seem to respond to the specific motions used by HWK EE hominins to fracture rocks.

The role of knapping accidents in the fragmentation of the HWK EE debitage products is difficult to assess. This is due largely to the brittle features of the Olduvai quartzite, which often make it problematic to distinguish between inadequate strikes by the knapper and the particular fracturing mechanisms of this crystalline rock (Jones, 1994; Proffitt and de la Torre, 2014). This could explain in part the very low frequency of clear hinge/step fractures identified $(n=13)$. However, even Siret flakes (i.e., split fragments caused by excessive striking force), which are probably the easiest to identify and attribute to knapping error, were documented only occasionally ( $n=72$ Siret flakes; $2.3 \%$ of the total flake fragments). 
Whole flakes ( $n=1368)$ make up $7.6 \%$ of the entire stone tool assemblage and are, after small shatter and flake fragments, the third most abundant category of the HWK EE collection (Table 2). Weighing $21.9 \mathrm{~kg}$, whole flakes make the largest contribution (4.8\%) within the group of detached pieces to the weight of the overall stone tool assemblage. Although in absolute terms metamorphic flakes $(n=1084)$ are much more abundant than lava $(n=229)$ and chert $(n=54)$ flakes (see details in Table 3$)$, relative frequencies of whole flakes per raw material are higher in the latter two than in metamorphic rocks (Figure 3B).

Figure $5 \mathrm{E}$ and Figure $5 \mathrm{~F}$ show that most whole flakes measure between 20 and $40 \mathrm{~mm}$ in length and width, with an average of 31 and $22.7 \mathrm{~mm}$, respectively (see Table 4). Nonetheless, there is significant variation within the sample, with some flakes measuring nearly $100 \mathrm{~mm}$ in length, and others as small as $5 \mathrm{~mm}$ (Table 4). Some whole flakes under $20 \mathrm{~mm}$ are probably too small to be considered intentional knapping products and, either way, they are too few (see Figure 5E-F) to statistically alter size trends that cluster HWK EE flakes in the $20-40 \mathrm{~mm}$ range, and which yield an average weight of $16 \mathrm{~g}$ (Table 4).

Although whole flakes are slightly bigger in Tuff IIB (see Table 4; Figure 5A and 5C; Figure 6A and 6C), average flake dimensions do not vary greatly across the three intervals, and the Chi-squared test $\left(X^{2}\right.$ (3) $=3.79, p=0.2846$ ) confirms that no significant differences exist between the two assemblages with statistically comparable samples (i.e., Lemuta and LAS). In contrast, meaningful variability is observed in flake size when raw materials are compared; as shown in Table 5, lava flakes are on average significantly longer and heavier than metamorphic flakes, the mean weight of which in turn is much greater than that of chert flakes. With most chert flakes in the lower portion of the lengthwidth scatter plot (Figure 5H), Figure 6D shows a low frequency of chert flakes in the larger length classes (see also Table 6). These observations are supported by a Chi-squared comparison of length intervals $\left(X^{2}(8)=258.16, p<0.0001\right)$, which indicates statistically significant differences between lava, metamorphic, and chert flakes.

Flake striking platforms are mostly unifaceted $(70.6 \%$ of the entire flake assemblage) or cortical (26.9\%), and there is a very low percentage of flakes with two or more previous removals on their butts (see details in Table 6). Figure 6E does not show any evident stratigraphic trend, which is confirmed by the absence of statistically significant differences between the Lemuta and LAS intervals in the Chi-squared test $\left(X^{2}(3)=3.043, p=0.3850\right)$. Conversely, a correlation may exist between type of striking platform and particular raw materials; as suggested by Figure $6 \mathrm{~F}$ and confirmed in the Chi-Square test $\left(X^{2}(6)=91.60, p<0.0001\right)$, significant differences exist, with the Fisher test $(p=0.0069)$ highlighting the overrepresentation of cortical striking platforms on lava flakes, of unifaceted quartzite, and bifaceted chert flakes.

Further analysis of cortex on striking platforms and its connection with cortex coverage on the dorsal surface of flakes is shown in Figure $6 \mathrm{G}$, Figure $6 \mathrm{H}$ and Table 6 . It can be seen that pieces retaining some cortex make up $52.5 \%$ of the entire flake assemblage, as opposed to fully non-cortical flakes (i.e., Toth's type $\mathrm{VI}=47.5 \%)$. Statistically, no clear stratigraphic patterns are discerned $\left(X^{2}(5)=4.25\right.$, $p=0.5138)$, but there are significant differences per raw material $\left(X^{2}(10)=284.31, p<0.0001\right)$, with the adjusted residues highlighting more strongly the underrepresentation of non-cortical (i.e. type VI) lava and chert flakes, and fully or mostly cortical (types I, II and IV) metamorphic flakes.

Core-edge flakes (Figure 4G) are scarce (5.9\% of the flake assemblage; see Table 6), suggesting that rejuvenation of flaking surfaces via removal of core striking platforms was rare. Although most whole flakes are 'regular' in shape (i.e., wide and short; elongation index $=1.40$, with one or more sharp edges adjacent or distal to the striking platform), it is worth mentioning some flake 
morphologies that are associated with particular raw materials. Quartier d'orange flakes (i.e., with cortex running from the striking platform along one side of the flake; see examples in Figure 7L-N) are exclusively associated with lavas or quartzite from fluvial sources (Table 6), further emphasizing the low reduction intensity of lavas.

We use the term 'blocky' to characterise some short flakes (elongation index=1.32) with very thick sections which remove the two parallel ends of cores (see Figure 4C). These are exclusively associated with metamorphic rocks (Table 6), attest to the slab morphology of quartzite blocks used as core blanks, and often correspond to initial stages of flake production -both the proximal end (i.e., the flake butt) and distal part (opposite side of the slab) are cortical. A number of quartzite flakes of a 'regular' shape pertain to the same stage of the reduction sequence and to a similar area of the core; with cortex on butts and one/two of the edges, these flakes were produced from the corners of the quartzite blocks, and often show abrupt, blunt natural edges (see examples in Figure $7 \mathrm{H}, 7 \mathrm{~J})$.

Distal esquillées/écaillés or other features typical of bipolar knapping were identified on only $6.9 \%$ of whole flakes (Table 6; see examples in Figure 4D). However, since bipolar flaking often does not leave diagnostic marks on the Olduvai products (e.g., Byrne et al., 2016), we cannot exclude the possibility that a portion of the 'regular' flakes correspond to this technique. Bipolar flakes are also clearly associated with a specific raw material; $8.3 \%$ of bipolar flakes are on metamorphic rocks, as opposed to only $1.7 \%$ on lavas, and none on chert.

HWK EE detached pieces produced a total of $64.43 \mathrm{~m}$ of cutting edges ( $37.54 \mathrm{~m}$ on flakes, and 26.89 $\mathrm{m}$ on flake fragments). The average cutting edge on flakes is $35.9 \mathrm{~mm}$, and $22.0 \mathrm{~mm}$ on flake fragments, with a standard deviation of 26.9 and 19.7, respectively. It should be stressed that a considerable number of whole flakes ( $n=288 ; 21.0 \%$ ) have cutting edges less than $20 \mathrm{~mm}$, and a part of this sample $(n=83 ; 6 \%)$ less than $10 \mathrm{~mm}$. Given the average flake weight (see Table 5), edge length productivity of whole flakes (calculated here as $\mathrm{cm} / \mathrm{g}$ ) is 0.22 (i.e., an average cutting edge of $~ 3.6$ $\mathrm{cm}$ in cutting edge and $16 \mathrm{~g}$ in weight), a rather low value.

\section{Cores}

Our excavations in HWK EE unearthed a substantial collection of cores $(n=925)$ and core fragments $(n=63)$, which together amount to over $274 \mathrm{~kg}$ of raw materials flaked at the site (Table 2). Lavas $(n=521)$-particularly phonolites ( $n=245)$ - are the most abundant of the core assemblage, followed at a distance by metamorphic cores $(n=384)$, while chert cores $(n=20)$ are rare (see details in Table 3). In terms of mass contribution, quartzite is the largest group $(83.5 \mathrm{~kg})$, followed by basalt ( $75 \mathrm{~kg}$ ), phonolite $(69.6 \mathrm{~kg})$ and trachyte-trachyandesite $(34.6 \mathrm{~kg}$; see Table 3$)$.

With an average length of $70 \mathrm{~mm}$ and a weight of $\sim 289 \mathrm{~g}$ (Table 4), there is significant size variability among cores (see standard deviations in Table 4). The small size of some cores should be noted, with some specimens under $40 \mathrm{~mm}$ in length and width (see patterns in Figure $5 \mathrm{G}$ and Figure $5 \mathrm{H}$ ). Cores are slightly larger in Tuff IIB and Lemuta than in LAS (see Figure 8A and details in Table 4). Core length classes (Table 7 and Figure $8 C$ ) present statistically significant differences per interval $\left(X^{2}(8)\right.$ $=37.70, p<0.0001$ ), a pattern that core weight classes (Table 7 and Figure $8 \mathrm{E}$ ) also support $\left(\mathrm{X}^{2}(10)\right.$ $=75.47, p<0.0001$ ).

Core size differences are evident per raw material (e.g., Figure 8B). As shown in Table 5, lava cores are on average bigger than quartzite, nearly twice as long as chert cores, and far heavier. Most chert cores are in the 20-39 mm length class, while the majority of metamorphic and lava cores are in the 40-59 $\mathrm{mm}$ and $60-79 \mathrm{~mm}$ ranges respectively (Table 7 and Figure 8D), with the three raw materials 
showing statistically significant differences $\left(X^{2}(8)=284.83, p<0.0001\right)$. This is also applicable to weight classes per raw material (Figure $8 \mathrm{~F}$ ), where differences are significant as well $\left(\mathrm{X}^{2}(10)\right.$ $=249.05, p<0.0001$ ), thus reinforcing observations on the larger dimensional pattern of lava over metamorphic and chert cores.

Only $11.2 \%$ of cores are fully non-cortical, while $56 \%$ preserve most of the cortex. As shown in Table 7 and Figure 9A, cortex ratios are similar in the Lemuta and LAS intervals, whereas Tuff IIB cores have less surface cortex. Observed differences are statistically significant $\left(X^{2}(4)=22.53, p=0.0002\right)$. Figure $9 \mathrm{~B}$ shows that lava cores are mostly cortical, while most metamorphic and chert cores preserve less than $50 \%$ cortex (see values in Table 7), a pattern that shows statistically significant differences per raw material $\left(X^{2}(4)=166.01, p<0.0001\right)$.

Reduction intensity can also be explored via the number of flake scars preserved on HWK EE cores. As shown in Table 7, $82.5 \%$ of cores preserve six or fewer flake scars, and only $2.8 \%$ have more than nine removals. Figure $9 \mathrm{H}$ shows reduction intensity patterning in raw material, which is statistically significant $\left(X^{2}(6)=24.14, p<0.0005\right)$. The Fisher test $(p=0.0005)$ confirms predominance of $1-3$ scars in lavas, 4-6 scars in metamorphic cores, and 7-9 scars in chert. The Fisher test also highlights the lower-than-expected frequency of 1-3 scar patterns on chert cores, which is to be emphasised, given their reduced dimensions. Significant statistical differences in scar classes are also observed per interval $\left(X^{2}(6)=28.85, p<0.0001\right)$. Whereas for Tuff IIB, the prevalence of cores with a high number of scars ( $58.3 \%$ of cores have seven or more removals; see Table 7 ) could genuinely be linked to heavier reduction intensity than in the earlier assemblages, in the case of Lemuta and LAS variation is probably linked to dominance of particular raw materials; lava cores are more abundant in LAS (57.9\%) than in Lemuta $(52.7 \%)$, a pattern that is reversed with metamorphic cores $(39.3 \%$ in LAS and $47.2 \%$ in Lemuta), and which would explain the predominance of 1-3 removals in the upper interval and of 4-6 removals in Lemuta (see also Figure 7G).

There is a clear dependency between core blank type and raw materials $\left(X^{2}(10)=617.89, p<\right.$ 0.0001 ), with all cobble blanks being lavas, all block blanks associated with metamorphic rocks, and nodules with chert (Table 7 and Figure 9D). This core blank-rock type correlation is dictated by the distinct sourcing of each raw material (river streams for lavas and some metamorphic rocks, hillslopes for most of the quartzite, and exposed lacustrine sediments for chert; see discussion in McHenry and de la Torre, 2018), and also influences core blank variations throughout the sequence. Although statistically significant differences between intervals exist $\left(X^{2}(10)=38.61, p<0.0001\right)$, cobbles are the most common blanks in Lemuta and (especially) LAS (see values in Table 7, and Figure 9C), thus following the overall prevalence of lava cores across the sequence.

The most common knapping accident in HWK EE cores is step scars; a minimum of 266 cores (i.e., $28.7 \%$ of the core sample) show this accident, which is often responsible for the abandonment of knapping surfaces, blank rotation/ flipping in pursuit of fresh flaking volumes, or final discard of the core. In absolute terms, step scars are more frequent in metamorphic $(n=140)$ than in lava $(n=117)$ and chert $(n=9)$ cores. Proportionally, however, chert shows the highest frequency of step scars on cores ( $45 \%$ of the total sample, $n=20)$, followed by metamorphic $(36.4 \%)$ and lava $(22.4 \%)$.

In addition to tools with a primary pounding function (see below; Arroyo and de la Torre, 2018), percussive features were found in $32.5 \%$ of HWK EE cores. Most are impact marks, for which an attribution either to knapping (e.g., missed blows on striking surfaces during flaking) or pounding (via their use as active hammers) is sometimes unclear. However, these impact marks are often concentrated on pitted cortical areas opposite flaked edges, which suggest a polyvalent use of blanks both as hammerstones and (probably later) as cores. Fractures attributed to percussive 
motions are found on $\mathbf{2 . 7 \%}$ of all cores, and are likely associated with the dual hammerstone/core use of blanks. Esquillées attributed to fracturing of distal parts of cores in contact with the anvil was observed on $6.3 \%$, which provides a minimum estimate for the occurrence of bipolar flaking in the assemblage. Frequencies of battering marks (see Table 7 and Figure 7E-7F) do not differ significantly per interval $\left(X^{2}(6)=12.94, p=0.04\right)$, but are statistically significant $\left(X^{2}(6)=79.64, p<0.0001\right)$ per raw material; the Fisher test $(p<0.0001)$ underlines higher proportions of esquillée marks on quartzite and chert cores, and of percussive fractures on lavas.

\section{Flaking methods}

Table 8 shows freehand and bipolar flaking methods identified in the HWK EE assemblage, to which (at least some) split cobbles (scarce but consistently present throughout the sequence: see Table 2), could be added. The potential association of split cobbles with bipolar flaking merits discussion. Split cobbles are almost exclusively on lavas (Table 3 ) and, given the high number of unmodified lava pieces in the Lemuta and (especially) LAS assemblages (see details in de la Torre et al., 2018), it cannot be ruled out that some split cobbles respond to natural processes. However, most show fresh fractures and percussive features that suggest human agency in cobble splitting. Human action could involve either intentional splitting of cobbles with a hammerstone and anvil, and/or unintentional fracturing of hammerstones in two halves during core flaking. Our experiments with local Olduvai lavas indicate that axial strikes against cobbles resting on an anvil readily produce splitting (sets JJ1, JJ3, JJ5 in Supplementary Online Material [SOM] 1 videoclip), but they also show that hammerstones can break in half (JJ4 in SOM1), resulting in virtually indistinguishable end products. While split cobbles with clear distal esquillées were classified as bipolar products and those with concentrated pitting on dorsal surfaces as hammerstone fragments, blanks with unclear features are subject to equifinality and hence were not included among the knapping techniques compiled in Table 8. Nevertheless, intentionally fractured or not, it is clear that hominins engaged in subsequent use of split cobbles, as evidenced by their usage as core blanks (see Tables 7 and 8 , and discussion section below).

Aside from split cobbles, the active-hammer and passive-anvil technique is recognised on a number of cores and cobbles that show unequivocal bipolar features (see examples in Figure 10). Bipolar cobbles bear inverted $V$-shaped striking platforms and esquillées on one or (often) both ends (Figure $10 A-B$, and SOM 2). Scars are superficial and therefore resulting flakes would have been rather thin. Reduction intensity is low, probably due to the unsuitability of inverted V-shaped striking platforms for prolonged reduction sequences, and to the prompt generation of hinged scars on the flaking surfaces which would obstruct further flake removals. Bipolar cobbles recorded at HWK EE are not small (see, for example, Figure 10A-B), and therefore the use of this technique does not seem to be size-mediated. Nonetheless, shape might have been a factor, as it is observed that most bipolar cobbles are particularly flat. HWK EE natural lava cobbles are usually spherical (see Table 11 and SOM7 in de la Torre et al., 2018), which may have had an impact on the length of freehand reduction sequences (Pante and de la Torre, 2018; see also discussion below). Therefore, the fact that most bipolar cobbles were made on flat blanks may indicate hominin selectivity of specific shapes for this technique.

While bipolar cobbles were exclusively manufactured on lavas, bipolar cores are mostly on chert (35\% of chert cores show bipolar features) and quartzite (16.5\%; see Table 8). Bipolar cores show a great variability in terms of size, morphology and flaking schemes. Figure 10C-H illustrates this diversity, from large blocks with numerous scars (e.g., Figure 10G) to bipolar core blanks of less than $20 \mathrm{~mm}$ (Figure 10H). Although some cores have a single striking platform opposed to a distal end resting on the anvil (e.g. Figure 10D), most bipolar cores are multifacial, and suggest no organization 
of flaking; instead, they indicate a continuous rotation in search of suitable flaking platforms that causes widespread battering as the result of both hammerstone striking and anvil rebound. In addition, some cores present flake scars that may correspond to freehand knapping, thus highlighting the flexibility of technical choices employed by HWK EE hominins, who used both techniques not only in the same assemblages but, on occasion, even on the same cores.

As shown in Table 8, the most common flaked artefacts in HWK EE are test cores. Considering as such blanks with one or two random scars (see examples in Figure $11 \mathrm{~A}-\mathrm{C}$ ), it is noticeable that many have just a single flake removal. Test cores are often on lava cobbles (Table 8), which is consistent with the considerable abundance of such cobbles in the local environment (see de la Torre et al., 2018). Occasionally, test cores are on vesicular lavas of mediocre quality (see details in McHenry and de la Torre, 2018) which, nonetheless, are rare among cores that underwent longer reduction sequences. In effect, this suggests that hominins were trialling knapping feasibility and that abundant blanks were discarded after one or two strikes, presumably due to their being deemed unfit for further reduction.

Figure 12A shows BALP (see Figure 2 for description of flaking scheme abbreviations) to be the next abundant flaking modality after test cores (see also Table 8). Despite their wide size variability (see Figure 13A-F; SOM 3), BALP frequencies are similar in lava and quartzite (Figure 12C), both showing consistent flaking patterns characterised by very short reduction sequences. In fact, some BALP cores at HWK EE have just two scars (see Figure 13A-B), and can only be considered separately from test cores when the analyst prioritizes that the first removal on BALP cores serves as the striking platform for the second flake, while strikes are random on test cores. Because BALP cores correspond to consecutive alternating of the striking platform within a single flaking sequence (see examples in Figure 14A), there is no obliteration of earlier reduction stages -the latter being a common occurrence in more sophisticated reduction schemes (e.g., BHC, discoid). Sequences are always short, and even the most heavily reduced BALP cores rarely bear more than 5-6 flake removals.

USP and BSP flaking schemes are similar to BALP cores both morphologically -the three groups would fall within Leakey's (1971) chopper/chopping tool morphotypes- and in their technological features. The only difference between BALP and BSP flaking schemes at HWK EE is that, while in BALP schemes previous scars serve as striking platforms for the next removal in a continuous, alternating sequence, in BSP schemes one surface is flaked first, and then acts as the striking platform for flaking on another surface, without further bifacial interaction. As in BALP cores, USP and BSP schemes are also characterised by the prevalence of short reduction sequences across a restricted part of the blank's perimeter. Figure 15 illustrates that the unifacial or bifacial edge is usually opposite a cortical area, and flaking surfaces show no recurrence (see also SOM 4 and SOM 5); after a short series of removals, cores are rotated towards unworked areas, and rarely is a surface with previous scars flaked again during a subsequent series.

The main difference between the flaking schemes described above and UAU/BAP cores is the wider angle between the striking platform and the flaking surface in the latter (see Figure 2). It is therefore unsurprising that UAU/BAP flaking schemes at HWK EE, which typologically could be classified as heavy-duty scrapers (cf. Leakey, 1971), were also characterised by the shortness of reduction sequences. Where blanks are elongated, UAU1 flaking often occurs at one end of such blanks, in which natural angles may facilitate removals from cortical platforms (Figure 14B1). Nonetheless, as mentioned above, most HWK EE cobbles have rounded shapes, and natural suitable angles are rare. This could explain the abundance of UAU1 cores with flaking surfaces covered by step scars, produced by unsuccessful attempts to remove flakes once the naturally-occurring angles have been 
exhausted (see further details in Figure 14B2). An option to overcome this constraint might have been the UAU2 scheme shown in Figure 14C1, where there is no bifacial interaction, but scars from one flaking surface are used to start a new, short sequence of removals.

Some BAP cores show consistent bifacial interaction between two flaking surfaces (see Figure 13K-L), but it is often the case that one surface has a single scar, which is then used as a striking platform for several removals on the other surface. The use of split cobbles as blanks for UAU1 flaking is observed in some instances (Table 8). Here, the ventral face of the split cobble is used as the striking platform; this serves the same function as the single scar on one of the surfaces of many BAP cores mentioned above, and hints at the eclecticism of technical solutions sought by knappers in order to overcome the lack of suitable angles on lava cobbles. Such eclecticism is supported by the differential treatment given to the two main raw materials; as shown in Figure 12C, metamorphic BAP cores are much less abundant than lavas. This is explained by the flat surfaces that naturally occur on metamorphic blanks, which obviate the preparation of knapping platforms (as is the case for lavas) via cobble splitting or bifacial flaking.

While elsewhere we have portrayed the multifacial scheme as the continuation of flaking once a more organized flaking method of the core is abandoned (de la Torre and Mora, 2004), that is not the case in HWK EE. In this assemblage, multifacial cores are usually of large dimensions, which suggests that the number of such platforms is greatly influenced by the available flaking area and, especially, by the number of suitable angles. This pattern applies particularly to quartzite blocks (which because of their angular shapes were more amenable to multidirectional flaking), and is also observed on fragmented hammerstones recycled as cores (see e.g., Figure 11J). Large size alone does not explain the proportional predominance of multifacial chert cores (see Figure 12C), as these are all small (Figure 8). In the case of chert, it is the presence of suitable angles, and potentially the value attributed by knappers to the quality of this raw material (see Discussion below), which may explain the higher number of scars across multiple faces of cores.

Whether multifacial schemes are explained by raw material or blank size, or a combination of both, these cores are also characterised by short reduction sequences. Flaking is mostly opportunistic, in the sense that removals are usually observed wherever a suitable natural angle is present, and are thus randomly positioned around the core area. However, there are some exceptions, where a bifacial edge guides most of the flaking sequence, and then other scars are present on unrelated knapping surfaces, either unifacial (Figure 14D1) or also bifacial (Figure 14D2). Although here we ascribe the usual conception of multifacial to those cores with three or more striking platforms (which therefore should include the flaking schemes from Figure 14D), a number of HWK EE multifacial cores showing such bifacial edges suggest that randomness in the striking of any available plane, while the most common, was not always the rule. Furthermore, some artefacts classified as subspheroids show multifacial flaking prior to battering of surfaces (see details in Arroyo and de la Torre, 2018), thus adding further variability to knapping schemes that involve three or more exploitation surfaces.

Frequencies of flaking schemes requiring maintenance of the same flaking surface around the entire perimeter of the core, (i.e., UP, BALT, BP, BHC and discoid) are negligible through the HWK EE sequence (see Table 8), although they are proportionally more common in the Tuff IIB interval (see Figure 12B). Most of these cores correspond to schemes that do not exploit the whole flaking surface but rather the volume close to the edge of the core (UP, BALT, BP), which leads to rapid exhaustion of suitable angles, and hence does not allow long reduction sequences. Frequency of flaking schemes where there is volumetric control of a series of removals, such as BHC (Figure 16D) and discoid (Figure 16B-C) are only episodically attested (see Table 8). Although there is variability in 
size, most cores showing exploitation around their entire perimeter are small (see examples in Figure 13G, I, J; Figure 16B-D), with some having undisputable flake removals under $20 \mathrm{~mm}$.

The Chi-square test strongly indicates statistically significant differences of flaking schemes per stratigraphic interval $\left(X^{2}(32)=89.39, p<0.0001\right)$, while the Fisher test $(p=0.05)$ highlights the relative abundance of test cores in LAS, and of discoid and bipolar in Tuff IIB. Figure 12D also indicates that discoid and BHC are outliers in the regular flaking schemes of HWK EE, and associates multifacial cores with Lemuta, while most other schemes are clustered around the LAS interval. Flaking methods are influenced by blank type, and statistically significant differences ( $X^{2}(33)=194.27$, $p<0.0001)$ are observed in the breakdowns of Table 8; Pearson's adjusted residuals $(p=0.05)$ highlight the association of bipolar cores with block and fragment blanks, UAU2 and multifacial schemes with blocks, BAP, USP and BSP flaking schemes with cobbles, and BP and BALT with cores on fragments. Comparisons of flaking schemes per raw material also suggest statistically significant differences $\left(\mathrm{X}^{2}(32)=211.25, p<0.0001\right)$, and the CFA (Figure 12E) shows clear clustering of particular methods around lava and metamorphic cores. The case of chert, which appears to be associated with discoid flaking in Figure 12E, should be considered with caution, given the very limited chert sample (see Table 8) when compared to lava and metamorphic cores. Core dimensions per flaking scheme (Table 9) also show statistically significant differences both in length $\left(X^{2}(44)=108.61\right.$, $p<0.0001)$ and weight $\left(X^{2}(55)=130.37, p<0.0001\right)$ classes. Pearson's adjusted residuals $(p=0.05)$ of length classes point at the overabundance of bipolar cores in the smaller ranges ( $<60 \mathrm{~mm}$ ), BALT cores in the $20-39 \mathrm{~mm}$ class, BP in the $40-59 \mathrm{~mm}$ class, BSP in the $60-79 \mathrm{~mm}$ class, and bipolar cobbles larger than $100 \mathrm{~mm}$. Pearson's adjusted residuals $(p=0.05)$ of weight are consistent with length patterns and, additionally, highlight the underrepresentation of $<50 \mathrm{~g}$ BSP cores and the overabundance of multifacial cores heavier than $800 \mathrm{~g}$.

\section{Retouched tools}

Although the relative frequency of retouched tools excavated by OGAP in HWK EE is small when compared to other technological categories (see Table 2), the sample is still considerable $(n=161)$. As shown in Table 10, most retouched tools were made on flakes or flake fragments, while blocks were used only episodically (1.3\%) as blanks. Mean dimensions of retouched tools (see Table 4) are consistently larger than that of complete flakes. Given that retouched artefacts also include flake fragments, the overall larger dimensions of retouched tools over whole flakes become more accentuated, therefore suggesting a possible selection of larger blanks for retouching.

Retouching was mostly made using ventral faces as the striking platform (i.e., direct retouch: 63\%), with much lower frequencies of inverse retouching (23.3\%) or others (see Table 10). Retouched edges are mostly convex (41.1\%) or concave (26\%), and usually follow the original delineation of edges (i.e., there is no major modification of the original blank profile).

With reference to tool types, denticulates (see Figure 17) dominate the assemblage $(51.6 \%)$, followed by notches and side scrapers (see frequencies in Table 10). Although convergent tools are the least abundant tool type (7\%), they are consistently found in the assemblage, and therefore they may respond to a shaping pattern geared to obtain pointed artefacts. In most cases, these convergent tools have denticulate edges (Figure 18), and in some instances larger notches are present on each side of the tip, creating a 'bec'-type shape. It was observed that, in a number of cases, artefacts had one lateral edge shaped by direct retouch and the other by indirect retouch. This retouching pattern also included tip shaping, with some convergent tools showing a direct/inverse notching of the convergent area. 
Chi-square tests per interval $\left(X^{2}(6)=1.73, p=0.94\right)$ and raw material $\left(X^{2}(6)=8.65, p=0.19\right)$ reject any statistically significant differences between retouched tool types. Nonetheless, a strong pattern of raw material selectivity exists when retouched tools are compared to the rest of the technological assemblage. As discussed above (see also Figure 3F), chert is strongly linked to retouched artefacts, clearly indicating selection of chert for flake shaping. In addition, a prevalence of higher quality, medium-to-fine-grained quartzite, was also observed among the metamorphic retouched tools. These quartzites (group 7.5 of McHenry and de la Torre, 2018), which are rare in the other technological categories, are probably from a different source to that of the coarse quartzite pervasive in the HWK EE lithic assemblage (McHenry and de la Torre, 2018), and would reinforce, along with chert, human selectivity of higher quality raw materials for tool shaping.

\section{Pounded artefacts}

The overall number of pounded artefacts $(n=349)$ is low when compared to other technological groups (see Table 2). However, their contribution to the total amount of raw material used at HWK $\mathrm{EE}$ is considerable, with over $107 \mathrm{~kg}$ of stone tools whose primary role is associated to battering. The relevance of pounding in the lithic assemblage is further emphasized when we take into account the number of cores which are reused hammerstones (see counts and discussion in Arroyo and de la Torre, 2018), and that some split cobbles we have grouped along with flaked pieces could be broken hammerstones (see description above).

Most of the battered assemblage consists of complete hammerstones $(n=119)$ and fragments $(n=$ 142; see Arroyo and de la Torre, 2018, for further differentiation of hammerstone fragments) associated with flaking activities. Dimensions of knapping hammerstones vary significantly (Table 4), from small $(\sim 30 \mathrm{~mm})$ pebbles probably used for retouching, to large, nearly $1.5 \mathrm{~kg}$ cobbles. Nevertheless, the average length of hammerstones $(\sim 75 \mathrm{~mm})$ is similar to that of cores (see Table 4), and generally corresponds to the appropriate size required to strike the $30-40 \mathrm{~mm}$ flakes that dominate the HWK EE assemblage. Most pitted stones are probably also associated with knapping, although, in this case, most likely bipolar (see Jones, 1994). These pitted stones could have served either as active elements (i.e., hammerstones used on axial striking; see Figure 14F2) or as passive elements (i.e., anvils on which the bipolar core was placed; see discussion in Arroyo and de la Torre, 2018). Other percussive elements such as anvils, subspheroids, and hammerstones with fracture angles or active edges, could have been involved in activities other than knapping, and their morphological, macro and microscopic features are discussed elsewhere (Arroyo and de la Torre, 2018).

Figure 3 shows clear patterns in raw material, with a strong preference for lava (always cobbles) for knapping hammerstones versus quartzites (often non-ergonomic blocks). Among lava hammerstones, trachyte-trachyandesites and basalts predominate over phonolites, even though the latter are much more abundant in cores (see Table 3). This seems to suggest a preference for certain raw materials as hammerstones which, potentially, could be linked to the higher density we observed in some rock types such as trachyte-trachyandesites. Pitted stones are on lavas, although in this case that is not necessarily related to a lack of use of metamorphic rocks for the same activities, but rather to the influence of petrological properties on wear development, since pitting is rarely formed on hard metamorphic rocks (see discussion in Benito-Calvo et al., 2015). Thus, some anvils (which are all quartzite) could have served the same activities as pitted stones (i.e., mostly bipolar), but different fracture mechanisms would lead to a separate techno-morphological classification. Nonetheless, the microscopic features of HWK EE anvils (see Arroyo and de la Torre, 2018) point to an additional function for these objects, and therefore their sole association with 
quartzite may be genuine. The same applies to subspheroids, exclusively made on quartzite (see Table 3).

Stratigraphic trends may also exist; while the higher frequency of hammerstones in LAS than in Lemuta is negligible (Figure $3 \mathrm{C}$ ), multivariate analysis (Figure $3 \mathrm{E}$ ) indicates a relative overabundance of percussive tools in the Tuff IIB interval. While this trend should be considered with caution, given the small sample of the Tuff IIB assemblage (see Table 2), it may also indicate some functional or temporal differences when compared to the other two intervals.

\section{Discussion}

Raw materials dictate patterns in sourcing, flaking modalities and tool types

Considerable progress has been achieved in recent years with regards to Oldowan raw material economy, and selectivity patterns have been identified according to grain size (Stout et al., 2005; Goldman-Neuman and Hovers, 2012), edge durability (Braun et al., 2009), and blank morphology (Harmand, 2009; Goldman-Neuman and Hovers, 2012). While in most cases raw materials were sourced from nearby conglomerates (Stout et al., 2005; Goldman-Neuman and Hovers, 2012; Harmand, 2009), transport of several km has been attested (Braun et al., 2008), and distance-based models are proposed to govern reduction intensity of some rock types (Blumenschine et al., 2008).

It has been stressed elsewhere (e.g., Proffitt and de la Torre, 2014; Proffitt, 2018) that the Oldowan technology at Olduvai Gorge is greatly influenced by the different properties of raw material present in each assemblage. This observation is well supported in HWK EE, where clear patterns are discerned in raw material procurement, reduction sequence modalities and tool types. McHenry and de la Torre (2018) detail raw material sourcing for HWK EE, and propose a local origin for most raw materials. This includes lavas (which would be available as cobbles in immediately available river beds), and most metamorphic rocks (mainly coarse-grained quartzite blocks which hominins collected from Naibor Soit, $\sim 2 \mathrm{~km}$ from HWK EE). Chert provenance is unknown but was probably not available in the immediate vicinity of the site, and it is also possible that some finer-grained quartzite was procured from a source further afield than Naibor Soit, potentially Naisiusiu (see discussion in McHenry and de la Torre, 2018).

It is likely that distance to raw material sources played a role in reduction intensity. Thus, Figure 8 and Table 4 show that lava cores are larger than metamorphic and chert cores, have larger cortical areas and fewer flake scars (Table 7; Figure 9), all consistent with a less intense reduction of immediately available lava cobbles. Nonetheless, sourcing distance alone does not explain the differences observed in each raw material group, and other variables clearly influenced rock type selection. For example, McHenry and de la Torre (2018) report that most stone tools were made of coarse-grained/porphyritic material, instead of finer-grained lavas which were immediately available in the vicinity of HWK EE. Such finer-grained lavas (usually basalts) are normally rounded cobbles with few naturally available angles suitable for flaking. Instead, HWK EE hominins chose quartzite blocks for flaking, due to the wider availability of flaking planes in this raw material. The relative abundance of phonolite over trachyte-trachyandesite and basalt (McHenry and de la Torre, 2018) and of flat cobbles for bipolar flaking (see above), also support a preferential selection unrelated to the conchoidal properties of rocks.

Albeit certainly dictated by raw material, reduction intensity is not explained exclusively by procurement distance. For instance, cortical patterns on flake striking platforms suggest that HWK EE hominins were aware of the mechanical properties of each rock type; it is likely that the higher frequency of cortex on lava flake butts (see Figure 6) is connected to the natural smoothness of lava 
cobble surfaces, which enables striking and to some extent makes platform preparation unnecessary. In contrast, Olduvai chert nodules have irregular, chalky cortical surfaces unsuitable for flaking, which require cortex removal before flake production (de la Torre and Mora 2005), and hence explain the higher frequency of bifaceted chert flakes.

To a great extent, raw material morphology also dictates flaking schemes shown in Table 8 and Figure 12. Hominins took advantage of naturally available planes in each raw material through a combination of freehand and bipolar techniques, and cores were often discarded once natural angles on lava cobbles and quartzite blocks were exhausted. Potential exceptions to this least-effort reduction strategy are lava cores made on split cobbles, and chert cores. Cores on split cobbles could potentially indicate preparation of striking platforms via halving of blanks as a response to the oftenintractable spherical shape of lava cobbles. As discussed above, preparation of flaking platforms on chert cores is related to removal of cortex.

Patterning also exists between particular raw materials and some technological categories (see Figure $3 F$ ). This is most evident in the case of retouched tools, where there is a clear preference for finer-grained raw materials. Thus, while the general trend in HWK EE cores and flakes is towards a selection of coarse-grained quartzites over fine lavas (see discussion above), in the case of retouched tools an overrepresentation of finer-grained quartzite (group 7.5 of McHenry and de la Torre, 2018) and chert exists. This is particularly true of chert which, despite the conservative approach followed in the identification of retouched edges (see methodology section), stands out dramatically over any other raw material; as shown in Table 11, ratios of retouched tools on chert are 10 to 60 times higher than on lava and metamorphic rocks (see also Figure $19 \mathrm{H}$ ). Curation of rarer raw materials could be invoked to explain dominance of retouched tools on chert, and (to a minor extent) on finergrained quartzites (potentially derived from a non-local source such as Naisiusiu). However, it is likely that petrological properties of chert, which produces much sharper edges than lavas and metamorphic rocks, but is also more prone to blunting, explain better its preferential use for retouching. In fact, a substantial number of chert flakes show use wear on their edges, thus supporting the proposal that chert detached pieces were actively employed at the site.

Overall, raw material economy evident at HWK EE conforms with patterns identified at other Oldowan sites (e.g., Harmand, 2009; Stout et al., 2005; Braun et al., 2008; Goldman-Neuman and Hovers, 2012). Most raw materials were available in the immediate surroundings (lavas) or from local, <2 km sources (quartzites; see discussion in McHenry and de la Torre, 2018), and a preferential reduction of better quality rocks such as chert is observed (see details above). Since lavas are generally less exploited than quartzite, and chert cores are heavily reduced, a model where reduction intensity can be linked to sourcing distance (Blumenschine et al., 2008) is loosely applicable to HWK EE. However, it is important to emphasise that distance-based predictions of reduction intensity are only applicable in broad terms; as shown in Figure 12C, test cores (characterised by showing almost no reduction) are abundant also in quartzite, despite this material not being immediately available. Cores with three or fewer scars predominate in the assemblage (Table 7) and, combining all raw materials, total $75.9 \mathrm{~kg}$ of rocks that underwent very little reduction. Inability to further reduce large blanks cannot be invoked, as HWK EE contains abundant evidence of very small-sized cores (see discussion below, and Figure 5G-H and Figure 8). Instead, it could be suggested that economization of raw materials does not exist in HWK EE; procurement of lavas in particular, but also quartzites, should have been so low-cost, or available rocks so abundant, as to allow the 'waste' of large quantities of raw materials. On the other hand, the large variability observed in the reduction intensity of quartzite blanks (which show high standard deviations and contain cores $>1 \mathrm{~kg}$ in the same contexts as cores $<10 \mathrm{~g}$; Table 5), emphasize the fact that we are yet 
to fully comprehend the meaning of flaking decisions, and that caution is needed when applying optimization models that do not necessarily capture the rationale underlying Oldowan technological strategies.

The variability of HWK EE reduction sequences and the fragmentation of chaînes opératoires

An assessment of the integrity of chaînes opératoires must also consider the dramatic differences observed per raw material. Table 11 shows that there are between $\sim 3$ and 10 flake/ flake fragments per quartzite core. This ratio is in agreement with the average number of flake scars observed on quartzite cores and, added to the sheer amount of metamorphic shatter (see Table 3), indicates that all stages of the quartzite chaîne opératoire are present at HWK EE. Given that most metamorphic rocks are Naibor Soit quartzite, it is realistic to picture unmodified blocks being transported by hominins from the hill source and flaked and used on site. With regards to chert, flake cortex proportions (e.g. Figure 6), deficit of small debris (Table 3) and lower ratios of flake: core scars (Figure 19D), indicate that initial flaking could have occurred offsite. Potentially, this could be extended to retouched chert tools, as some chert cores are simply too small (Figure $5 \mathrm{H}$ ) to have been the source of the retouched blanks. Nevertheless, and despite the absence of some elements in the chert reduction sequence, debitage:core ratios are reasonably consistent (Table 11; Figure 19B) which, added to the abundance of flakes with use wear, suggest that knapping and use of chert occurred on site.

The case of lavas, however, is completely different to metamorphic and chert patterns, and indicates a strongly fragmented chaîne opératoire. As shown in Table 11, HWK EE contains less than half a flake per core, and not even when flake fragments are included (0.94) is a consistent pattern observed. The low intensity reduction reported on lava cores (see section above) does not explain the paucity of debris, and in fact detached pieces: core scar ratios (Table 11) only amplify this severe deficit, which is even more dramatic when the almost virtual absence of lava debris (Table 3 ) is considered.

Explanation of this mismatch between flaked and detached lavas is challenging. Attribution of the deficit of lava debris to fluvial disturbance is unrealistic, as the massive amount of quartzite debris present at the site demonstrates that water was not the winnowing agent. If human agency is invoked, then alternatives are either that flaked cobbles were knapped somewhere else and then brought to HWK EE, or that the opposite occurred and it was flakes which were transported offsite. The first option would probably require considering most worked cobbles as genuine tools (sensu Leakey, 1971) rather than as cores which, however, is widely ruled out for both Oldowan assemblages in general (Toth, 1982), and in the case of Olduvai in particular (de la Torre and Mora, 2005). At HWK EE, flaked lava cobbles are generally fresh, bear intact edges, and therefore are considered here as cores. This consideration of worked lavas as sources of flakes rather than as tools, in addition to the abundance of natural cobbles in the HWK EE deposits (see de la Torre et al., 2018), make the scenario of an input of already-flaked cobbles at the site rather implausible. The alternative is that HWK EE hominins flaked lava cobbles onsite, and resulting detached artefacts were curated. While we privilege this interpretation here, such a scenario still does not explain the nearly virtual absence of lava debris (which would be produced if flaking took place on site), or the reasons why a similar imbalance is not observed in quartzite and chert. All in all, this pattern is likely to represent a particular case of the dynamics of artefact transport at Olduvai Gorge which, although discerned some time ago (Binford, 1987) and discussed more recently (McNabb, 1998; de la Torre and Mora, 2005), is yet to be fully understood.

Oldowan skill and efficiency at HWK EE 
Recent years have seen a growing interest in the study of Oldowan skill (e.g., Semaw, 2000; Delagnes and Roche, 2005; de la Torre, 2004; de la Torre and Mora, 2005; Stout et al., 2010). Thus, it has been proposed that abilities of early knappers included high flaking productivity (Delagnes and Roche, 2005; Stout et al., 2010), manual precision and technical adaptability to raw material challenges (de la Torre, 2004), sophisticated understanding of rock fracture mechanics (Semaw, 2000), and abidance by particular technical patterns (Delagnes and Roche, 2005), among others. Overall, a new picture has emerged where flaking in some Oldowan sites is portrayed as skilled (Delagnes and Roche, 2005; Stout et al., 2010). The HWK EE evidence supports some of these findings (e.g., precision grip, technical adaptability to rock-type idiosyncrasies), is ambiguous on others (such as the existence of particular technical templates), and shows a reverse pattern to high flaking productivity, which thus highlights the variability of Oldowan technological patterns in East Africa.

Considerable manual precision at HWK EE can be argued for from the remarkably small size of many flakes and cores (see Table 4 and Table 5). This 'miniaturization' is often associated with bipolar flaking (e.g., Hiscock, 2015), which is indeed attested at HWK EE (Figure 10H). However, this assemblage also contains examples of a substantial number of small-sized flakes, retouched tools and cores that seem to have been freehand-reduced (Figure 11E; Figure 13J), and which thus suggest a significant precision grip and aim during knapping.

Adaptability of technical solutions to raw material properties is one of the most prominent aspects of HWK EE and, as detailed above, flaking schemes are largely dictated by the 'knappability' of different rock types and (especially) shapes. To some extent, it could be argued that particular technical rules (cf. Delagnes and Roche, 2005) exist, as some flaking schemes show some patterning. However, blank shape seems to be the ruling factor in the organization of flaking and, if specific technical templates are to be (reluctantly) invoked, then they would be raw-material dependent.

A good understanding of rock fracture mechanics can also be drawn from the search in each raw material of those natural angles suitable for flaking, and from the preparation of striking platforms via cobble splitting and cortex removal on lava and chert. For example, it is observed on some BSP and BAP lava cores that bifacial interaction consisted of the removal from a cortical surface of a single, large flake, whose scar served as a striking platform for subsequent removals on the other side. An alternative to overcome lack of angles in rounded blanks was cobble splitting. Nevertheless, cores on split cobbles are too scarce (see Table 7) to propose the existence of a recurrent pattern and, although it has been argued that cobble splitting is skill dependent (Duke and Pargeter, 2015), in the particular case of Olduvai cobbles the process is rather simple (see SOM 1). With regards to chert, we have discussed above that HWK EE knappers removed systematically cortex from core striking platforms to ensure viable core reduction. This pattern, added to the strong preference for chert for retouched tool manufacture, could convey hominin awareness of the higher flaking and cutting qualities of chert. On the other hand, many cores (regardless of raw material) often bear consecutive series of stepped scars, which are the result of repeated failed attempts to remove flakes from exhausted angles; to some extent, this challenges our earlier statement that knappers were fully aware of the opportunities and limitations of flaking angles once those naturally available had been exhausted.

The emphasis observed on the exploitation of natural angles, absence of clear rejuvenation products, low number of scars on cores, high percentages of cortex, and predominance of cores with a single series of removals, all reinforces a notion that we have stressed throughout this paper: HWK EE flake production technology was remarkably simple -understanding as such methods that only require a basic conceptual scheme and minimal skills (Inizan et al., 1999: 60)-, and was based on short reduction sequences dependent on the expedient exploitation of naturally available planes. 
Thus, none of the high flaking productivity reported in other Oldowan sites (e.g., Delagnes and Roche, 2005; Stout et al., 2010) is observed at HWK EE, where flake:core ratios are extremely low (Table 11), even once post-depositional and/or hominin transport dynamics are considered (see previous section).

This low flake productivity at HWK EE seems to be accompanied by a remarkably poor performance in the production of sharp edges. In an earlier section, we highlighted the abundance of shatter with no edges (e.g., Figure 4B), and the overall poor quality of a considerable part of detached pieces. We measured $\sim 72 \mathrm{~m}$ of sharp edges in the whole HWK EE detached assemblage (see SOM 7), a figure that is not particularly high when the overall core mass $(267 \mathrm{~kg})$ is considered, and which in fact results in an extremely low return of debitage cutting edge:core mass ratio $(0.03 \mathrm{~cm} / \mathrm{g}$; see Table 11). Although the edge length ratio is substantially higher for chert than for lava and metamorphic rocks (Figure 19F), even then the index for chert is far below experimental expectations (e.g., Muller and Clarkson, 2016). If edge length may be used as a proxy to assess blank utility and, ultimately, technological efficiency (see a recent discussion in Dogandžić et al., 2015), then the extremely low ratios of the HWK EE lithics would characterise this assemblage as a rather inefficient one overall.

HWK EE technology in the context of Olduvai Gorge: assemblage relevance, diachronic trends and the question of the Developed Oldowan A

The HWK EE assemblage studied in this paper comprises $456 \mathrm{~kg}$ (see breakdown in Table 2) of metamorphic, lava and chert tools (Figure 20). This figure excludes unmodified material (see details on this category in de la Torre et al., 2018), even though, at least in the case of natural blocks of quartzite, they probably correspond to human action. While this nearly half a ton of artefacts alone would make HWK EE one of the richest archaeological assemblages at Olduvai Gorge, the figure becomes much higher when the lithic collection excavated by Leakey (Pante and de la Torre, 2018) is considered; as shown in Table 12, the sum of both assemblages exceeds $686 \mathrm{~kg}$ of worked lithics, with nearly 21,000 artefacts that include over 1,500 cores and more than 18,000 detached pieces. The sheer number of stone tools and abundance of fossils (Pante et al., 2018) at HWK EE, alongside other assemblages excavated by Leakey (1971) in a similar stratigraphic position, highlights the high density of remains around the Tuff IIA stratigraphic period, which is one of the most archaeologically productive in Olduvai Gorge.

The taphonomic meaning of HWK EE artefact densities has been discussed elsewhere (de la Torre et al., 2018) but, independent of the potential role of post-depositional processes in the site formation, the remarkable size of the HWK EE lithic collection makes this assemblage a pivotal reference for the understanding of technological dynamics in the Olduvai Lower Pleistocene. The possible existence of stratigraphic patterns within the HWK EE sequence has been explored throughout this paper (see Results); Figure 12D, for instance, associates (the scant examples of) structured debitage methods with Tuff IIB, and supports our qualitative observations, which attribute a better knapping quality to the lithic assemblage of this interval when compared to the underlying deposits. Given the archaeological hiatus between the top and lower units (see Figure 1 and details in de la Torre et al., 2018), the chrono-stratigraphic proximity of the HWKEE Tuff IIB deposits to handaxe-bearing sites (Leakey, 1971), and the technological features which differ from the Lemuta and LAS assemblages, it is not unlikely that the Tuff IIB assemblage corresponds to a technology separate from that of the underlying units. Nonetheless, the absence of handaxes and the very limited size of the collection due to modern erosion (see details in de la Torre et al., 2018), precludes a clearer attribution of the Tuff IIB assemblage to the Oldowan or Acheulean. 
On the other hand, differences between the Lemuta and LAS assemblages seem to be more related to site formation dynamics (e.g., overabundance of small shatter in Lemuta; Figure 3E) or intensity of reduction (cores, flakes and retouched tools are smaller in LAS; Table 4), than to clear diachronic trends in technology. The absence of clear technological differences between these two main assemblages is interesting, given the stratigraphic unconformity (and hence temporal gap) separating the Lemuta Member from the overlying Middle Bed II sandstone units (Hay, 1976; Stanistreet et al., 2018).

As a whole, the technological attribution of the main bulk of the HWK EE assemblage (i.e., Lemuta and LAS) remains to be assessed in the wider context of diachronic trends in the Oldowan at Olduvai. Although Leakey never published her excavations at HWK EE (see Pante and de la Torre, 2018), assemblages from the Lower Augitic Sandstone were attributed to the Developed Oldowan A (DOA) (Leakey, 1971, 1975). She defined the DOA as a cultural entity directly derived from the Oldowan, and characterised by an increase in spheroids and subspheroids, and in the number and variety of light-duty tools (Leakey, 1971). The validity of this term, its relationship to the Oldowan, Developed Oldowan B (DOB) and the Acheulean, as well as the issue of diachronic trends in the Oldowan at Olduvai, have been discussed -and often challenged-for nearly half a century (Leakey, 1971; Bower, 1977; Stiles, 1980; Gowlett, 1988; Kimura, 1999; de la Torre and Mora, 2005, 2014; Semaw et al., 2009; see Proffitt, 2018 for an updated review). Based on a re-analysis of the Leakey (1971) assemblages, we were among the advocates of downplaying differences between the Oldowan and DOA (de la Torre and Mora, 2005). The remarkably large collection of HWK EE enables us now to frame Leakey's $(1971,1975)$ observations within a substantially larger statistical sample derived from newly excavated contexts.

While subspheroids are not abundant at HWK EE (see Table 2), they are a discreet morpho-type (see details in Arroyo and de la Torre, 2018) consistently present in the assemblage. Their presence at HWK EE and other so-called DOA sites assemblages (e.g., Proffitt, 2018) contrast with earlier, 'classic' (i.e., Bed I and Lower Bed II) sites, where the few purported subspheroids/spheroids (Leakey, 1971) are deemed unclear (de la Torre and Mora, 2005). Thus, even if Bed II subspheroids were not intentionally shaped artefacts but rather cores with battering superimposed (de la Torre and Mora, 2005; Arroyo and de la Torre, 2018), technical gestures involved in their production (Sánchez-Yustos et al., 2016) have not been clearly documented in earlier 'classic' Oldowan assemblages, and seem to be characteristic of DOA and more recent sites. Similarly, it is worth noting that bipolar flaking, which seems to be abundant in some Upper Bed II sites (Díez-Martin et al., 2009) and is pervasive in Beds III-IV (Jones, 1994), is well documented in HWK EE (Table 8), but is not common in any of the largest 'classic' Oldowan assemblages such as FLK Zinj and DK (de la Torre and Mora, 2005). Thus, given that no clear differences in freehand core reduction are found between Oldowan and DOA assemblages (de la Torre and Mora, 2005; Proffitt, 2018), future studies should confirm whether the increase in bipolar flaking commenced with the Tuff IIA assemblages, as HWK EE suggests, in which case an additional distinction between the Oldowan and the so-called DOA could be invoked.

The frequency of retouched tools is at the crux of the discussion on the Oldowan-DOA distinction. An increase in the number of retouched artefacts was first identified by Leakey (1971), and supported more recently by Kimura $(1999,2002)$ and Proffitt (2018). We have identified over 200 retouched tools at HWK EE (see Table 12), a total that is higher than the sum of Leakey's (1971) DOA assemblages put together (de la Torre and Mora, 2005: their table 9.12). Still, the proportion of retouched tools is low when compared with the detached assemblage (regardless of the detached blanks with which retouched artefacts are rated: see Table 11), and not even the highest ratio (i.e., 
retouched tools:flakes $>2 \mathrm{~cm}$; see Table 11) is significantly different from those we calculated for any pre-Upper Bed II Leakey sites (de la Torre and Mora, 2005: their figure 9.30).

With regard to the techno-typological features of retouched tools, Leakey (1971) reported the existence of proto-bifaces, and noted an increase in the variety of tool types and the preference for chert in tool retouching in the DOA (Leakey, 1975). A few HWK EE retouched artefacts are atypically large (Figure 17k, 17n), and some (e.g., Figure 17n; Figure18j, 18r) could potentially have been considered as proto-bifaces by Leakey. The artefact from Figure $17 \mathrm{n}$, for instance, is $\sim 110 \mathrm{~mm}$ in length, and thus technically exceeds Kleindienst's (1959) requirement for retouched pieces to be considered as handaxes. Additionally, while elsewhere we have questioned the existence of discrete retouched types in the Olduvai Oldowan (de la Torre and Mora, 2005), Table 10 shows that convergent tools are present at HWK EE and, in a few examples (e.g., Figure 18e, 18i), it is tempting to propose that intentional shaping of points does exist. If confirmed, this could lead to interesting implications, as the imposition of shape is one of the thresholds identified in human technological evolution (e.g., Wynn, 1989) that is widely dismissed for the classic Oldowan, but which could then be potentially identifiable in the later stages of this technology (e.g., Gallotti and Mussi, 2015).

Overall, it appears that HWK EE is not helping to close the debate on the distinction between the 'classic' Oldowan and post-Tuff IIA assemblages. While some authors (e.g., Semaw et al., 2009; Proffitt, 2018), including ourselves (de la Torre and Mora, 2005), have been emphatic in dismissing the differences, more recently we have also acknowledged (de la Torre and Mora, 2014) the accuracy of many of Leakey's (1971) observations. Furthermore, the addition of the large assemblage of HWK EE to the sample available seems to reinforce some of her notions. Freehand core reduction methods may be undistinguishable in pre- and post-Tuff II A assemblages (de la Torre and Mora, 2005; Proffitt, 2018), and frequencies of retouched tools -even if slightly larger in postTuff IIA assemblages (Leakey, 1971; Kimura, 1999, 2002; Proffitt, 2018)- may not be dramatically different from 'classic' Oldowan sites. However, some morpho-types such as subspheroids seem to appear with the so-called DOA (de la Torre and Mora, 2005; Proffitt, 2018), just as Leakey (1971, 1975) proposed, and are perhaps associated with an increase in bipolar flaking (see discussion above). Potentially, this might be accompanied by the appearance of some patterning in the shaping of retouched tools, as opposed to the casual retouching that dominates pre-Tuff IIA assemblages. While variability in tool type frequencies could be linked to inter-assemblage functional differences (thus playing down any potential diachronic patterns), appearance of new morphotypes may represent a departure (be it technical and/or functional-related) from pre- Tuff IIA sites, and thus mark a true behavioural difference between the classic and the later Oldowan at Olduvai.

The recognition of techno-typological variability and temporal patterns (or lack thereof) within the Oldowan is a key aspect of current discussions in other East African basins (e.g., Isaac et al., 1997; Roche, 2005; Delagnes and Roche, 2005; Harmand, 2009; Stout et al., 2010; Goldman-Neuman and Hovers, 2012). The Olduvai sequence is important in this discussion, as it contains a wealth of Oldowan assemblages within a well-constrained time span ( 1.9-1.7 Ma), and provides a highresolution dataset to identify technological dynamics of change and stasis just before the advent of the Acheulean. Recent work has been inclined to highlight technological continuity between the Beds I and II Oldowan (de la Torre and Mora, 2005; Semaw et al., 2009; Proffitt, 2018). According to the results of our HWK EE analysis, however, it appears that research on Olduvai diachronic trends may require further work before we can definitely drop terms and concepts once defined by Leakey (1971), and perhaps we should not yet tar all the non-handaxe assemblages with the same brush. With the addition of HWK EE to the published record of archaeological assemblages at Olduvai Gorge, we now have a substantial sample for the post-Tuff IIA record with which to compare the 
classic Bed I Oldowan, and differences should be acknowledged. Nonetheless, given the culturalhistorical connotations attached to the Developed Oldowan and DOA concepts (see discussion in de la Torre and Mora, 2014), it might be best to avoid these terms, and instead use a less-charged one such as late Oldowan.

\section{Conclusions}

HWK EE contains one of world's largest Oldowan assemblages, with over $686 \mathrm{~kg}$ and 21,000 artefacts. The largest part of this lithic assemblage has been described in the present paper, which focuses on the main technological features of the collection excavated by OGAP. HWK EE hominins exploited three main raw materials (i.e., quartzite, lavas and chert), and our results indicate conspicuous differences in the management of each of them. The lava reduction sequence is characterised by very short flaking series and a largely fragmented chaîne opératoire in which most of the detached assemblage is missing. All stages of the quartzite reduction sequence are well represented at the site, so probably hominins were directly sourcing blocks from the local $(\sim 2 \mathrm{~km})$ Naibor Soit hills and flaking and using them on site. Chert seems not to have been available in the immediate surroundings of HWK EE, and it is likely that hominins were preferentially curating it.

Flaking methods at HWK EE are influenced by the intrinsic features of each raw material but, in general, they are remarkably simple, correspond to very short reduction sequences, and are largely expedient. HWK EE hominins seem to have been uninterested and/or unable to exploit cores intensively and, if we are to use modern standards of productivity and efficiency, both were generally very low. Despite these expedient patterns, clear selectivity is observed in raw material use for some specific tool types, particularly retouched artefacts. It is precisely the relative abundance of retouched artefacts, and the consistent appearance of some particular shapes (namely pointed tools), which seem to separate HWK EE from earlier classic Oldowan sites, and suggest that lumping all pre-handaxe assemblages within the same group might be unadvisable, at least until a better understanding of technological variability across the Olduvai stratigraphy is achieved.

Overall, raw material management differences, fragmentation of some chaînes opératoires, remarkably expedient flaking methods, poor productivity and relatively high proportions of retouched tools of good quality raw material, portray for HWK EE a multifaceted picture of the late Oldowan technology in Olduvai Gorge at $1.7 \mathrm{Ma}$. Given the sheer size of the assemblage and the consistent patterns observed in the two main stratigraphic intervals, HWK EE should be a reference for the understanding of technical patterns during the late Oldowan, at the same time as it highlights the variability of hominin technological strategies in eastern Africa during the Oldowan-Acheulean transition.

\section{Acknowledgements}

Fieldwork at HWK EE by OGAP was authorized by the Commission for Science and Technology (COSTECH), the Ngorongoro Conservation Area Authority, and the Department of Antiquities, Tanzania. We thank three anonymous reviewers for their comments on an earlier version of his paper, and OGAP researchers for support. We are also grateful for their contributions to A. Arroyo and T. Proffitt (excavation), C. Martin-Ramos (finds processing), J. Ogutu (flaking experiments), and A. Theodoropoulou (drawings). Funding by the NSF (BCS-0852292) and the European Research Council-Starting Grants (283366) is acknowledged. 


\section{References}

Arroyo, A. and de la Torre, I. (2018). Pounding tools in HWK EE and EF-HR (Olduvai Gorge, Tanzania): percussive activities in the Oldowan - Acheulean transition. J. Hum. Evol., in press.

Barsky, D., Chapon-Sao, C., Bahain, J.-J., Beyene, Y., Cauche, D., Celiberti, V., Desclaux, E., Lumley, H. de, Lumley, M.-A. de, Marchal, F., Moullé, P.-E., Pleurdeau, D., 2011. The Early Oldowan Stone-Tool Assemblage from Fejej FJ-1A, Ethiopia. J. Afr. Archaeol. 9, 207-224.

Benito-Calvo, A., Carvalho, S., Arroyo, A., Matsuzawa, T., de la Torre, I., 2015. First GIS Analysis of Modern Stone Tools Used by Wild Chimpanzees (Pan troglodytes verus) in Bossou, Guinea, West Africa. PLoS One 10, e0121613.

Binford, L.R., 1987. Searching for camps and missing the evidence?: another look at the Lower Paleolithic, in: Soffer, O. (Ed.), The Pleistocene Old World: Regional Perspectives. Plenum Press, New York, pp. 17-31.

Blumenschine, R.J., Masao, F.T., Stollhofen, H., Stanistreet, I.G., Bamford, M.K., Albert, R.M., Njau, J.K., Prassack, K.A., 2012. Landscape distribution of Oldowan stone artifact assemblages across the fault compartments of the eastern Olduvai Lake Basin during early lowermost Bed II times. J. Hum. Evol. 63, 384-394.

Blumenschine, R.J., Masao, F.T., Tactikos, J.C., Ebert, J.I., 2008. Effects of distance from stone source on landscape-scale variation in Oldowan artifact assemblages in the Paleo-Olduvai Basin, Tanzania. J. Archaeol. Sci. 35, 76-86.

Bower, J.R.F., 1977. Attributes of Oldowan and Lower Acheulean tools: "tradition" and design in the Early Lower Palaeolithic. The South African Archaeological Bulletin 32, 113-126.

Braun, D.R., Plummer, T., Ditchfield, P., Ferraro, J.V., Maina, D., Bishop, L.C., Potts, R., 2008. Oldowan behavior and raw material transport: perspectives from the Kanjera Formation. J. Archaeol. Sci. 35, 2329-2345.

Braun, D.R., Plummer, T., Ferraro, J.V., Ditchfield, P., Bishop, L.C., 2009. Raw material quality and Oldowan hominin toolstone preferences: evidence from Kanjera South, Kenya. J. Archaeol. Sci. $36,1605-1614$.

Braun, D.R., Rogers, M.J., Harris, J.W.K., Walker, S.J., 2008b. Landscape-scale variation in hominin tool use: Evidence from the Developed Oldowan. J. Hum. Evol. 55, 1053-1063.

Byrne, F., Proffitt, T., Arroyo, A., de la Torre, I., 2016. A comparative analysis of bipolar and freehand experimental knapping products from Olduvai Gorge, Tanzania. Quatern. Intl. 424, 58-68.

Chavaillon, J., 1979. Essai pour une typologie du matériel de percussion. Bulletin de la Societé Préhistorique Française 76, 230-233.

Delagnes, A., Roche, H., 2005. Late Pliocene hominid knapping skills: The case of Lokalalei 2C, West Turkana, Kenya. J. Hum. Evol. 48, 435-472.

de la Torre, I. 2004. Omo Revisited. Evaluating the Technological Skills of Pliocene Hominids. Curr. Anthropol. 45, 439-465. 
de la Torre, I., 2011. The Early Stone Age lithic assemblages of Gadeb (Ethiopia) and the Developed Oldowan / early Acheulean in East Africa. J. Hum. Evol. 60, 768-812.

de la Torre, I., Albert, R.M., Arroyo, A., Macphail, R., McHenry, L.J., Mora, R., Njau, J.K., Pante, M.C., Rivera-Rondón, C.A., Rodríguez-Cintas, Á., Stanistreet, I.G., Stollhofen, H., Wehr, K., 2018. New excavations at the HWK EE site: Archaeology, paleoenvironment and site formation processes during late Oldowan times at Olduvai Gorge, Tanzania. J. Hum. Evol., in press.

de la Torre, I., Mora, R., 2004. El Olduvayense de la Sección Tipo de Peninj (Lago Natron, Tanzania). CEPAP, vol. 1, Barcelona.

de la Torre, I., Mora, R., 2005. Technological Strategies in the Lower Pleistocene at Olduvai Beds I \& II. ERAUL 112, Liege.

de la Torre, I., Mora, R., 2014. The Transition to the Acheulean in East Africa: an Assessment of Paradigms and Evidence from Olduvai Gorge (Tanzania). J. Archaeol. Method Th. 21, 781-823.

de la Torre, I., Mora, R., Domínguez-Rodrigo, M., Luque, L., Alcalá, L., 2003. The Oldowan industry of Peninj and its bearing on the reconstruction of the technological skills of Lower Pleistocene hominids. J. Hum. Evol. 44, 203-224.

Díez-Martín, F., Sánchez, P., Domínguez-Rodrigo, M., Mabulla, A., Barba, R., 2009. Were Olduvai Hominins making butchering tools or battering tools? Analysis of a recently excavated lithic assemblage from BK (Bed II, Olduvai Gorge, Tanzania). J. Anth. Arch. 28, 274-289.

Dogandžić, T., Braun, D.R., McPherron, S.P., 2015. Edge Length and Surface Area of a Blank: Experimental Assessment of Measures, Size Predictions and Utility. PLoS One 10, e0133984.

Duke, H., Pargeter, J., 2015. Weaving simple solutions to complex problems: an experimental study of skill in bipolar cobble-splitting. Lithic Technology 40, 349-365.

Goldman-Neuman, T., Hovers, E., 2012. Raw material selectivity in Late Pliocene Oldowan sites in the Makaamitalu Basin, Hadar, Ethiopia. J. Hum. Evol. 62, 353-366.

Gowlett, J.A.J., 1988. A case of Developed Oldowan in the Acheulean? World Archaeol. 20, 13-26.

Harmand, S., 2009. Variability in Raw Material Selectivity at the Late Pliocene sites of Lokalalei, West Turkana, Kenya, in: Hovers, E., Braun, D.R. (Eds.), Interdisciplinary Approaches to the Oldowan. Springer, Dordrecht, pp. 85-97.

Hay, R.L., 1976. Geology of the Olduvai Gorge. University of California Press, Berkeley.

Hiscock, P., 2015. Making it small in the Palaeolithic: bipolar stone-working, miniature artefacts and models of core recycling. World Archaeol. 47, 158-169.

Isaac, G.L., Harris, J.W.K., Kroll, E.M., 1997. The Stone Artefact Assemblages: A Comparative Study, in: Isaac, G.L. (Ed.), Koobi Fora Research Project. Volume 5: Plio-Pleistocene Archaeology. Oxford University Press, Oxford, pp. 262-362.

Jones, P.R., 1994. Results of experimental work in relation to the stone industries of Olduvai Gorge, in: Leakey, M.D., Roe, D.A. (Eds.), Olduvai Gorge. Volume 5. Excavations in Beds III, IV and the Masek Beds, 1968-1971. Cambridge University Press, Cambridge, pp. 254-298. 
Kimura, Y., 1999. Tool-using strategies by early hominids at Bed II, Olduvai Gorge, Tanzania. J. Hum. Evol. 37, 807-831.

Kimura, Y., 2002. Examining time trends in the Oldowan technology at Beds I and II, Olduvai Gorge. J. Hum. Evol. 43, 291-321.

Kleindienst, M.R., 1959. Composition and significance of a Late Acheulian assemblage based on an analysis of East African occupation sites. Unpublished PhD, University of Chicago, Chicago.

Kuhn, S.L., 1991. "Unpacking" Reduction: Lithic Raw Material Economy in the Mousterian of WestCentral Italy. J. Anth. Arch. 10, 76-106.

Laplace, G., 1972. La typologie analytique et structurale: Base rationnelle d'étude des industries lithiques et osseuses. Colloques nationaux du Centre National de la Recherche scientifique. Banques de données aechéologiques 932, 91-143.

Leakey, M.D., 1971. Olduvai Gorge. Vol 3. Excavations in Beds I and II, 1960-1963. Cambridge University Press, Cambridge.

Leakey, M.D., 1975. Cultural Patterns in the Olduvai Sequence, in: Butzer, K.W., Isaac, G.L. (Eds.), After the Australopithecines. Stratigraphy, Ecology, and Cultural Change in the Middle Pleistocene. Mouton, Chicago, pp. 477-493.

Lemorini, C., Plummer, T.W., Braun, D.R., Crittenden, A.N., Ditchfield, P.W., Bishop, L.C., Hertel, F., Oliver, J.S., Marlowe, F.W., Schoeninger, M.J., Potts, R., 2014. Old stones' song: Use-wear experiments and analysis of the Oldowan quartz and quartzite assemblage from Kanjera South (Kenya). J. Hum. Evol. 72, 10-25.

McHenry, L.J., Stanistreet, I.G., 2018. Tephrochronology of Bed II, Olduvai Gorge, Tanzania, and the chronology of the Oldowan-Acheulean transition. J. Hum. Evol., in press.

McHenry, L., de la Torre, I. (2018). Hominin raw material procurement in the Oldowan-Acheulean transition at Olduvai Gorge. J. Hum. Evol., in press.

McNabb, J., 1998. On the Move. Theory, Time Averaging and Resource Transport at Olduvai Gorge, in: Ashton, N., Healy, F., Pettit, P. (Eds.), Stone Age Archaeology. Essays in honour of John Wymer. Oxbow Monograph 102, Oxford, pp. 15-22.

Mora, R., Martínez, J., Terradas, X., 1991. Un proyeto de análisis: el Sistema Lógico Analítico (SLA), in: Mora, R., Terradas, X., Parpal, A., Plana, C. (Eds.), Tecnología y cadenas operativas líticas. Treballs d’Arqueologia, 1, Universidad Autónoma de Barcelona, Barcelona, pp. 173-199.

Mora, R., De la Torre, I., 2005. Percussion tools in Olduvai Beds I and II (Tanzania): Implications for early human activities. J. Anth. Arch. 24, 179-192.

Muller, A., Clarkson, C., 2016. Identifying Major Transitions in the Evolution of Lithic Cutting Edge Production Rates. PLOS ONE 11, e0167244.

Pante, M.C., de la Torre, I., 2018. A hidden treasure of the Lower Pleistocene at Olduvai Gorge, Tanzania: The Leakey HWK EE assemblage. J. Hum. Evol., in press 
Pante, M.C., Njau, J.K., Hensley-Marschand, B., Keevil, T.L., Martín-Ramos, C., Peters, R.F., de la Torre, I., 2018. The carnivorous feeding behavior of early Homo at HWK EE, Bed II, Olduvai Gorge, Tanzania. J. Hum. Evol., in press.

Proffitt, T. 2018. Diachronic changes in Oldowan technology in Beds I and Lower Bed II. J. Hum. Evol., in press.

Proffitt, T., de la Torre, I., 2014. The effect of raw material on inter-analyst variation and analyst accuracy for lithic analysis: a case study from Olduvai Gorge. J. Archaeol. Sci. 45, 270-283.

Reti, J.S., 2016. Quantifying Oldowan Stone Tool Production at Olduvai Gorge, Tanzania. PLOS One 11, e0147352.

Rivals, F., Uno, K.T., Bibi, F., Pante, M.C., Njau, J., de la Torre, I., 2018. Dietary traits of the ungulates from the HWK EE site at Olduvai Gorge (Tanzania): Diachronic changes and seasonality. J. Hum. Evol., in press.

Rogers, M.J., Harris, J.W.K., Feibel, C.S., 1994. Changing patterns of land use by Plio-Pleistocene hominids in the Lake Turkana Basin. J. Hum. Evol. 27, 139-158.

Rogers, M.J., Semaw, S., 2009. From Nothing to Something: The Appearance and Context of the Earliest Archaeological Record, in: Camps, M., Chauhan, P. (Eds.), Sourcebook of Paleolithic Transitions. Methods, Theories, and Interpretations. Springer, New York, pp. 155-171.

Sánchez Yustos, P., Diez-Martín, F., Díaz, I.M., Duque, J., Fraile, C., Domínguez, M., 2015. Production and use of percussive stone tools in the Early Stone Age: Experimental approach to the lithic record of Olduvai Gorge, Tanzania. J. Archaeol. Sci.: Reports 2, 367-383.

Semaw, S., 2000. The World's Oldest Stone Artefacts from Gona, Ethiopia: Their Implications for Understanding Stone Technology and Patterns of Human Evolution Between 2.6-1.5 Million Years Ago. J. Archaeol. Sci. 27, 1197-1214.

Semaw, S., Rogers, M.J., Quade, J., Renne, P., Butler, R.F., Domínguez-Rodrigo, M., Stout, D., Hart, W.S., Pickering, T.R., Simpson, S.W., 2003. 2.6-Million-year-old stone tools and associated bones from OGS-6 and OGS-7, Gona, Afar, Ethiopia. J. Hum. Evol. 45, 169-177.

Semaw, S., Rogers, M.J., Stout, D., 2009. The Oldowan-Acheulian Transition: Is there a "Developed Oldowan" Artifact Tradition?, in: Camps, M., Chauhan, P. (Eds.), Sourcebook of Paleolithic Transitions. Methods, Theories, and Interpretations. Springer, New York, pp. 173-193.

Stanistreet, I., Stollhofen, H., McHenry, L.J., de la Torre, I., 2018. Bed II Sequence Stratigraphic context of EF-HR and HWK EE archaeological sites, and the Oldowan/ Acheulean succession at Olduvai Gorge, Tanzania. J. Hum. Evol., in press.

Stiles, D., 1980. Industrial Taxonomy in the Early Stone Age of Africa. Anthropologie XVIII, 189-207.

Stout, D., Quade, J., Semaw, S., Rogers, M.J., Levin, N.E., 2005. Raw material selectivity of the earliest stone toolmakers at Gona, Afar, Ethiopia. J. Hum. Evol. 48, 365-380.

Stout, D., Semaw, S., Rogers, M.J., Cauche, D., 2010. Technological variation in the earliest Oldowan from Gona, Afar, Ethiopia. J. Hum. Evol. 58, 474-491.

Texier, P.-J., Roche, H., Harmand, S., 2006. Kokiselei 5, Formation de Nachukui, West Turkana 
(Kenya): Un témoignage de la variabilité ou de l'évolution des comportements techniques au Pléistocène Ancien?, International Congress of Prehistoric and Protohistoric Sciences (14th : 2001 : Université de Liège): Préhistoire en Afrique : sessions générales et posters. BAR International Series, 1522, Oxford, pp. 11-22.

Toth, N., 1982. The Stone Technologies of Early Hominids at Koobi Fora, Kenya; An Experimental Approach, Unpublished Ph. D., Berkeley, University of California.

Toth, N., Schick, K., 2009. The Oldowan: The Tool Making of Early Hominins and Chimpanzees Compared. A. Rev. Anthropol. 38, 289-305.

Wynn, T., 1989. The Evolution of Spatial Competence. University of Illinois Press, Illinois.

\section{Figure captions}

Figure 1. A) Location of HWK EE in Olduvai Gorge. B) Aerial view of HWK EE trenches. C) Photogrammetric reconstruction of T1-Main Trench, with cross-sections of archaeological units plotted on the back and sidewalls, and plan view of L10. D) Synthetic stratigraphic sequence of HWK EE trenches.

Figure 2. Idealized schemes of free-hand core reduction (expanded from de la Torre et al., 2003; de la Torre and Mora, 2005; de la Torre, 2011). See de la Torre (2011) for detailed description of all schemes, apart from TC and USP2 (defined here for the first time).TC: cores with 1-2 randomly distributed removals. USP2: Flaking is unidirectional and limited to one plane, from a natural striking platform, and the angle between the striking platform and the flaking surface is $<45$ degrees. Although there are two knapping planes, there is no interaction between their respective striking platforms and flaking surfaces. Many of Leakey's (1971) double-sided choppers fall into this group. Abbreviations: TC: Test core. USP: Unifacial simple partial exploitation. USP2: Unifacial simple partial exploitation on two independent knapping surfaces. BSP: Bifacial simple partial exploitation. UAU1: Unidirectional abrupt unifacial exploitation on one knapping surface. UAU2: Unidirectional abrupt unifacial exploitation on two independent knapping surfaces. UAUT: Unifacial abrupt unidirectional total exploitation. UABI: Unifacial abrupt bidirectional exploitation. BAP: bifacial abrupt partial exploitation. BALP: bifacial alternating partial exploitation. BALT: bifacial alternating total exploitation. UP: Unifacial peripheral exploitation. BP: bifacial peripheral. UC: Unifacial centripetal exploitation. BHC: Bifacial hierarchical centripetal.

Figure 3. A-B) Number of artefacts in the main technological categories* per stratigraphic interval (A) and raw material (B). C-D) Relative frequencies of weight of main technological categories per stratigraphic interval (C) and raw material (D). *Detached frag.: flake fragments and all shatter. Core: includes core fragments and split cobbles. Retouched: includes retouched tool fragments. Knapp. Hamm.: includes knapping hammerstone fragments. Other battered: all pounded artefacts apart from knapping hammerstones. E-F) Correspondence factor analysis of all technological categories per stratigraphic interval $(E)$ and raw material $(F)$, based on artefact frequency. 
Figure 4. Examples of HWK EE debitage A) Degree of roundness (R), from fresh (R1) to heavily abraded (R4). B) Cuboidal-shaped shatter. C) Thick ('blocky') flakes. D) Bipolar flakes. E) Freehand 'regular' flakes. F) Flake with edge modification interpreted as use-wear. G) Edge-core flakes. Bars on all scales throughout the paper are $1 \mathrm{~cm}$ each (i.e., total scale length in Fig. 4 is $3 \mathrm{~cm}$ ). Yellow arrows indicate position of the striking platform.

Figure 5. Dimensions of main technological categories in HWK EE. A-D) Length (A-B) and weight (C-D) of lithic categories per stratigraphic interval (A \& C) and raw material (B \& D). E-H) Scatter plots of length and width of flakes ( $E \& F)$ and cores $(G \& H)$ per interval $(E \& G)$ and raw material $(F \& H)$.

Figure 6. Attributes of whole flakes in the HWK EE assemblage, per stratigraphic interval (left) and raw materials (right). A-B) Mean dimension (length, width and thickness in $\mathrm{mm}$, weight in grams). CD) Size ranges. E-F) Types of striking platforms (NF: non-faceted. UF: unifaceted. BF: bifaceted. MF: multifaceted). G-H) Percentage of cortex on flakes, following Toth's (1982) types.

Figure 7. Whole flakes from T1-Main Trench at HWK EE. A-K) Quartzite. L-T) Phonolite. U-W) Trachyte-trachyandesite. X-Y) Basalt. Z-CC) Chert. Black arrows indicate position of the striking platform.

Figure 8. Dimensional attributes of cores per stratigraphic interval (left) and raw materials (right). AB) Mean dimension (length, width and thickness in $\mathrm{mm}$, weight in $\mathrm{g}$ ).C-D) Core length classes. E-F) Core weight classes.

Figure 9. Technical attributes of cores, per stratigraphic interval (left) and raw materials (right). A-B) Cortex coverage. C-D) Core blank. E-F) Battering features. G-H) Number of previous removals.

Figure 10. Bipolar cobbles (A-B) and cores (C-H) at HWK EE. All examples from T1-Main Trench with the exception of (G) (from T29). See videoclips of bipolar cobbles in SOM 2. Arrows with a dotted end indicate direction of flaking scars preserving the striking point. Single arrows: direction of flaking scars with no striking point preserved. Double arrows: scars attributed to battering (e.g., bipolar damage) rather than flaking.

Figure 11. HWK EE cores. A-C) Test cores. D-G) Unifacial abrupt cores (D-E, G: UAU1. F: UAU2). H) Polyhedron. I-K) Multifacial cores (11J is a hammerstone recycled as a core). All specimens from T1Main Trench. Arrows indicate flaking direction of scars with the striking point preserved (arrows with a dotted end) or without it (single arrows). Dots refer to percussion points on scars in the adjacent flaking surface. Abbreviations as defined in Figure 2. 
Figure 12. Freehand flaking techniques at HWK EE. A-C) Relative frequencies of the entire assemblage (A), per stratigraphic interval (B) and per raw material (C). D-E) Correspondence Factor Analysis of freehand flaking techniques per interval (D) and raw material (E). Abbreviations as defined in Figure 2.

Figure 13. Bifacial alternating partial (BALP) cores (A-F), bifacial alternating total exploitation (BALT) (cores G-J), and bifacial abrupt partial cores (BAP) (K-L). All cores from T1-Main Trench, excepting (E) and (F), from T28 and T29, respectively. See Fig. 11 for symbol keys.

Figure 14.A) Examples of BALP (bifacial alternating partial) flaking in T1-Main Trench in which the order of removals can be reconstructed. (A1, A2, A4) Archaeological unit L1. (A3, A6) Archaeological unit L4. (A5) Archaeological unit L6-LCHA. B1) UAU1 (unidirectional abrupt unifacial exploitation on one knapping surface) flaking at HWK EE often occurs at one end of elongated blanks. B2) Stepping of flaking surfaces produced by inadequate angles in consecutive series of removals; in Series 1, flakes are successfully obtained from suitable angles naturally present on the core blank. Once those angles are used, flaking attempts in Series 2 fail and cause stepping of exploitation surfaces. C) Modalities of UAU2 (unidirectional abrupt unifacial exploitation on two independent knapping surfaces) at HWKEE. D) Multifacial schemes with removals from one (D1) or two bifacial (D2) edges. E) Flaking of bipolar cobbles. F) Location of battering on regular hammerstones (F1) and pitted stones (F2).

Figure 15. Unifacial simple partial (USP) (A-C) and bifacial simple partial (BSP) (D-I) flaking schemes in HWK EE. All cores from T1-Main Trench, excepting (F-G), from T27. See Fig. 11 for symbol keys.

Figure 16. A) Bifacial peripheral (BP) core from archaeological unit L4. B-C) Discoid cores from archaeological units L1E (B) and L6-LCHA (C). D) Bifacial centripetal hierarchical (BHC) core from archaeological unit L1C. All cores from LAS (A, C) and Tuff IIB (B-D) intervals in T1-Main Trench. See Fig. 11 for symbol keys.

Figure 17. Denticulate (A-T) and notch (U) retouched tools from HWK EE. A-F) Lava. G-N, U) Metamorphic. O-T) Chert. All artefacts from T1-Main Trench, excepting (O) (T27) and (R-S) (T29). See $3 \mathrm{D}$ model videoclips of Figure $17 \mathrm{~h}, 17 \mathrm{i}$ and $17 \mathrm{~s}$, in SOM 6A, 6B and 6C, respectively.

Figure 18. Convergent tools (A-I) and scrapers (J-W) from HWK EE. A-F, H, J-P) Metamorphic. G, I, Q, S-W) chert. R) Lava. All retouched tools from T1-Main Trench excepting (W), from T27. See 3D model videoclip of Figure $18 \mathrm{E}$ in SOM 6D.

Figure 19. Core, debitage and retouched tool ratios per stratigraphic interval (left) and raw materials (right). See Table 11 for details. 
Figure 20. The HWKEE lithic assemblage excavated by OGAP in T1-Main Trench (A-C) and T27-T29 (D). A) Metamorphic artefacts. B) Chert assemblage C) Lava cores. D) All categories and raw materials per archaeological unit. 


\section{TABLE Captions}

Table 1. Main technological groups per archaeological unit and general raw material. ${ }^{a}$

Table 2. Technological categories per stratigraphic interval in the entire HWK EE assemblage.

Table 3. Technological categories per individualised raw material. ${ }^{a}$

Table 4. Dimensions ( $\mathrm{mm}$ and $\mathrm{g}$ ) of main technological categories per stratigraphic interval. ${ }^{\mathrm{a}}$

Table 5. Dimensions ( $\mathrm{mm}$ and g) of main technological categories per raw material. ${ }^{\mathrm{a}}$

Table 6. Technological attributes of whole flakes.

Table 7. Attributes of HWK EE cores.

Table 8. Flaking schemes of HWK EE cores by raw material, stratigraphic interval and blank.

Table 9. Length $(\mathrm{mm})$ and weight $(\mathrm{g})$ classes of HWK EE core flaking schemes (see Table 8 for abbreviations).

Table 10. Techno-typological features of HWK EE retouched tools.

Table 11. Ratios of cores, debitage and retouched tools in the HWK EE assemblage. ${ }^{\mathrm{a}}$

Table 12. The entire HWK EE assemblage, including the OGAP (this paper) and the Leakey (Pante and de la Torre, 2018) collections, per stratigraphic interval (frequency of objects) and raw material (total mass per category). ${ }^{a}$ 


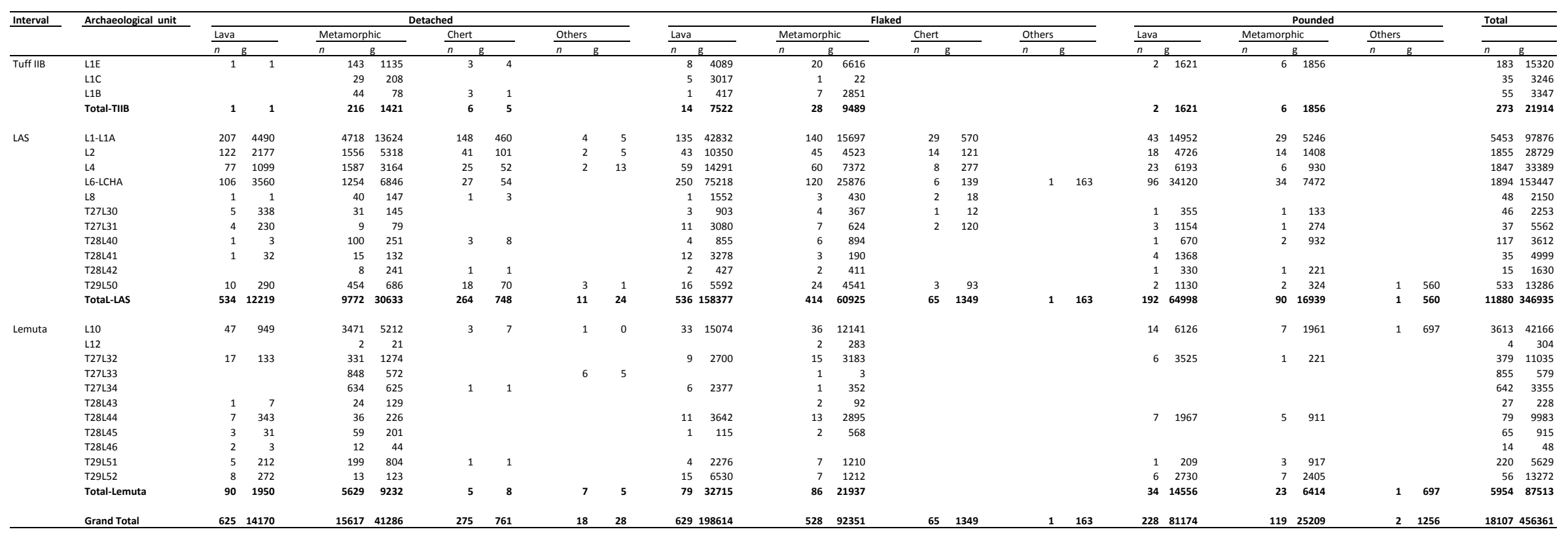

$$
\begin{aligned}
& \begin{array}{l}
\text { see } \\
\text { Figure } 10 \\
\text { for a } \\
\text { a }
\end{array} \\
& \begin{array}{l}
\text { for a } \\
\text { synthesis } \\
\text { of the }
\end{array} \\
& \begin{array}{l}
\text { of the } \\
\text { stratigrap }
\end{array} \\
& \text { hic } \\
& \begin{array}{l}
\text { successio } \\
n, \text { and de }
\end{array} \\
& \begin{array}{l}
\text { n, and de } \\
\text { la Torre et } \\
\text { al. (2018) }
\end{array} \\
& \text { for } \\
& \begin{array}{l}
\text { definition } \\
\text { of }
\end{array} \\
& \begin{array}{l}
\text { archaeolo } \\
\text { gical }
\end{array} \\
& \begin{array}{l}
\text { gical } \\
\text { units. LAS }
\end{array} \\
& \begin{array}{l}
\text { Augitic } \\
\text { Sandston }
\end{array}
\end{aligned}
$$




\begin{tabular}{|c|c|c|c|c|c|c|c|c|c|c|c|c|c|c|c|c|c|}
\hline & & \multicolumn{4}{|c|}{ Lemuta } & \multicolumn{4}{|c|}{ Lower Augitic Sandstone } & \multicolumn{4}{|c|}{ Tuff IIB } & \multicolumn{4}{|c|}{ Total } \\
\hline & & \multirow{2}{*}{\multicolumn{2}{|c|}{ Frequency }} & \multirow{2}{*}{\multicolumn{2}{|c|}{$\begin{array}{l}\text { Weight } \\
\mathrm{g}\end{array}$}} & \multicolumn{2}{|c|}{$\begin{array}{l}\text { Frequency } \\
\end{array}$} & \multirow{2}{*}{\multicolumn{2}{|c|}{$\begin{array}{l}\text { Weight } \\
\mathrm{g}\end{array}$}} & \multicolumn{2}{|c|}{$\begin{array}{l}\text { Frequency } \\
\end{array}$} & \multirow{2}{*}{\multicolumn{2}{|c|}{$\frac{\text { Weight }}{\mathrm{g}}$}} & \multirow{2}{*}{\multicolumn{2}{|c|}{$\frac{\text { Frequency }}{n}$}} & \multirow{2}{*}{\multicolumn{2}{|c|}{$\begin{array}{l}\text { Weight } \\
\mathrm{g}\end{array}$}} \\
\hline & & $n$ & & & & & & & & $\begin{array}{ll}n & 0\end{array}$ & & & & & & & \\
\hline \multirow[t]{5}{*}{ Detached } & Flake & 277 & 4.7 & 4021 & 4.6 & 1054 & 8.9 & 17204 & 5.0 & 37 & 13.6 & 686 & 3.1 & 1368 & 7.6 & 21911 & 4.8 \\
\hline & Flake Frag & 494 & 8.3 & 2614 & 3.0 & 2515 & 21.2 & 13881 & 4.0 & 72 & 26.4 & 449 & 2.0 & 3081 & 17.0 & 16943 & 3.7 \\
\hline & Shatter $<20 \mathrm{~mm}$ & 4766 & 80.0 & 3209 & 3.7 & 6253 & 52.6 & 3687 & 1.1 & 103 & 37.7 & 69 & 0.3 & 11122 & 61.4 & 6965 & 1.5 \\
\hline & Shatter $>20 \mathrm{~mm}$ & 194 & 3.3 & 1351 & 1.5 & 759 & 6.4 & 8851 & 2.6 & 11 & 4.0 & 223 & 1.0 & 964 & 5.3 & 10425 & 2.3 \\
\hline & Total Detached & 5731 & 96.0 & 11195 & 12.8 & 10581 & 89.0 & 43623 & 12.6 & 223 & 81.7 & 1427 & 6.5 & 16535 & 91.2 & 56245 & 12.3 \\
\hline \multirow[t]{6}{*}{ Flaked } & Core & 127 & 2.1 & 51124 & 58.4 & 763 & 6.4 & 199477 & 57.5 & 35 & 12.8 & 16389 & 74.8 & 925 & 5.1 & 266990 & 58.5 \\
\hline & Core Frag & 6 & 0.1 & 513 & 0.6 & 55 & 0.5 & 6327 & 1.8 & 2 & 0.7 & 275 & 1.3 & 63 & 0.3 & 7116 & 1.6 \\
\hline & Retouched tool & 18 & 0.3 & 1031 & 1.2 & 139 & 1.2 & 3536 & 1.0 & 4 & 1.5 & 56 & 0.3 & 161 & 0.9 & 4623 & 1.0 \\
\hline & Retouched tool frag. & 6 & 0.1 & 95 & 0.1 & 4 & 0.0 & 16 & 0.0 & & 0.0 & & 0.0 & 10 & 0.1 & 111 & 0.0 \\
\hline & Split Cobble & 8 & 0.1 & 1888 & 2.2 & 55 & 0.5 & 11459 & 3.3 & 1 & 0.4 & 291 & 1.3 & 64 & 0.4 & 13638 & 3.0 \\
\hline & Total Flaked & 165 & 2.8 & 54651 & 62.5 & 1016 & 8.6 & 220815 & 63.6 & 42 & 15.4 & 17011 & 77.6 & 1223 & 6.8 & 292478 & 64.1 \\
\hline \multirow{8}{*}{ Pounded } & Anvil & 4 & 0.1 & 1649 & 1.9 & 4 & 0.0 & 2959 & 0.9 & 1 & 0.4 & 688 & 3.1 & 9 & 0.0 & 5296 & 1.2 \\
\hline & Pitted stone & 4 & 0.1 & 1198 & 1.4 & 15 & 0.1 & 8405 & 2.4 & & 0.0 & & 0.0 & 19 & 0.1 & 9604 & 2.1 \\
\hline & Knapping Hammerst. & 10 & 0.2 & 4054 & 4.6 & 108 & 0.9 & 34919 & 10.1 & 1 & 0.4 & 165 & 0.8 & 119 & 0.7 & 39138 & 8.6 \\
\hline & Knapping Ham. Frag & 22 & 0.4 & 5509 & 6.3 & 119 & 1.0 & 22478 & 6.5 & 1 & 0.4 & 37 & 0.2 & 142 & 0.8 & 28024 & 6.1 \\
\hline & Subspheroid & 2 & 0.0 & 472 & 0.5 & 9 & 0.1 & 2458 & 0.7 & 1 & 0.4 & 492 & 2.2 & 12 & 0.1 & 3422 & 0.7 \\
\hline & Other pounded & 16 & 0.3 & 8784 & 10.0 & 28 & 0.2 & 11278 & 3.3 & 4 & 1.5 & 2095 & 9.6 & 48 & 0.3 & 22157 & 4.9 \\
\hline & Total Pounded & 58 & 1.0 & 21667 & 24.8 & 283 & 2.4 & 82496 & 23.8 & 8 & 2.9 & 3477 & 15.9 & 349 & 1.9 & 107640 & 23.6 \\
\hline & Grand Total & 5954 & 32.9 & 87513 & 19.2 & 11880 & 65.6 & 346935 & 76.0 & 273 & 1.5 & 21914 & 4.8 & 18107 & 100.0 & 456361 & 100.0 \\
\hline
\end{tabular}




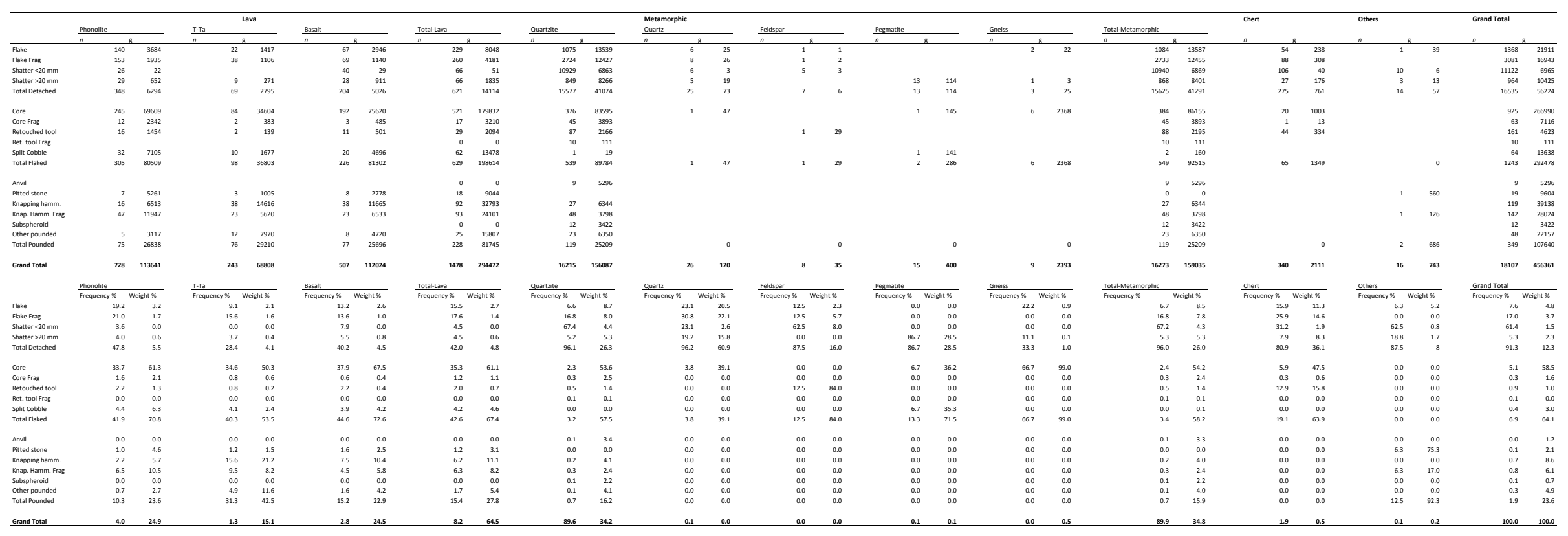

SSee Mcterny and
de la Irorre (2018)
for descrition of 


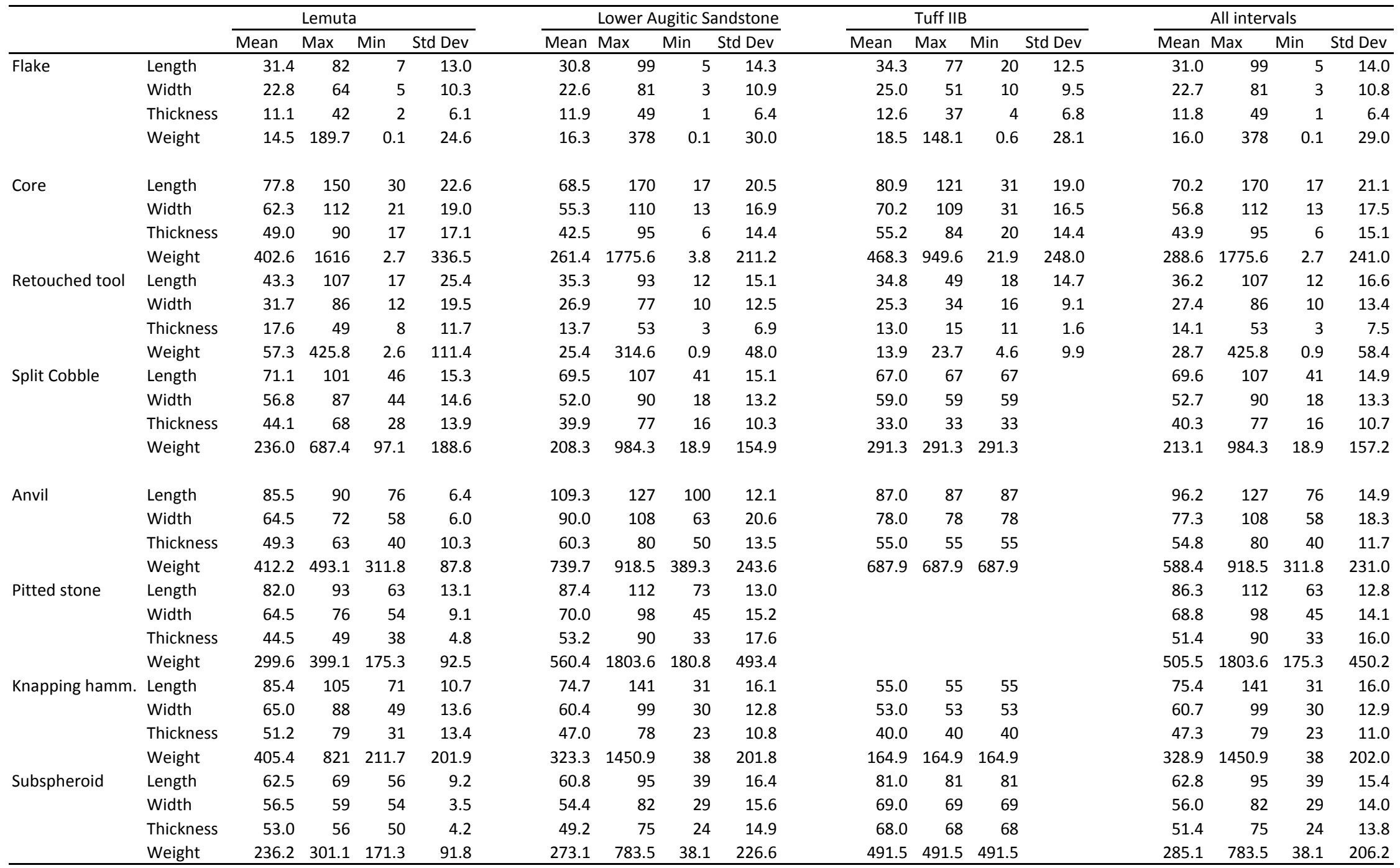

a $\operatorname{Min}=$ minimum, Max = maximum, Std

Dev $=$ standard deviation. 


\begin{tabular}{|c|c|c|c|c|c|c|c|c|c|c|c|c|c|c|c|c|c|}
\hline & & \multicolumn{3}{|c|}{ Lava } & \multirow[b]{2}{*}{$\overline{\text { Std Dev }}$} & \multicolumn{4}{|c|}{ Metamorphic } & \multicolumn{4}{|c|}{ Chert } & \multicolumn{4}{|c|}{ All raw materials } \\
\hline & & Mean & Max & Min & & Mean & Max & Min & Std Dev & Mean & Max & Min & Std Dev & Mean & Max & Min $S$ & Std Dev \\
\hline \multirow[t]{4}{*}{ Flake } & Length & 44.4 & 85 & 17 & 15.2 & 28.5 & 99 & 5 & 12.2 & 24.6 & 54 & 12 & 8.8 & 31.0 & 99 & 5 & 14.0 \\
\hline & Width & 32.5 & 66 & 10 & 12.0 & 20.8 & 81 & 3 & 9.4 & 17.4 & 38 & 9 & 6.4 & 22.7 & 81 & 3 & 10.8 \\
\hline & Thickness & 15.4 & 49 & 4 & 7.8 & 11.2 & 45 & 1 & 5.8 & 7.7 & 18 & 3 & 3.8 & 11.8 & 49 & 1 & 6.4 \\
\hline & Weight & 35.0 & 196 & 1.5 & 39.1 & 12.5 & 378 & 0.1 & 25.2 & 4.4 & 33 & 0.3 & 5.5 & 16.0 & 378 & 0.1 & 28.9 \\
\hline \multirow[t]{4}{*}{ Core } & Length & 78.5 & 170 & 35 & 15.9 & 60.1 & 150 & 17 & 22.5 & 42.1 & 75 & 29 & 12.0 & 70.2 & 170 & 17 & 21.1 \\
\hline & Width & 63.2 & 112 & 25 & 13.7 & 49.2 & 110 & 13 & 18.2 & 31.4 & 64 & 17 & 10.6 & 56.8 & 112 & 13 & 17.4 \\
\hline & Thickness & 48.2 & 95 & 8 & 13.1 & 39.0 & 92 & 6 & 15.5 & 24.9 & 60 & 12 & 11.9 & 43.9 & 95 & 6 & 15.1 \\
\hline & Weight & 345.7 & 1616 & 2.7 & 217.1 & 221.8 & 1776 & 3.8 & 254.1 & 50.1 & 243 & 9.3 & 55.9 & 288.8 & 1776 & 2.7 & 241.0 \\
\hline \multirow[t]{4}{*}{ Retouched tool } & Length & 51.0 & 93 & 23 & 20.7 & 35.9 & 107 & 17 & 14.9 & 26.9 & 56 & 12 & 8.3 & 36.2 & 107 & 12 & 16.6 \\
\hline & Width & 40.9 & 77 & 19 & 17.0 & 26.6 & 86 & 12 & 11.3 & 20.1 & 39 & 10 & 6.8 & 27.4 & 86 & 10 & 13.4 \\
\hline & Thickness & 18.6 & 53 & 6 & 10.7 & 14.9 & 49 & 8 & 6.6 & 9.7 & 21 & 3 & 3.9 & 14.1 & 53 & 3 & 7.5 \\
\hline & Weight & 72.2 & 315 & 4.2 & 89.4 & 24.9 & 426 & 2.6 & 53.0 & 7.6 & 37 & 0.9 & 6.8 & 28.7 & 426 & 0.9 & 58.4 \\
\hline \multirow[t]{4}{*}{ Split Cobble } & Length & 70.2 & 107 & 42 & 14.6 & 51.5 & 62 & 41 & 14.8 & & & & & 69.6 & 107 & 41 & 14.9 \\
\hline & Width & 53.5 & 90 & 24 & 12.7 & 30.5 & 43 & 18 & 17.7 & & & & & 52.7 & 90 & 18 & 13.3 \\
\hline & Thickness & 40.7 & 77 & 22 & 10.4 & 26.5 & 37 & 16 & 14.8 & & & & & 40.3 & 77 & 16 & 10.7 \\
\hline & Weight & 217.4 & 984 & 33.7 & 157.4 & 80.1 & 141 & 18.9 & 86.5 & & & & & 213.1 & 984 & 18.9 & 157.2 \\
\hline \multirow[t]{4}{*}{ Anvil } & Length & & & & & 96.2 & 127 & 76 & 14.9 & & & & & 96.2 & 127 & 76 & 14.9 \\
\hline & Width & & & & & 77.3 & 108 & 58 & 18.3 & & & & & 77.3 & 108 & 58 & 18.3 \\
\hline & Thickness & & & & & 54.8 & 80 & 40 & 11.7 & & & & & 54.8 & 80 & 40 & 11.7 \\
\hline & Weight & & & & & 588.4 & 919 & 311.8 & 231.0 & & & & & 588.4 & 919 & 311.8 & 231.0 \\
\hline \multirow[t]{4}{*}{ Pitted stone } & Length & 86.6 & 112 & 63 & 13.1 & & & & & & & & & 86.6 & 112 & 63 & 13.1 \\
\hline & Width & 68.7 & 98 & 45 & 14.5 & & & & & & & & & 68.7 & 98 & 45 & 14.5 \\
\hline & Thickness & 50.6 & 90 & 33 & 16.1 & & & & & & & & & 50.6 & 90 & 33 & 16.1 \\
\hline & Weight & 502.4 & 1804 & 175.3 & 463.1 & & & & & & & & & 502.4 & 1804 & 175.3 & 463.1 \\
\hline \multirow[t]{4}{*}{ Knapping hamm. } & Length & 78.4 & 141 & 47 & 14.5 & 65.1 & 93 & 31 & 16.8 & & & & & 75.4 & 141 & 31 & 16.0 \\
\hline & Width & 62.8 & 99 & 38 & 11.5 & 53.6 & 88 & 30 & 14.9 & & & & & 60.7 & 99 & 30 & 12.9 \\
\hline & Thickness & 48.5 & 78 & 24 & 10.3 & 43.0 & 79 & 23 & 12.3 & & & & & 47.3 & 79 & 23 & 11.0 \\
\hline & Weight & 356.4 & 1451 & 51.6 & 204.5 & 235.0 & 691 & 38 & 164.1 & & & & & 328.9 & 1451 & 38 & 202.0 \\
\hline \multirow[t]{4}{*}{ Subspheroid } & Length & & & & & 62.8 & 95 & 39 & 15.4 & & & & & 62.8 & 95 & 39 & 15.4 \\
\hline & Width & & & & & 56.0 & 82 & 29 & 14.0 & & & & & 56.0 & 82 & 29 & 14.0 \\
\hline & Thickness & & & & & 51.4 & 75 & 24 & 13.8 & & & & & 51.4 & 75 & 24 & 13.8 \\
\hline & Weight & & & & & 285.1 & 784 & 38.1 & 206.2 & & & & & 285.1 & 784 & 38.1 & 206.2 \\
\hline
\end{tabular}

${ }^{\mathrm{a}}$ Min = minimum,

Max = maximum,

Std Dev = standard

deviation. 


\begin{tabular}{|c|c|c|c|c|c|c|c|c|c|c|c|c|c|c|c|}
\hline \multirow[b]{4}{*}{ Length classes } & \multirow[b]{4}{*}{$<20 \mathrm{~mm}$} & \multicolumn{6}{|c|}{ Raw material $^{a}$} & \multicolumn{6}{|c|}{ Stratigraphic position } & \multicolumn{2}{|c|}{ Grand Total } \\
\hline & & \multicolumn{2}{|l|}{ Lava } & \multicolumn{2}{|l|}{ Metamorphic } & \multicolumn{2}{|l|}{ Chert } & \multicolumn{2}{|l|}{ Lemuta } & \multicolumn{2}{|l|}{ LAS } & \multicolumn{2}{|l|}{ Tuff IIB } & \multirow[b]{2}{*}{$n$} & \multirow[b]{2}{*}{$\%$} \\
\hline & & $n$ & $\%$ & $n$ & $\%$ & $n$ & $\%$ & $n \quad 9$ & & $n$ & $\%$ & $n \quad 9$ & $\%$ & & \\
\hline & & 1 & 0.43 & 200 & 18.5 & 13 & 24.1 & 35 & 12.6 & 179 & 17.0 & & 0.0 & 214 & 15.6 \\
\hline & $20-39 \mathrm{~mm}$ & 97 & 42 & 739 & 68.3 & 36 & 66.7 & 186 & 67.1 & 659 & 62.5 & 28 & 75.7 & 873 & 63.8 \\
\hline & $40-59 \mathrm{~mm}$ & 91 & 39.4 & 110 & 10.2 & 5 & 9.3 & 43 & 15.5 & 156 & 14.8 & 7 & 18.9 & 206 & 15.1 \\
\hline & $60-79 \mathrm{~mm}$ & 38 & 16.5 & 26 & 2.4 & & 0.0 & 12 & 4.3 & 50 & 4.7 & 2 & 5.4 & 64 & 4.7 \\
\hline & $80-99 \mathrm{~mm}$ & 4 & 1.73 & 7 & 0.6 & & 0.0 & 1 & 0.4 & 10 & 0.9 & & 0.0 & 11 & 0.8 \\
\hline & Total & 231 & 16.9 & 1082 & 79.1 & 54 & 3.9 & 277 & 20.2 & 1054 & 77.0 & 37 & 2.7 & 1368 & 100.0 \\
\hline \multirow[t]{5}{*}{ Striking platform preparation } & Non-faceted & 108 & 50.9 & 207 & 21.9 & 8 & 19.0 & 64 & 26.4 & 253 & 27.3 & 6 & 18.8 & 323 & 26.9 \\
\hline & Unifaceted & 94 & 44.3 & 725 & 76.6 & 29 & 69.0 & 170 & 70.2 & 654 & 70.5 & 25 & 78.1 & 849 & 70.6 \\
\hline & Bifaceted & 8 & 3.8 & 13 & 1.4 & 5 & 11.9 & 8 & 3.3 & 17 & 1.8 & 1 & 3.1 & 26 & 2.2 \\
\hline & Multifaceted & 2 & 0.9 & 2 & 0.2 & & 0.0 & & 0.0 & 4 & 0.4 & & 0.0 & 4 & 0.3 \\
\hline & Total & 212 & 17.6 & 947 & 78.8 & 42 & 3.5 & 242 & 20.1 & 928 & 77.2 & 32 & 2.7 & 1202 & 100.0 \\
\hline \multirow[t]{5}{*}{ Cortex dorsal side } & Cortical & 42 & 18.4 & 18 & 1.8 & 4 & 5.0 & 13 & 4.9 & 50 & 5.1 & 1 & 2.9 & 64 & 5.0 \\
\hline & Cortex $>50 \%$ & 69 & 30.3 & 79 & 7.9 & 9 & 12.3 & 37 & 14.0 & 117 & 11.9 & 4 & 11.4 & 158 & 12.3 \\
\hline & Cortex $<50 \%$ & 62 & 27.2 & 213 & 21.3 & 25 & 23.4 & 64 & 24.2 & 226 & 23.0 & 10 & 28.6 & 300 & 23.4 \\
\hline & Non-cortical & 55 & 24.1 & 692 & 69.1 & 12 & 59.3 & 150 & 56.8 & 589 & 60.0 & 20 & 57.1 & 759 & 59.3 \\
\hline & Total & 228 & 17.8 & 1002 & 78.2 & 50 & 3.9 & 264 & 20.6 & 982 & 76.7 & 35 & 2.7 & 1281 & 100.0 \\
\hline \multirow[t]{7}{*}{ Toth's flakes } & I & 28 & 13.3 & 7 & 0.7 & 1 & 2.4 & 4 & 1.7 & 31 & 3.3 & 1 & 3.1 & 36 & 3.0 \\
\hline & II & 60 & 28.4 & 79 & 8.4 & 7 & 16.7 & 29 & 12.0 & 114 & 12.3 & 3 & 9.4 & 146 & 12.2 \\
\hline & III & 20 & 9.5 & 121 & 12.8 & & 0.0 & 31 & 12.8 & 108 & 11.7 & 2 & 6.3 & 141 & 11.8 \\
\hline & IV & 13 & 6.2 & 10 & 1.1 & 3 & 7.1 & 8 & 3.3 & 18 & 1.9 & & 0.0 & 26 & 2.2 \\
\hline & V & 60 & 28.4 & 195 & 20.6 & 25 & 59.5 & 60 & 24.8 & 211 & 22.8 & 10 & 31.3 & 281 & 23.4 \\
\hline & $\mathrm{VI}$ & 30 & 14.2 & 534 & 56.4 & 6 & 14.3 & 110 & 45.5 & 444 & 47.9 & 16 & 50.0 & 570 & 47.5 \\
\hline & Total & 211 & 17.6 & 946 & 78.9 & 42 & 3.5 & 242 & 20.2 & 926 & 77.2 & 32 & 2.7 & 1200 & 100.0 \\
\hline \multirow[t]{6}{*}{ Flake types } & Regular flake & 191 & 82.7 & 903 & 83.5 & 50 & 92.6 & 231 & 83.4 & 884 & 83.9 & 30 & 81.1 & 1145 & 83.7 \\
\hline & "Quartier d'orange" & 22 & 9.5 & 3 & 0.3 & & 0.0 & 3 & 1.1 & 22 & 2.1 & & 0.0 & 25 & 1.8 \\
\hline & Core-edge & 14 & 6.1 & 63 & 5.8 & 4 & 7.4 & 22 & 7.9 & 57 & 5.4 & 2 & 5.4 & 81 & 5.9 \\
\hline & Blocky & & 0.0 & 23 & 2.1 & & 0.0 & 7 & 2.5 & 14 & 1.3 & 2 & 5.4 & 23 & 1.7 \\
\hline & Bipolar & 4 & 1.7 & 90 & 8.3 & & 0.0 & 14 & 5.1 & 77 & 7.3 & 3 & 8.1 & 94 & 6.9 \\
\hline & Total & 231 & 16.9 & 1082 & 79.1 & 54 & 3.9 & 277 & 20.2 & 1054 & 77.0 & 37 & 2.7 & 1368 & 100.0 \\
\hline
\end{tabular}

${ }^{\mathrm{a}}$ Breakdowns by raw material have one less item than by stratigraphic interval (rock type = other than lava, metamorphic or chert). LAS = Lower Augitic Sandstone. 


\begin{tabular}{|c|c|c|c|c|c|c|c|c|c|c|c|c|c|c|c|}
\hline & \multirow[b]{4}{*}{$<20 \mathrm{~mm}$} & \multicolumn{6}{|c|}{ Raw material $^{\mathrm{a}}$} & \multicolumn{4}{|c|}{$\begin{array}{c}\text { Stratigraphic position } \\
\end{array}$} & \multirow{2}{*}{\multicolumn{2}{|c|}{ Tuff IIB }} & \multicolumn{2}{|c|}{ Grand Total } \\
\hline & & \multicolumn{2}{|l|}{ Lava } & \multicolumn{2}{|c|}{ Metamorphic } & \multicolumn{2}{|c|}{ Chert } & \multicolumn{2}{|c|}{ Lemuta } & \multicolumn{2}{|l|}{ LAS } & & & \multirow{3}{*}{$n$} & \multirow[b]{2}{*}{$\%$} \\
\hline & & $n$ & $\%$ & $n$ & $\%$ & $n$ & $\%$ & $n$ & & $n$ & $\%$ & \multicolumn{2}{|c|}{$n \quad \%$} & & \\
\hline & & & 0.0 & 1 & 0.3 & & 0.0 & & 0.0 & 1 & 0.1 & & 0.0 & & 0.1 \\
\hline \multirow{5}{*}{ Length class } & $20-39 \mathrm{~mm}$ & 2 & 0.4 & 66 & 17.3 & 10 & 50.0 & 8 & 6.3 & 69 & 9.1 & 1 & 2.9 & 78 & 8.4 \\
\hline & $60-79 \mathrm{~mm}$ & 231 & 44.3 & 94 & 24.6 & 2 & 10.0 & 36 & 28.3 & 280 & 36.7 & 11 & 31.4 & 327 & 35.4 \\
\hline & $80-99 \mathrm{~mm}$ & 186 & 35.7 & 57 & 14.9 & & 0.0 & 39 & 30.7 & 191 & 25.1 & 14 & 40.0 & 244 & 26.4 \\
\hline & $>100 \mathrm{~mm}$ & 55 & 10.6 & 19 & 5.0 & & 0.0 & 23 & 18.1 & 45 & 5.9 & 6 & 17.1 & 74 & 8.0 \\
\hline & Total & 521 & 56.4 & 382 & 41.4 & 20 & 2.2 & 127 & 13.7 & 762 & 82.5 & 35 & 3.8 & 924 & 100.0 \\
\hline \multirow[t]{7}{*}{ Weight class } & $<50 \mathrm{~g}$ & 5 & 1.0 & 87 & 22.8 & 13 & 65.0 & 11 & 8.7 & 92 & 12.1 & 2 & 5.7 & 105 & 11.4 \\
\hline & $50-100 \mathrm{~g}$ & 21 & 4.0 & 65 & 17.0 & 4 & 20.0 & 10 & 7.9 & 80 & 10.5 & & 0.0 & 90 & 9.7 \\
\hline & $101-200 \mathrm{~g}$ & 111 & 21.3 & 86 & 22.5 & 2 & 10.0 & 25 & 19.7 & 171 & 22.4 & 4 & 11.4 & 200 & 21.6 \\
\hline & $201-400 \mathrm{~g}$ & 223 & 42.8 & 79 & 20.7 & 1 & 5.0 & 29 & 22.8 & 267 & 35.0 & 7 & 20.0 & 303 & 32.8 \\
\hline & $401-800 \mathrm{~g}$ & 139 & 26.7 & 49 & 12.8 & & 0.0 & 35 & 27.6 & 135 & 17.7 & 18 & 51.4 & 188 & 20.3 \\
\hline & $>800 \mathrm{~g}$ & 22 & 4.2 & 16 & 4.2 & & 0.0 & 17 & 13.4 & 17 & 2.2 & 4 & 11.4 & 38 & 4.1 \\
\hline & Total & 521 & 56.4 & 382 & 41.4 & 20 & 2.2 & 127 & 13.7 & 762 & 82.5 & 35 & 3.8 & 924 & 100.0 \\
\hline \multirow[t]{3}{*}{ Cortex } & Cortex $>50 \%$ & 280 & 78.2 & 105 & 32.3 & 8 & 40.0 & 56 & 52.8 & 336 & 57.7 & 2 & 12.5 & 394 & 56.0 \\
\hline & Cortex $<50 \%$ & 72 & 20.1 & 148 & 45.5 & 11 & 55.0 & 45 & 42.5 & 177 & 30.4 & 9 & 56.3 & 231 & 32.8 \\
\hline & Total & 358 & 50.9 & 325 & 46.2 & 20 & 2.8 & 106 & 15.1 & 582 & 82.7 & 16 & 2.3 & 704 & 100.0 \\
\hline \multirow[t]{7}{*}{ Blank } & Cobble & 440 & 88.9 & 28 & 11.1 & 1 & 6.3 & 54 & 50.5 & 403 & 63.8 & 13 & 50.0 & 470 & 61.4 \\
\hline & Block & & 0.0 & 89 & 35.2 & & 0.0 & 25 & 23.4 & 54 & 8.5 & 10 & 38.5 & 89 & 11.6 \\
\hline & Nodule & & 0.0 & & 0.0 & 8 & 31.3 & & 0.0 & 8 & 1.3 & & 0.0 & 8 & 1.1 \\
\hline & Fragment & 38 & 7.7 & 109 & 43.1 & 6 & 37.5 & 23 & 21.5 & 128 & 20.3 & 2 & 7.7 & 153 & 20.0 \\
\hline & Split Cobble & 15 & 3.0 & & 0.0 & & 0.0 & 2 & 1.9 & 13 & 2.1 & & 0.0 & 15 & 2.0 \\
\hline & Flake & 2 & 0.4 & 27 & 10.7 & 1 & 6.3 & 3 & 2.8 & 26 & 4.1 & 1 & 3.8 & 30 & 3.9 \\
\hline & Total & 495 & 64.8 & 253 & 33.1 & 16 & 2.1 & 107 & 14.0 & 632 & 82.6 & 26 & 3.4 & 765 & 100.0 \\
\hline \multirow[t]{5}{*}{ Battering } & Esquillees & 15 & 2.9 & 37 & 9.6 & 6 & 30.0 & 8 & 6.3 & 47 & 6.2 & 3 & 8.6 & 58 & 6.3 \\
\hline & Impacts & 97 & 18.6 & 120 & 31.3 & & 0.0 & 34 & 26.8 & 168 & 22.0 & 15 & 42.9 & 217 & 23.5 \\
\hline & Percus. fractures & 24 & 4.6 & 1 & 0.3 & & 0.0 & 6 & 4.7 & 19 & 2.5 & & 0.0 & 25 & 2.7 \\
\hline & Absent & 385 & 73.9 & 226 & 58.9 & 14 & 70.0 & 79 & 62.2 & 529 & 69.3 & 17 & 48.6 & 625 & 67.6 \\
\hline & Total & 521 & 56.3 & 384 & 41.5 & 20 & 2.2 & 127 & 13.7 & 763 & 82.5 & 35 & 3.8 & 925 & 100.0 \\
\hline \multirow[t]{4}{*}{ Number of scars } & $1-3$ scars & 169 & 51.8 & 121 & 39.4 & 2 & 10.5 & 33 & 32.0 & 259 & 48.1 & 1 & 8.3 & 293 & 44.9 \\
\hline & 4-6 scars & 106 & 32.5 & 130 & 42.3 & 10 & 52.6 & 46 & 44.7 & 196 & 36.4 & 4 & 33.3 & 246 & 37.7 \\
\hline & 7-9 scars & 44 & 13.5 & 45 & 14.7 & 7 & 36.8 & 19 & 18.4 & 72 & 13.4 & 5 & 41.7 & 96 & 14.7 \\
\hline & $>9$ scars & 7 & 2.1 & 11 & 3.6 & & 0.0 & 5 & 4.9 & 11 & 2.0 & 2 & 16.7 & 18 & 2.8 \\
\hline
\end{tabular}

${ }^{\mathrm{a} B r e a k d o w n s ~ b y ~ r a w ~ m a t e r i a l ~}$

have one less item than by stratigraphic interval (rock type = other than lava,

metamorphic or chert). LAS =

Lower Augitic Sandstone. 


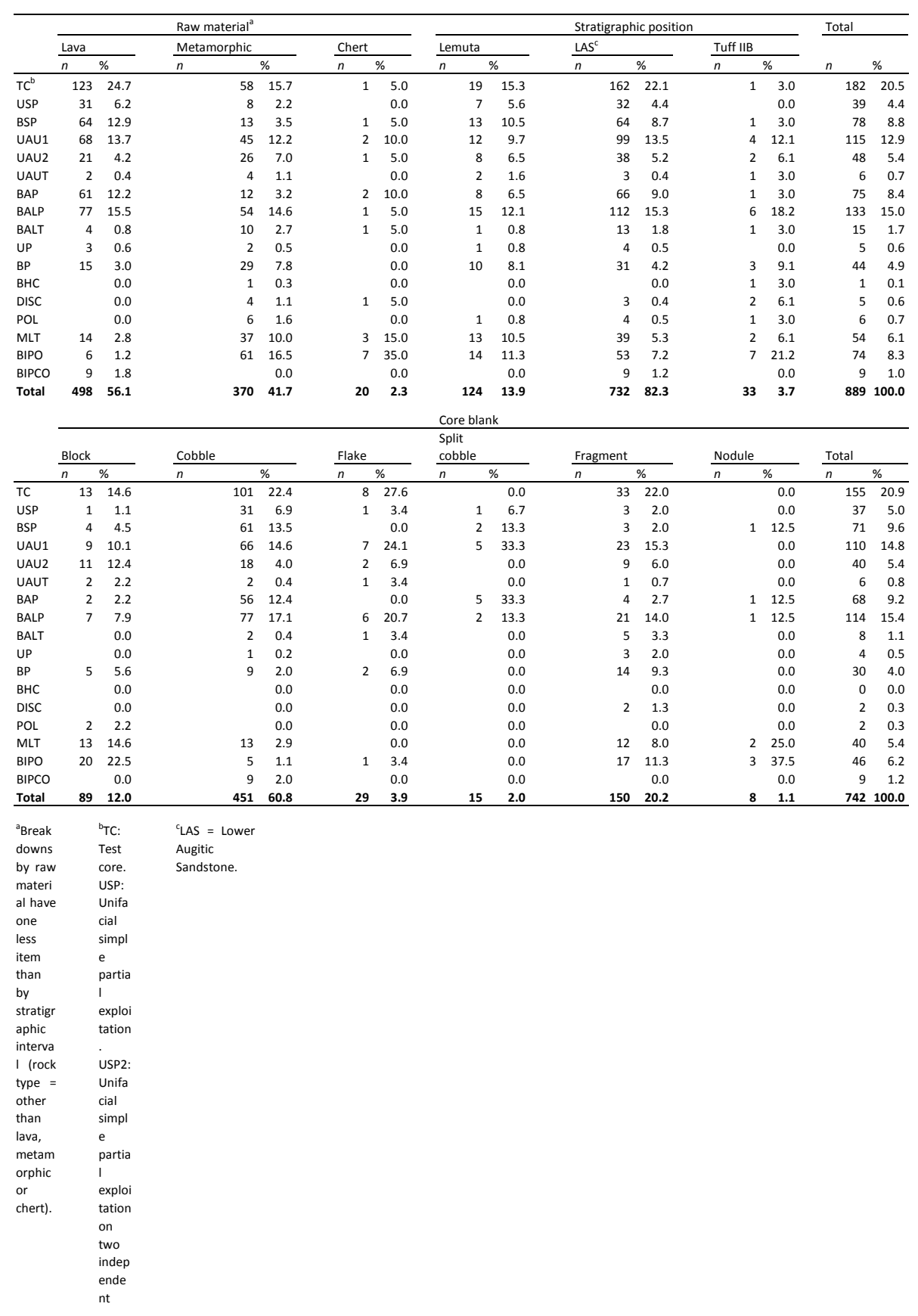




\begin{tabular}{|c|c|c|c|c|c|c|c|}
\hline \multirow[b]{2}{*}{ Absolute frequency } & \multicolumn{6}{|c|}{ Length class $(\mathrm{mm})$} & \multirow[b]{2}{*}{$<50$} \\
\hline & $<20$ & $20-39$ & $40-59$ & $60-79$ & $80-99$ & $>100$ & \\
\hline TC & & 12 & 34 & 67 & 56 & 13 & 20 \\
\hline USP & & 3 & 2 & 15 & 14 & 5 & 2 \\
\hline BSP & & 1 & 16 & 36 & 21 & 4 & 2 \\
\hline UAU1 & & 8 & 21 & 46 & 33 & 7 & 10 \\
\hline UAU2 & & 3 & 8 & 17 & 14 & 6 & 3 \\
\hline UAUT & & 1 & 1 & 3 & 1 & & 1 \\
\hline BAP & & 3 & 16 & 33 & 19 & 4 & 4 \\
\hline BALP & & 15 & 25 & 38 & 40 & 15 & 21 \\
\hline BALT & & 5 & 6 & 2 & 2 & & 7 \\
\hline UP & & 1 & 1 & 2 & & 1 & 1 \\
\hline BP & & 4 & 18 & 13 & 5 & 4 & 7 \\
\hline $\mathrm{BHC}$ & & 1 & & & & & 1 \\
\hline DISC & & 1 & 2 & 2 & & & 2 \\
\hline POL & & & 2 & 3 & 1 & & \\
\hline MLT & & 3 & 12 & 15 & 16 & 8 & 2 \\
\hline BIPO & 1 & 16 & 27 & 17 & 10 & 3 & 18 \\
\hline BIPCO & & & 1 & 4 & 1 & 3 & \\
\hline \multirow[t]{2}{*}{ Total } & 1 & 77 & 192 & 313 & 233 & 73 & 101 \\
\hline & \multicolumn{6}{|c|}{ Length class (mm) } & \\
\hline Relative frequency & $<20$ & $20-39$ & $40-59$ & $60-79$ & $80-99$ & $>100$ & $<50$ \\
\hline TC & 0.0 & 15.6 & 17.7 & 21.4 & 24.0 & 17.8 & 19.8 \\
\hline USP & 0.0 & 3.9 & 1.0 & 4.8 & 6.0 & 6.8 & 2.0 \\
\hline BSP & 0.0 & 1.3 & 8.3 & 11.5 & 9.0 & 5.5 & 2.0 \\
\hline UAU1 & 0.0 & 10.4 & 10.9 & 14.7 & 14.2 & 9.6 & 9.9 \\
\hline UAU2 & 0.0 & 3.9 & 4.2 & 5.4 & 6.0 & 8.2 & 3.0 \\
\hline UAUT & 0.0 & 1.3 & 0.5 & 1.0 & 0.4 & 0.0 & 1.0 \\
\hline BAP & 0.0 & 3.9 & 8.3 & 10.5 & 8.2 & 5.5 & 4.0 \\
\hline BALP & 0.0 & 19.5 & 13.0 & 12.1 & 17.2 & 20.5 & 20.8 \\
\hline BALT & 0.0 & 6.5 & 3.1 & 0.6 & 0.9 & 0.0 & 6.9 \\
\hline UP & 0.0 & 1.3 & 0.5 & 0.6 & 0.0 & 1.4 & 1.0 \\
\hline BP & 0.0 & 5.2 & 9.4 & 4.2 & 2.1 & 5.5 & 6.9 \\
\hline $\mathrm{BHC}$ & 0.0 & 1.3 & 0.0 & 0.0 & 0.0 & 0.0 & 1.0 \\
\hline DISC & 0.0 & 1.3 & 1.0 & 0.6 & 0.0 & 0.0 & 2.0 \\
\hline POL & 0.0 & 0.0 & 1.0 & 1.0 & 0.4 & 0.0 & 0.0 \\
\hline MLT & 0.0 & 3.9 & 6.3 & 4.8 & 6.9 & 11.0 & 2.0 \\
\hline BIPO & 100.0 & 20.8 & 14.1 & 5.4 & 4.3 & 4.1 & 17.8 \\
\hline BIPCO & 0.0 & 0.0 & 0.5 & 1.3 & 0.4 & 4.1 & 0.0 \\
\hline Total & 0.1 & 8.7 & 21.6 & 35.2 & 26.2 & 8.2 & 11.4 \\
\hline
\end{tabular}




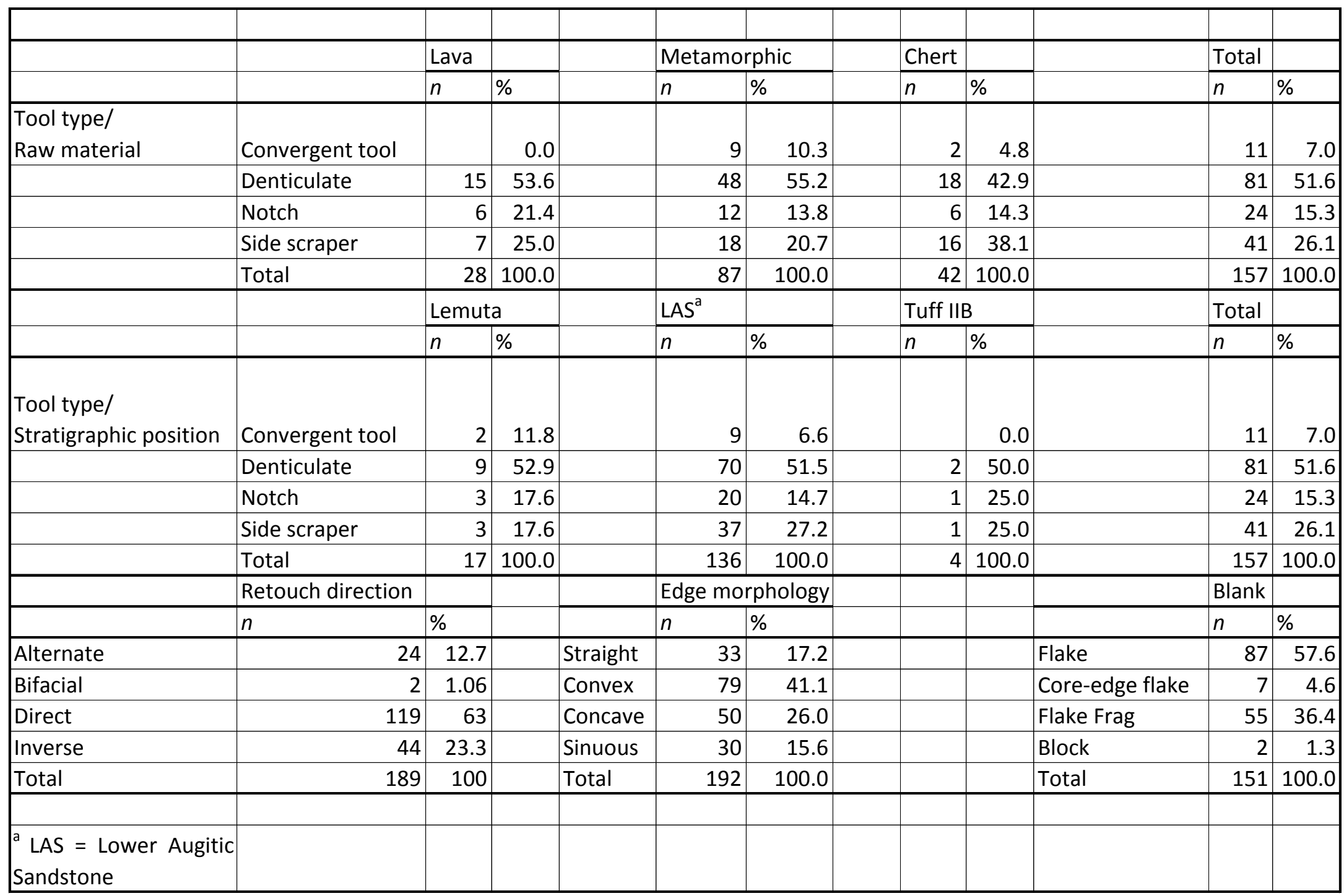




\begin{tabular}{|c|c|c|c|c|c|c|c|}
\hline & & \multicolumn{3}{|c|}{ Raw material } & \multicolumn{3}{|c|}{ Interval } \\
\hline & & Lava & Metamorphic & Chert & Lemuta & $\mathrm{LAS}^{\mathrm{b}}$ & Tuff IIB \\
\hline A.1 & Flake: core & 0.44 & 2.83 & 2.70 & 2.18 & 1.38 & 1.06 \\
\hline A.2 & Flake \& flake frag: core & 0.94 & 9.96 & 7.10 & 6.07 & 4.68 & 3.11 \\
\hline B.1 & Flake: core scars & 0.18 & 0.80 & 0.51 & 0.55 & 0.49 & 0.45 \\
\hline B.2 & Flake \& flake frag: core scars & 0.39 & 2.83 & 1.35 & 1.54 & 1.66 & 1.33 \\
\hline C & Detached pieces cutting edge $(\mathrm{cm})$ : Core mass $(\mathrm{g})$ & 0.01 & 0.05 & 0.37 & 0.03 & 0.03 & 0.01 \\
\hline D.1 & Retouched tool: detached pieces $\geq 12 \mathrm{~mm}$ & 0.05 & 0.01 & 0.21 & 0.01 & 0.02 & 0.02 \\
\hline D.2 & Retouched tool: flake or flake frag $\geq 20 \mathrm{~mm}$ & 0.06 & 0.04 & 0.59 & 0.03 & 0.06 & 0.05 \\
\hline D.3 & Retouched tool: flake $\geq 20 \mathrm{~mm}$ & 0.13 & 0.10 & 1.07 & 0.07 & 0.16 & 0.11 \\
\hline
\end{tabular}




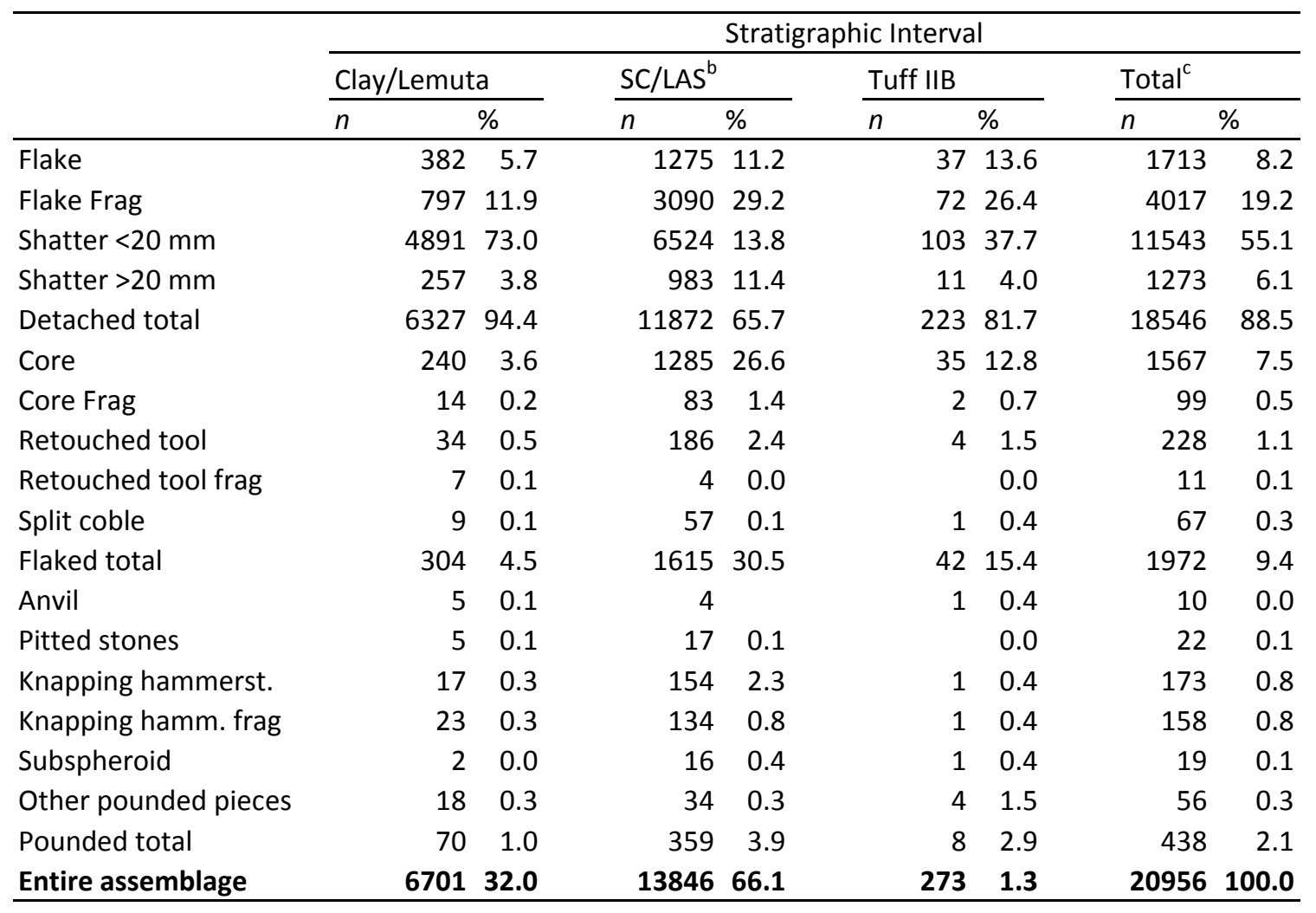

${ }^{a}$ See Pante and de la ${ }^{b} \mathrm{SC}=\quad d$

$\begin{array}{lll}\text { Torre (2018) for details Sandy } & { }^{\mathrm{C}} \text { Incl Inclu } \\ \text { on the correlation Conglome }\end{array}$

on the correlation Conglome udes des
between OGAP and rate. LAS $=u_{\text {piec }} 743$

Leakey's stratigraphic Lower piec $g$

intervals. Augitic from from

Sandstone from 'othe

Leak ${ }^{\prime}$

ey raw

colle mate

ction rials.

not

assig

ned

to

Clay

or

SC. 


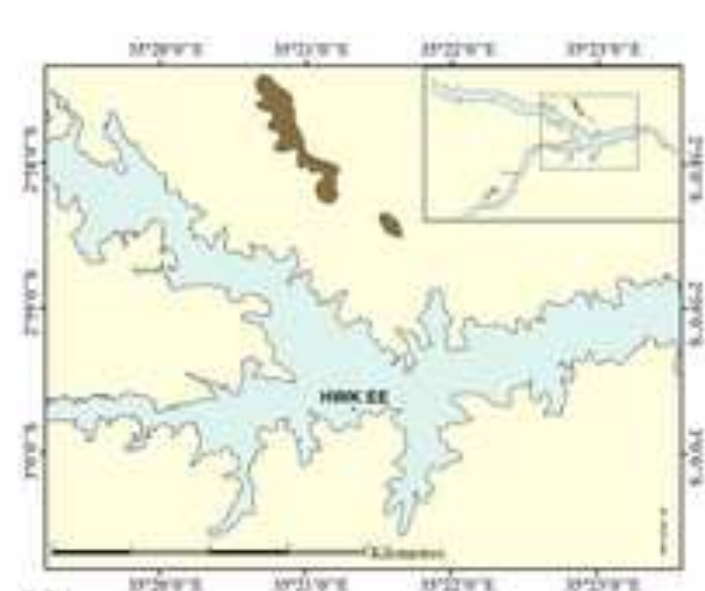

A)
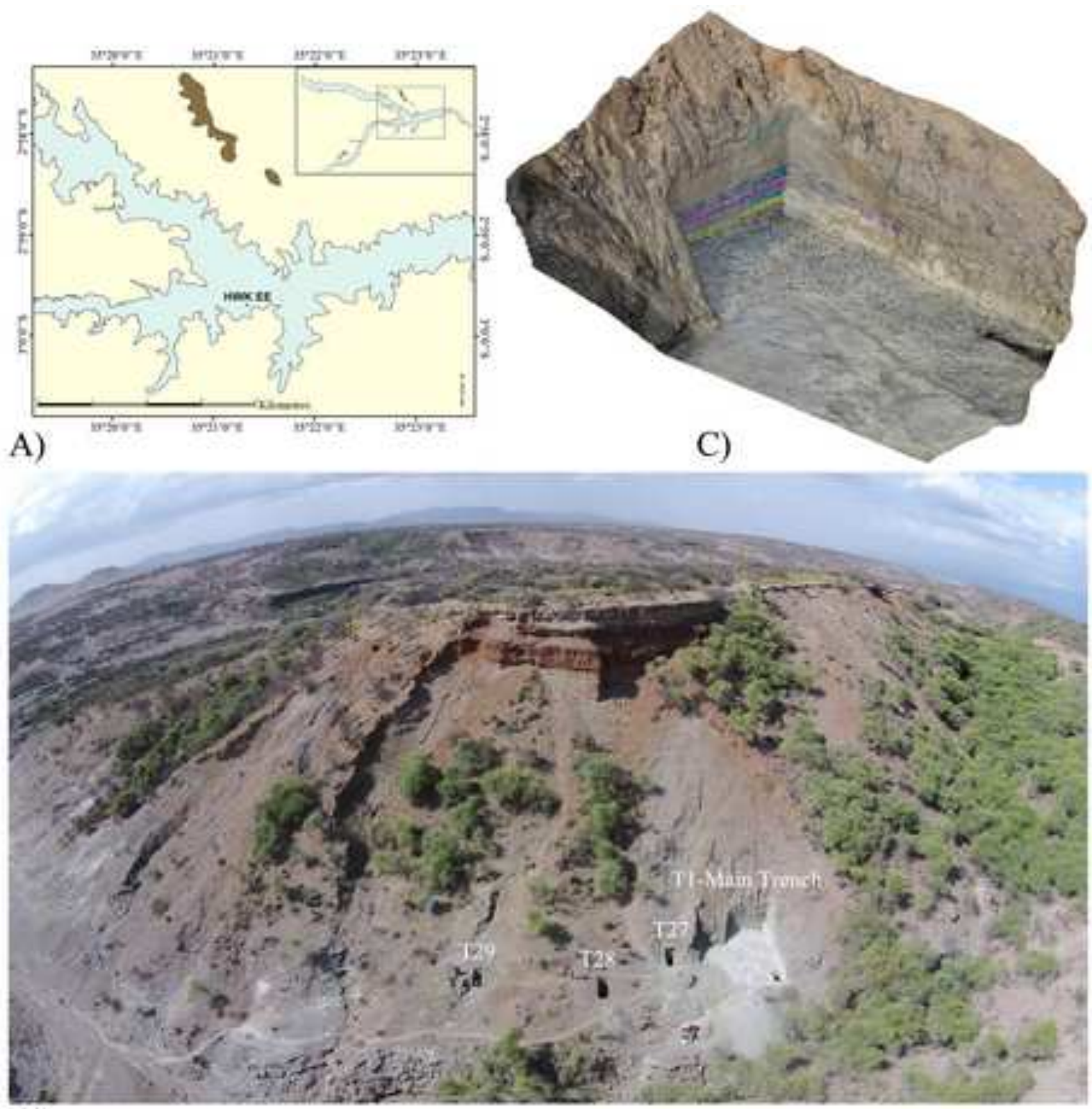

B)

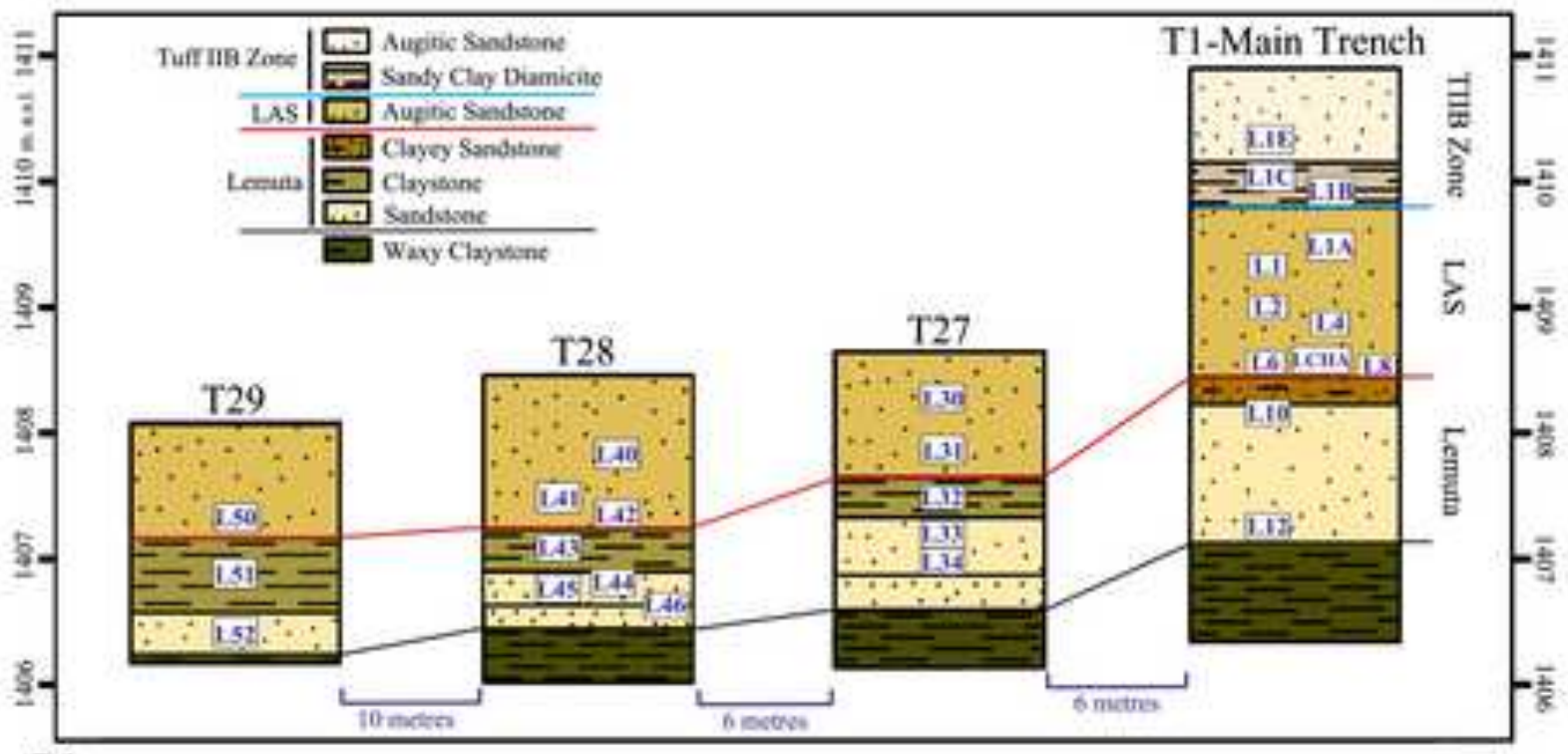

D) 
Figure_2
Click here to download high resolution image
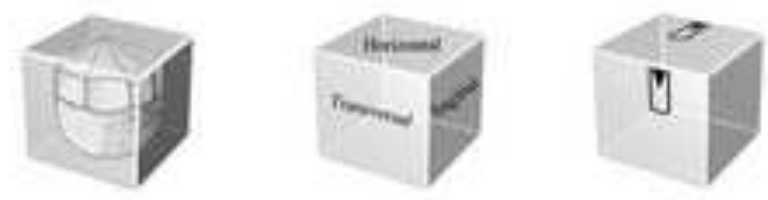

TC
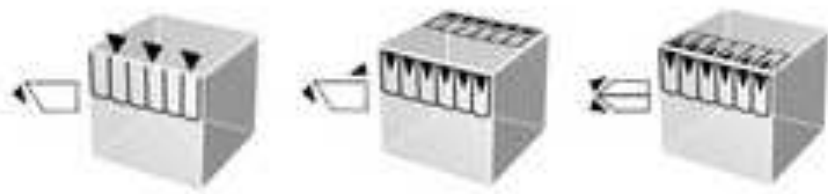

USP

USP2

BSP
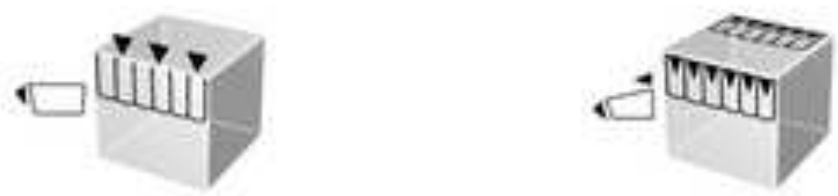

UAUI

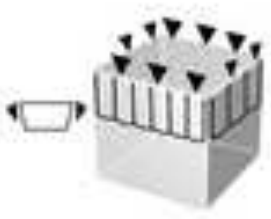

UAU2

UAUT
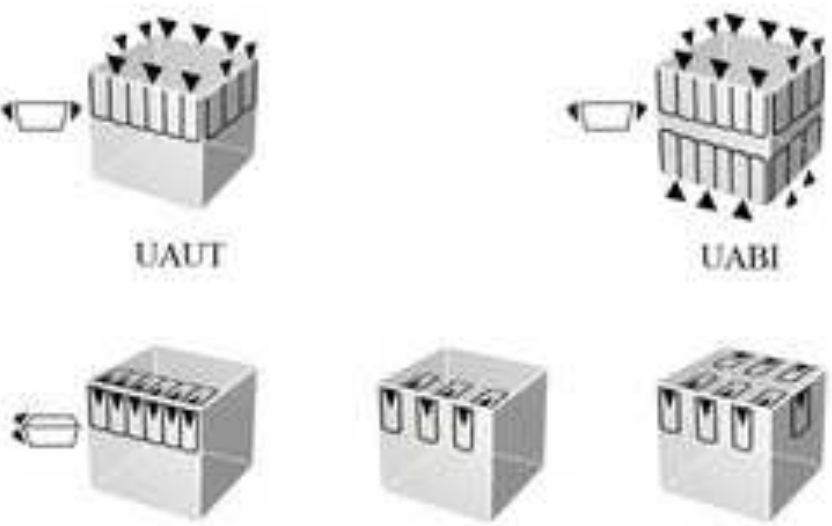

BAP

BALP

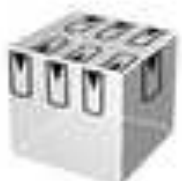

BALI

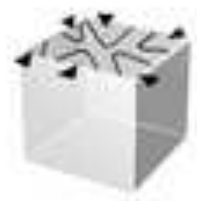

UP

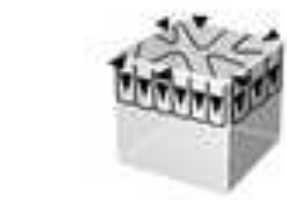

BP
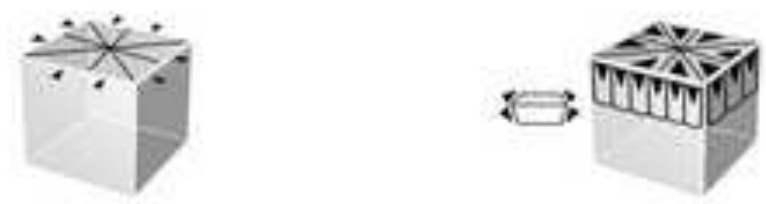

uc

BHC
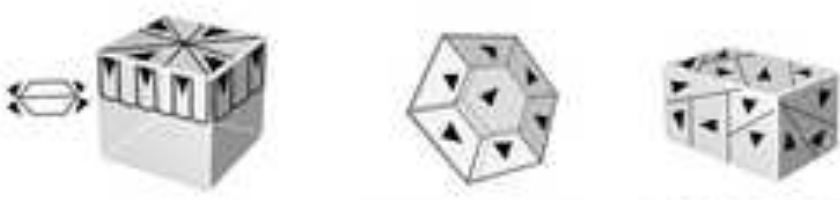

DISCOID

POLYHEDRAI

MUITIFACLA 
Figure_3

Click here to download high resolution image
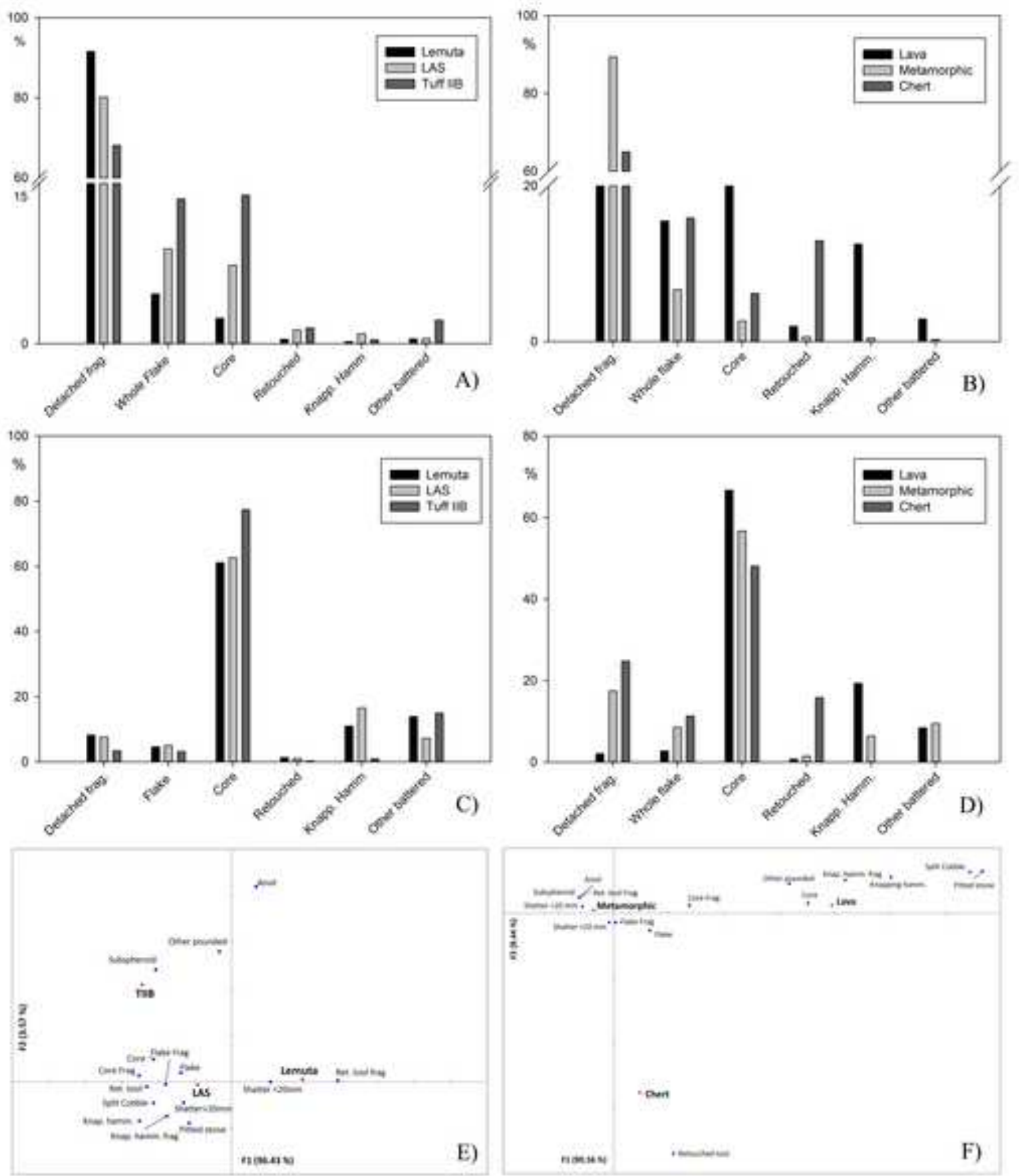
Figure_4
Click here to download high resolution image
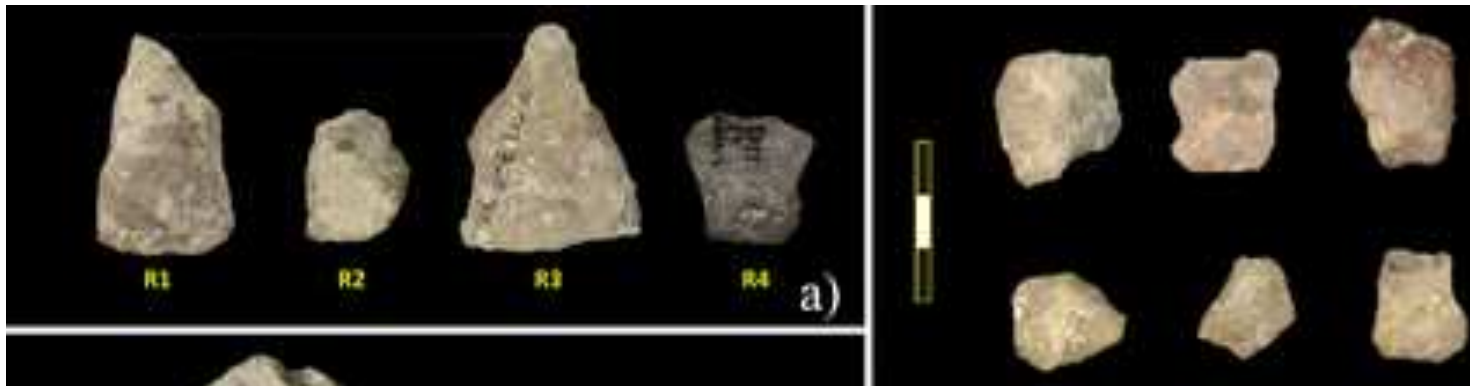

b)
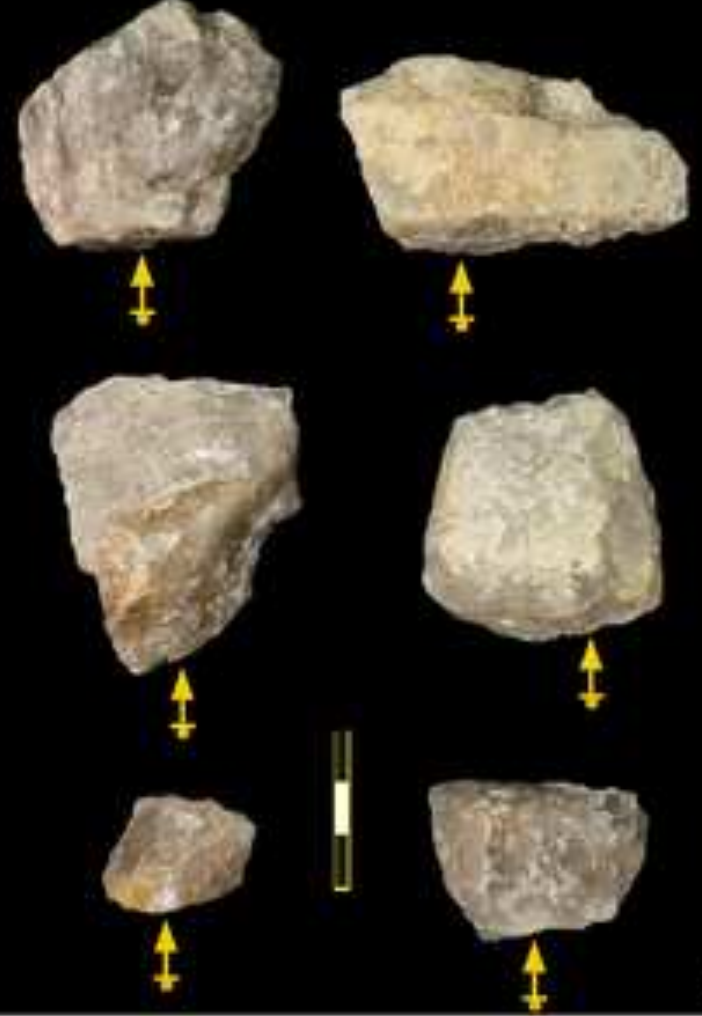

c)

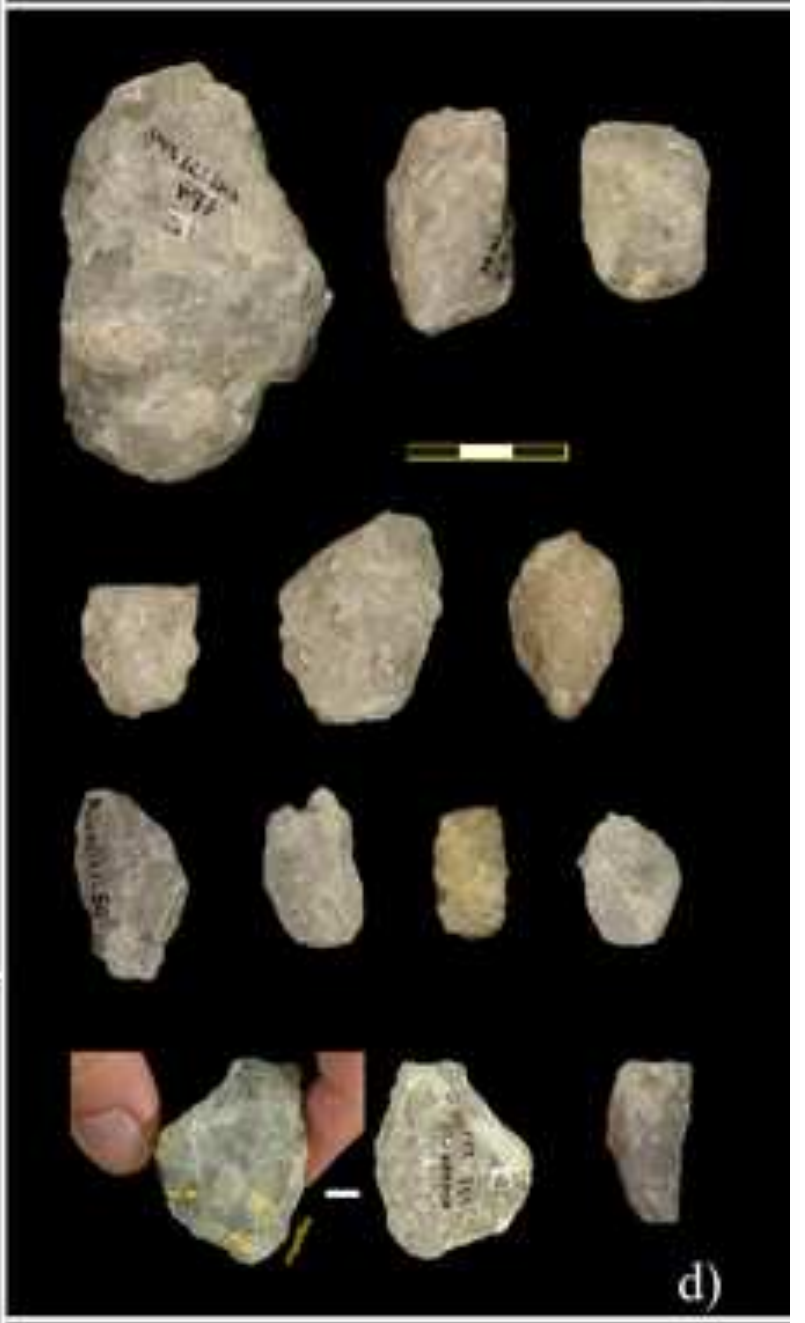

I
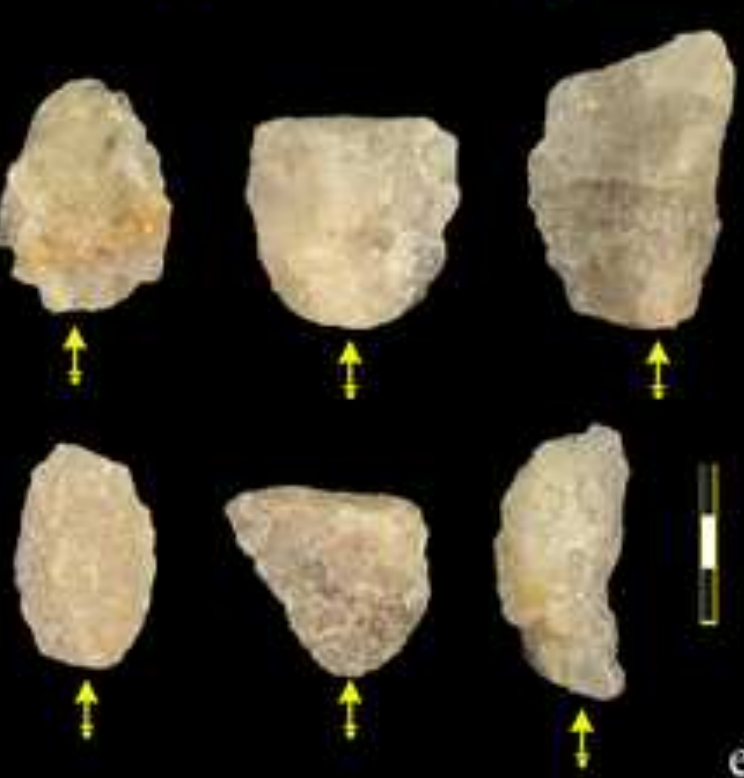

e)

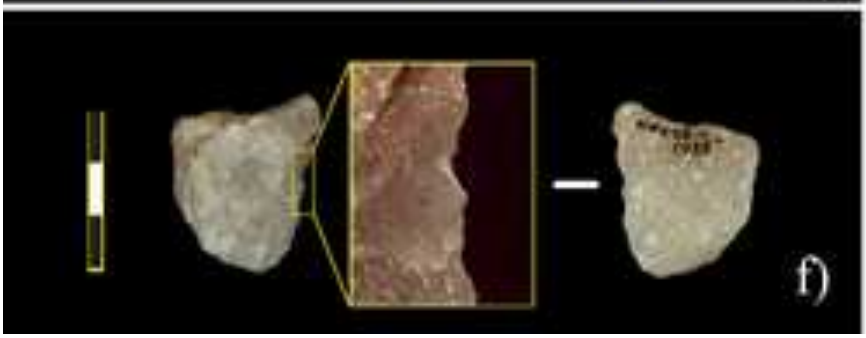

f)
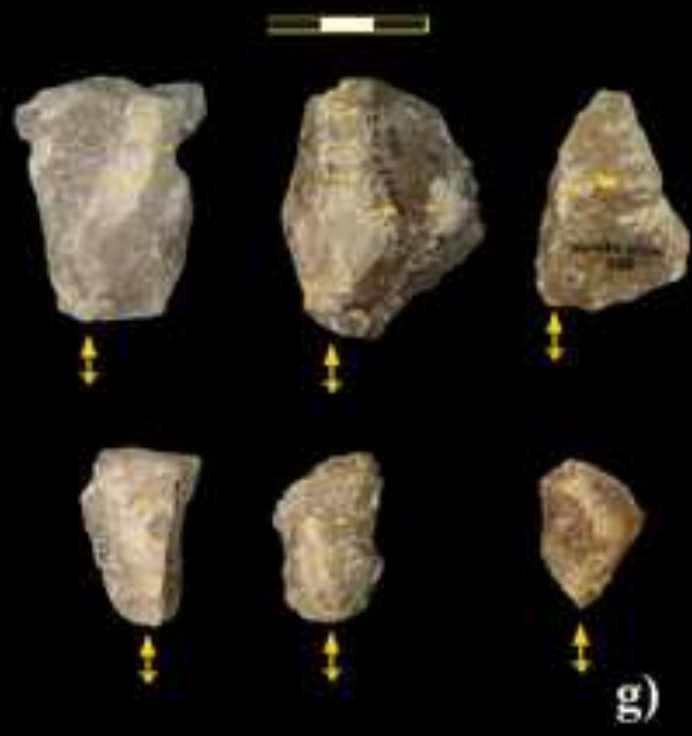
Figure_5

Click here to download high resolution image
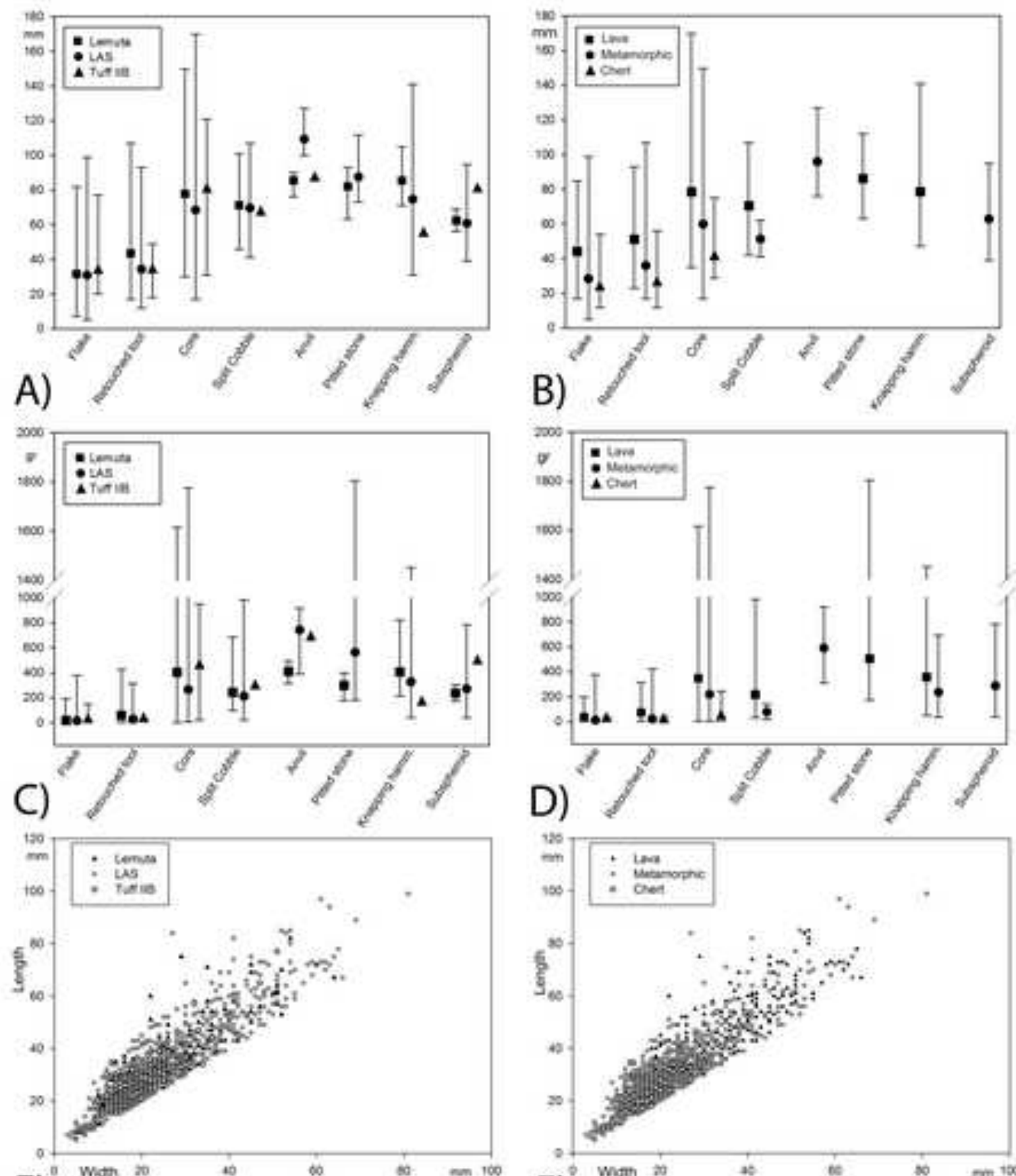

E)
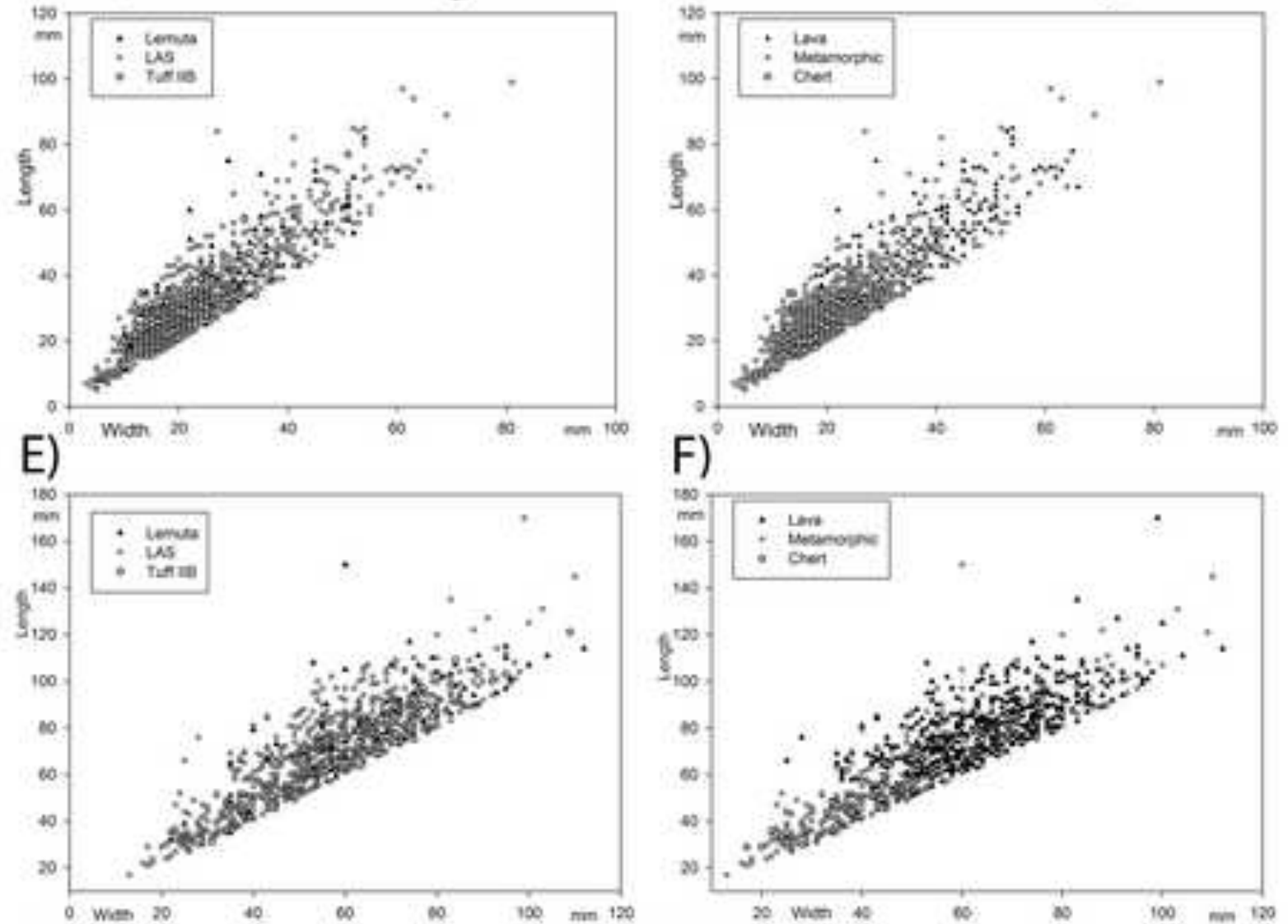

G)

F)

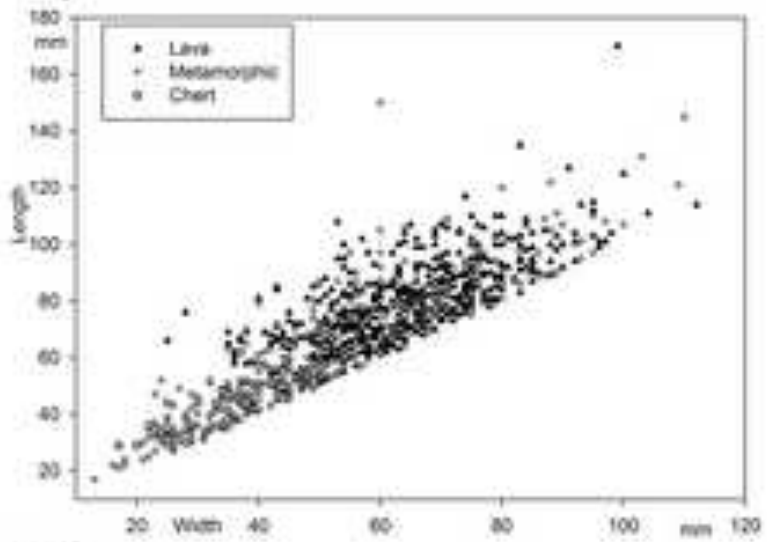

H) 
Figure_6

Click here to download high resolution image
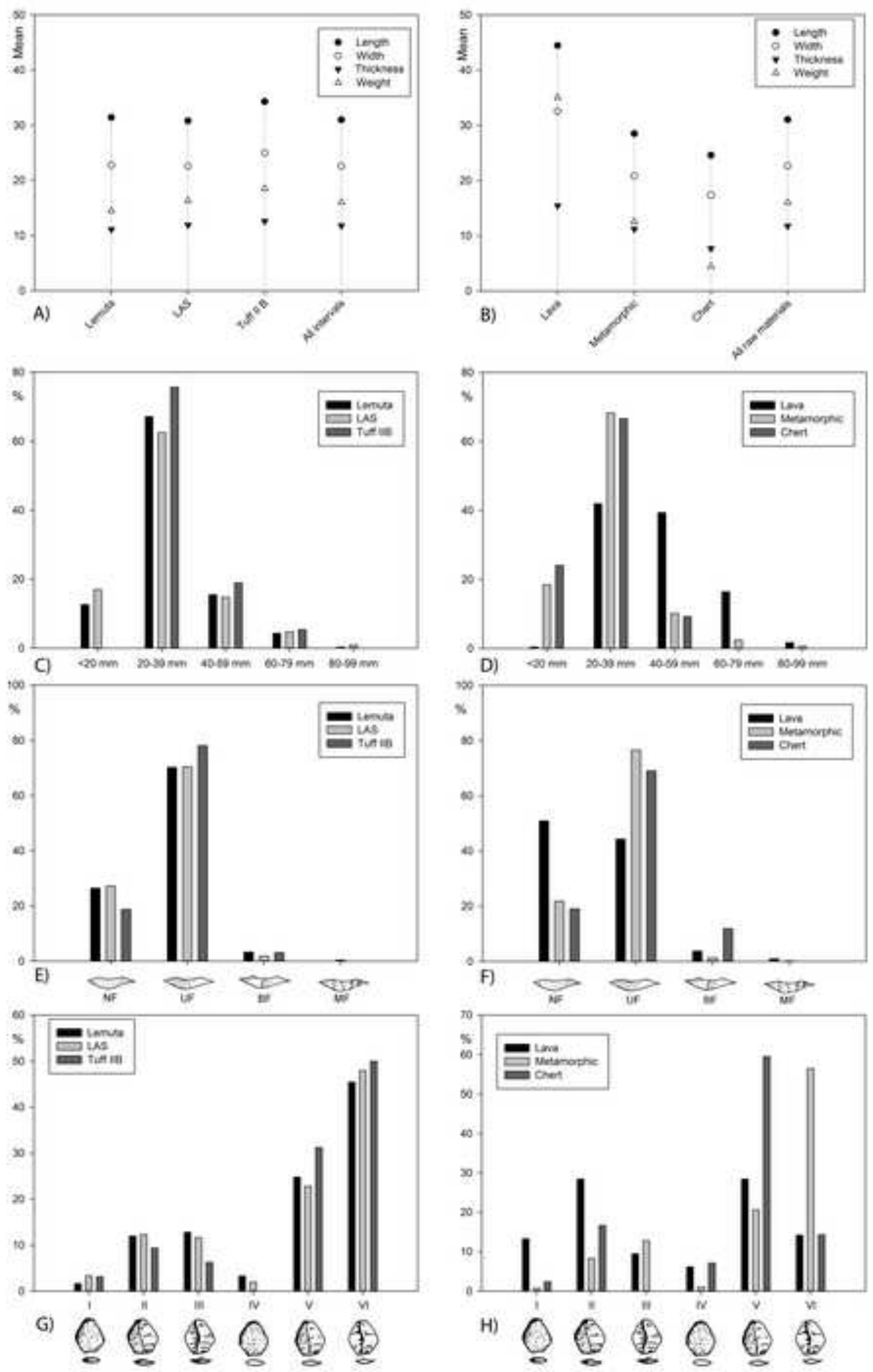

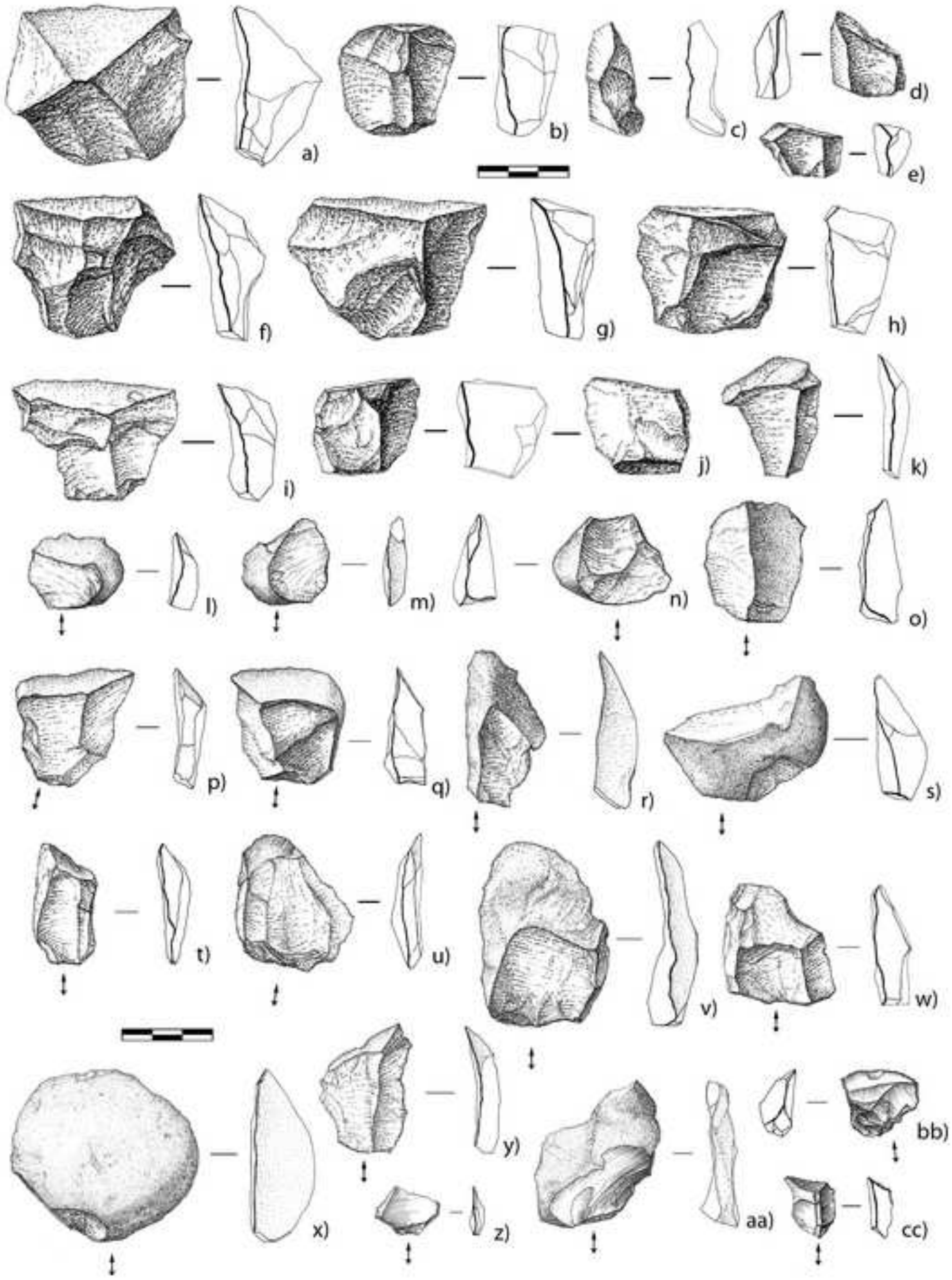
Figure_8

Click here to download high resolution image

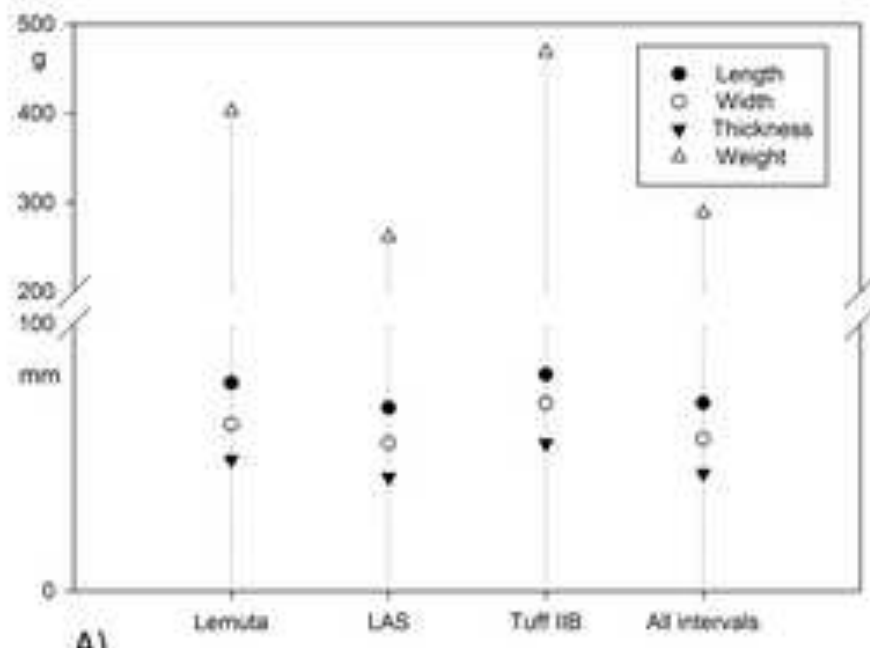

A)
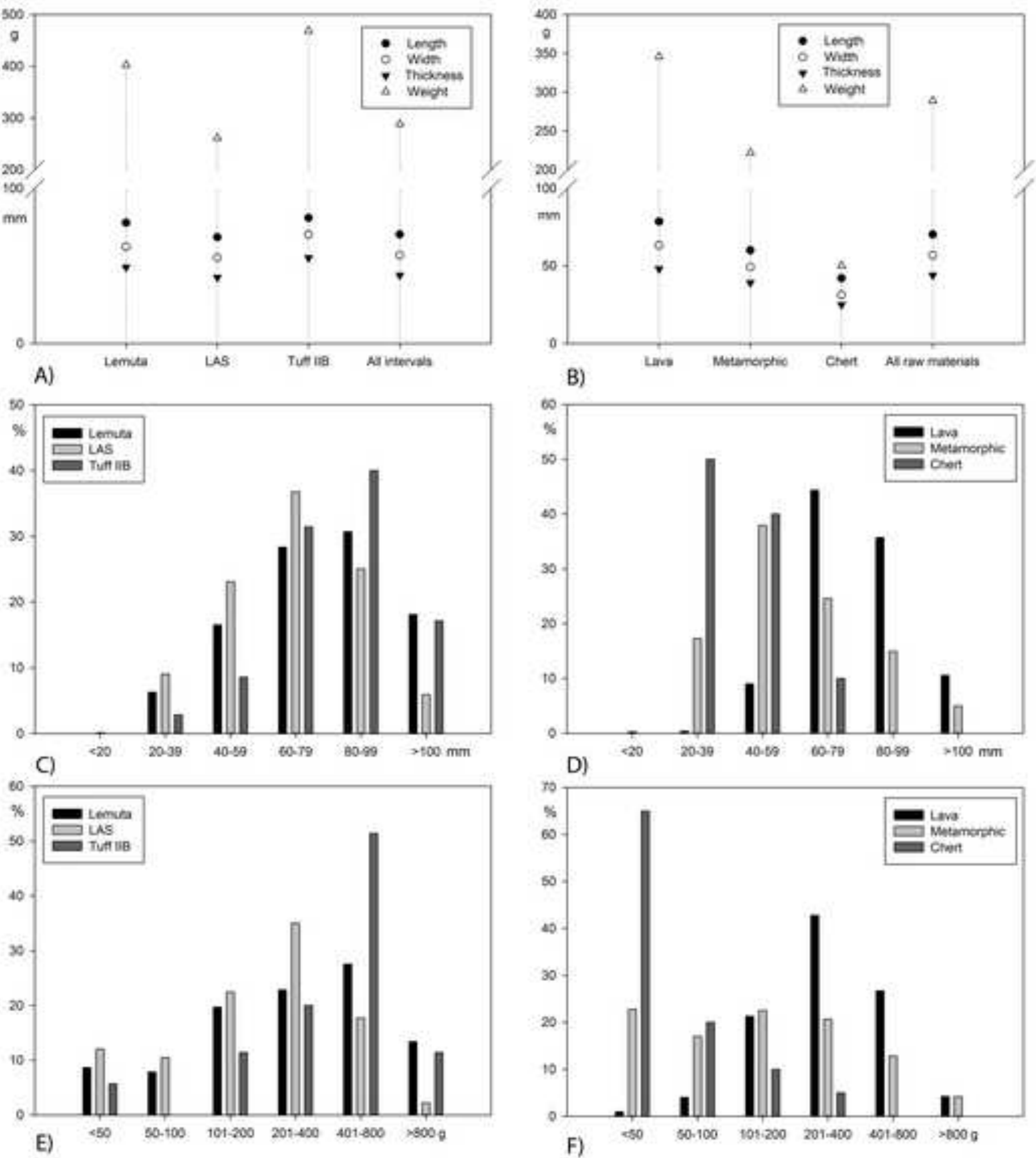

B)
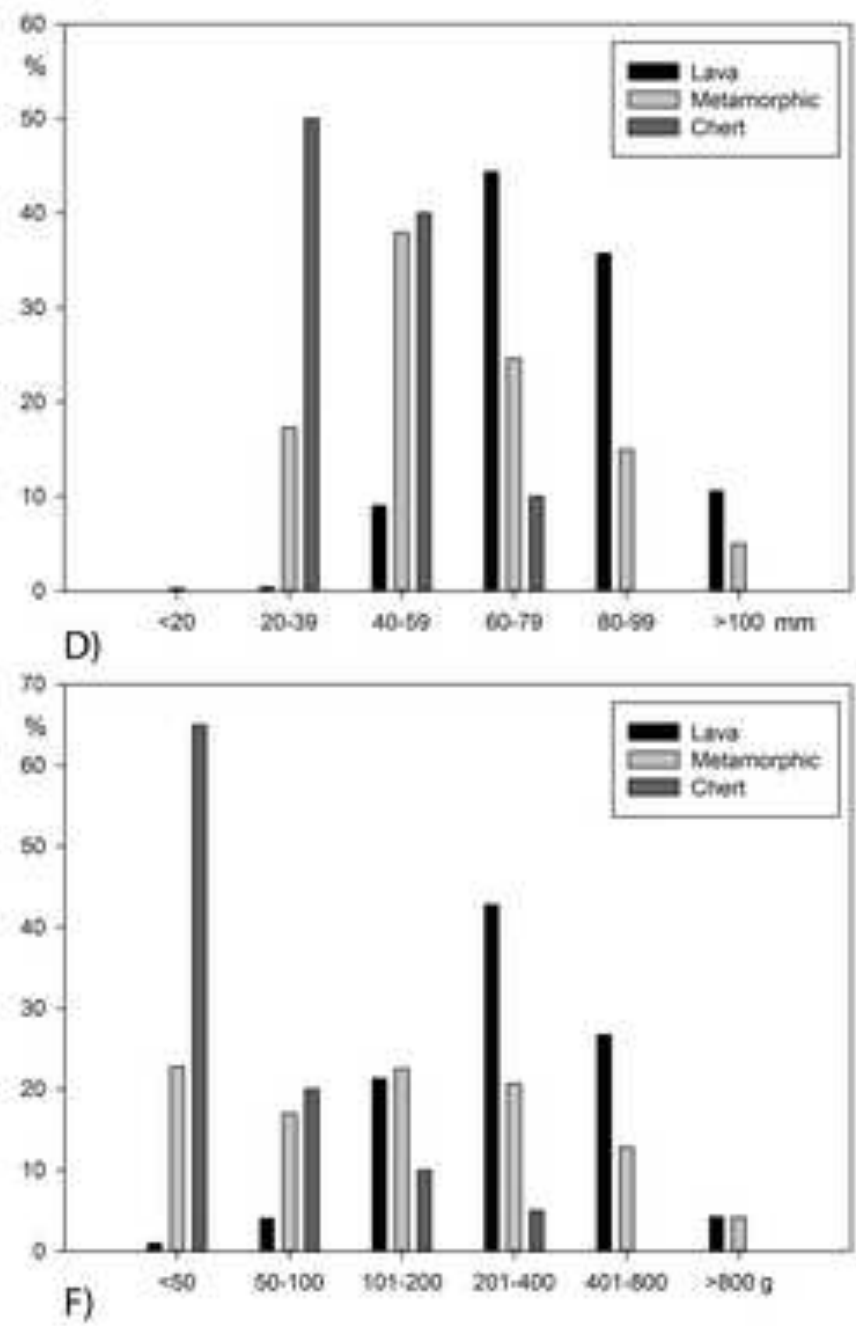
Figure_9
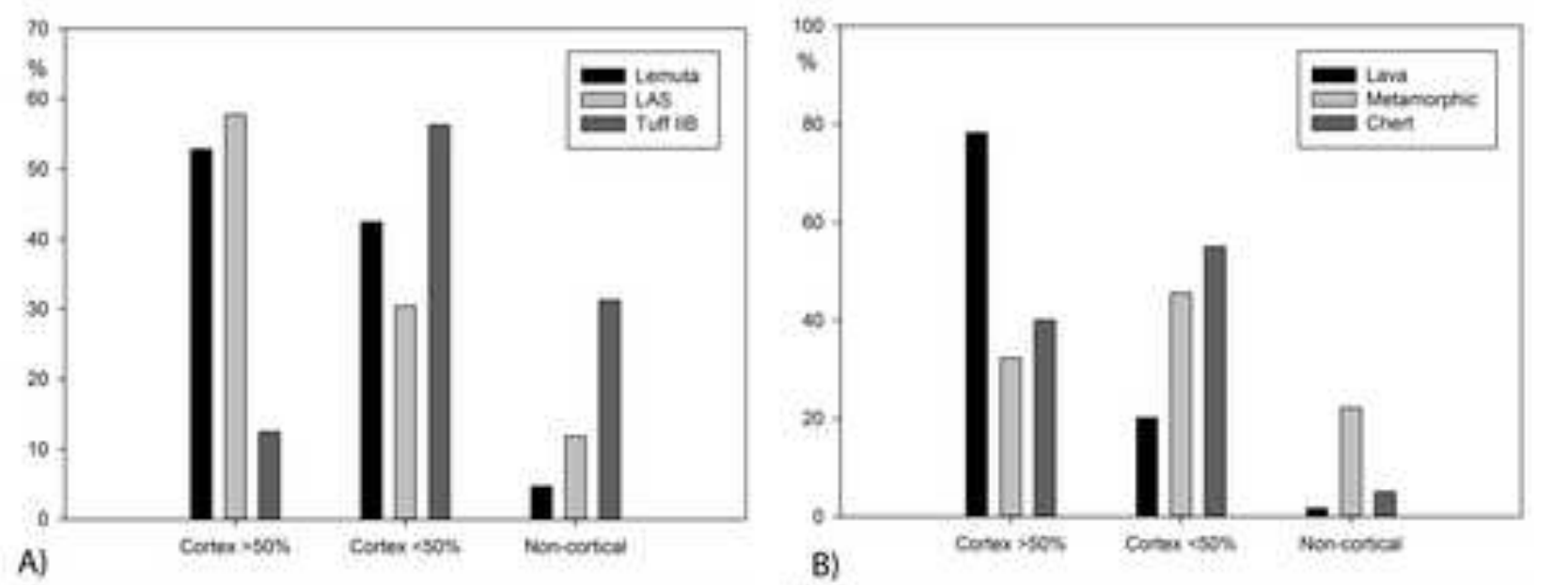

H)

Click here to download high resolution image
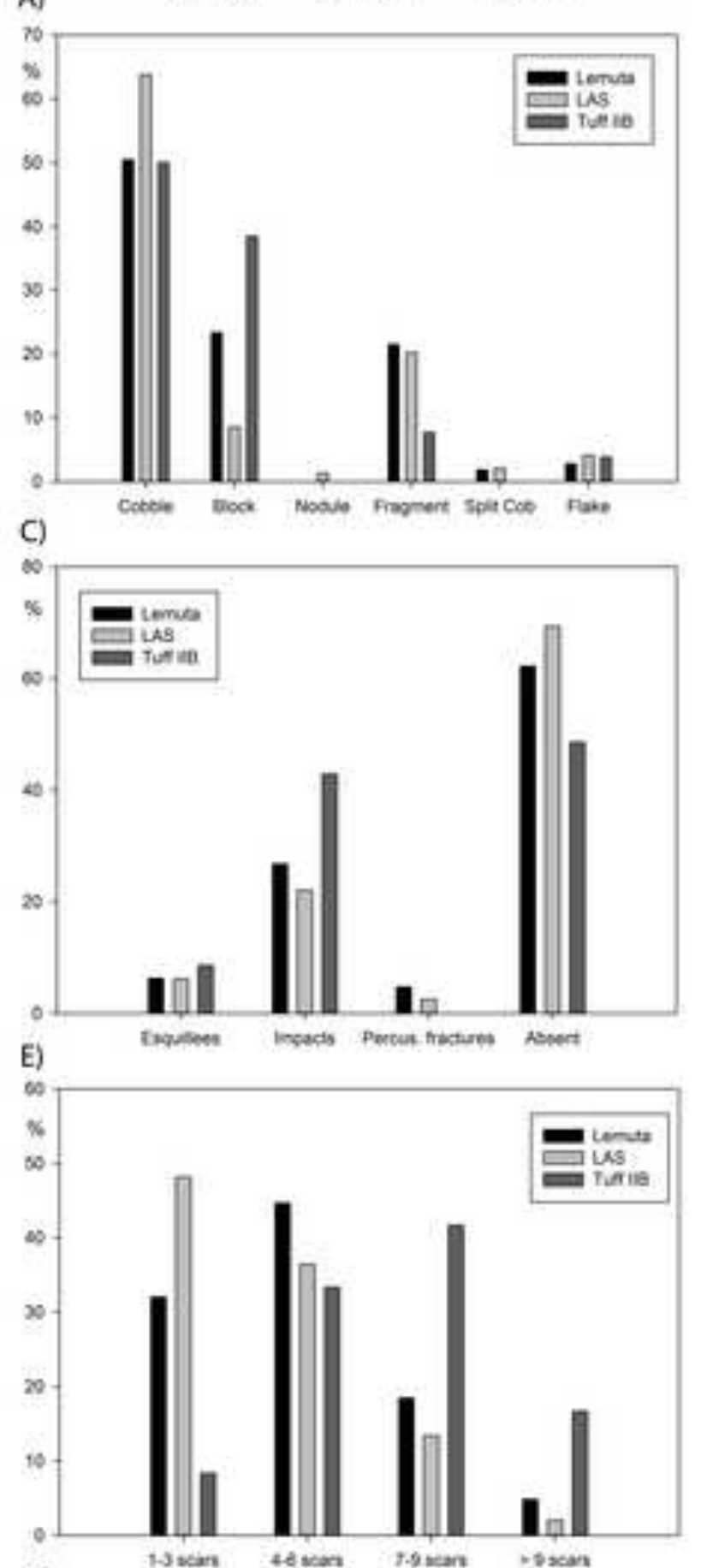

G)

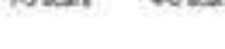

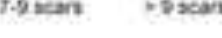

B)

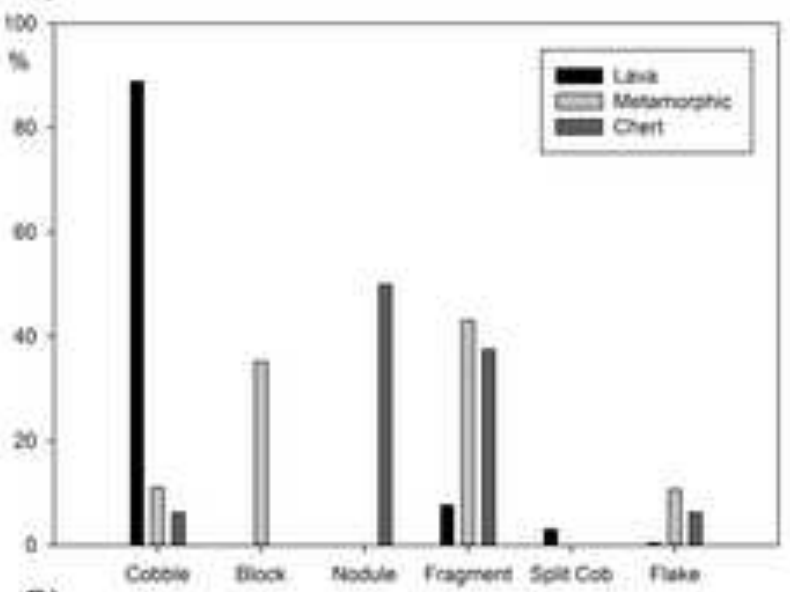

D)

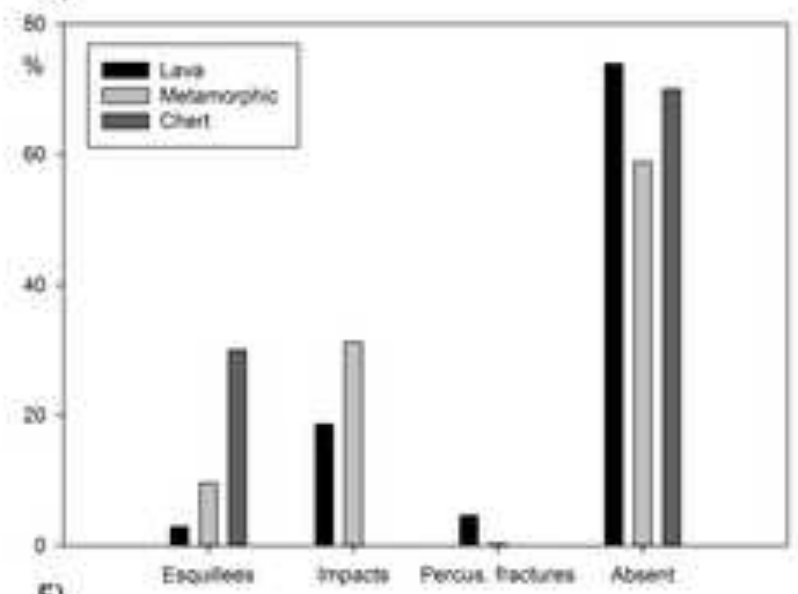

F)

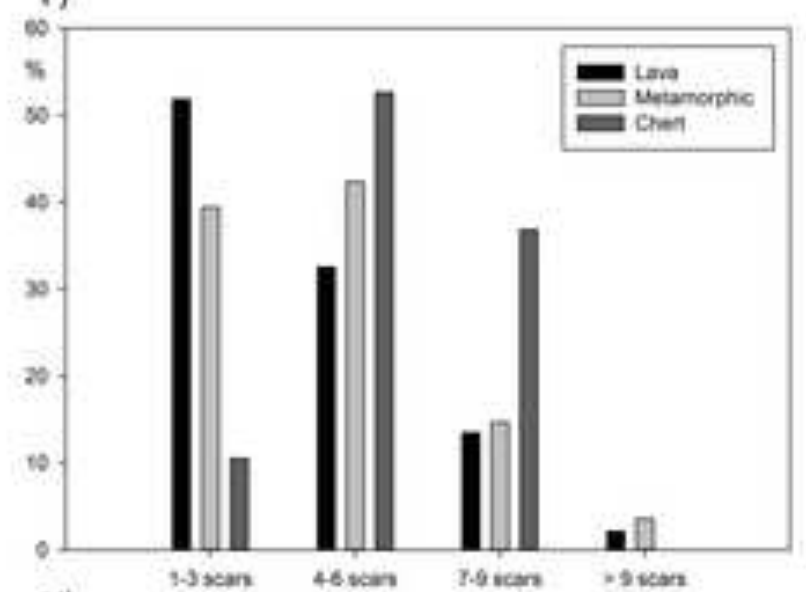
Wear 


\section{Click here to download high resolution image}
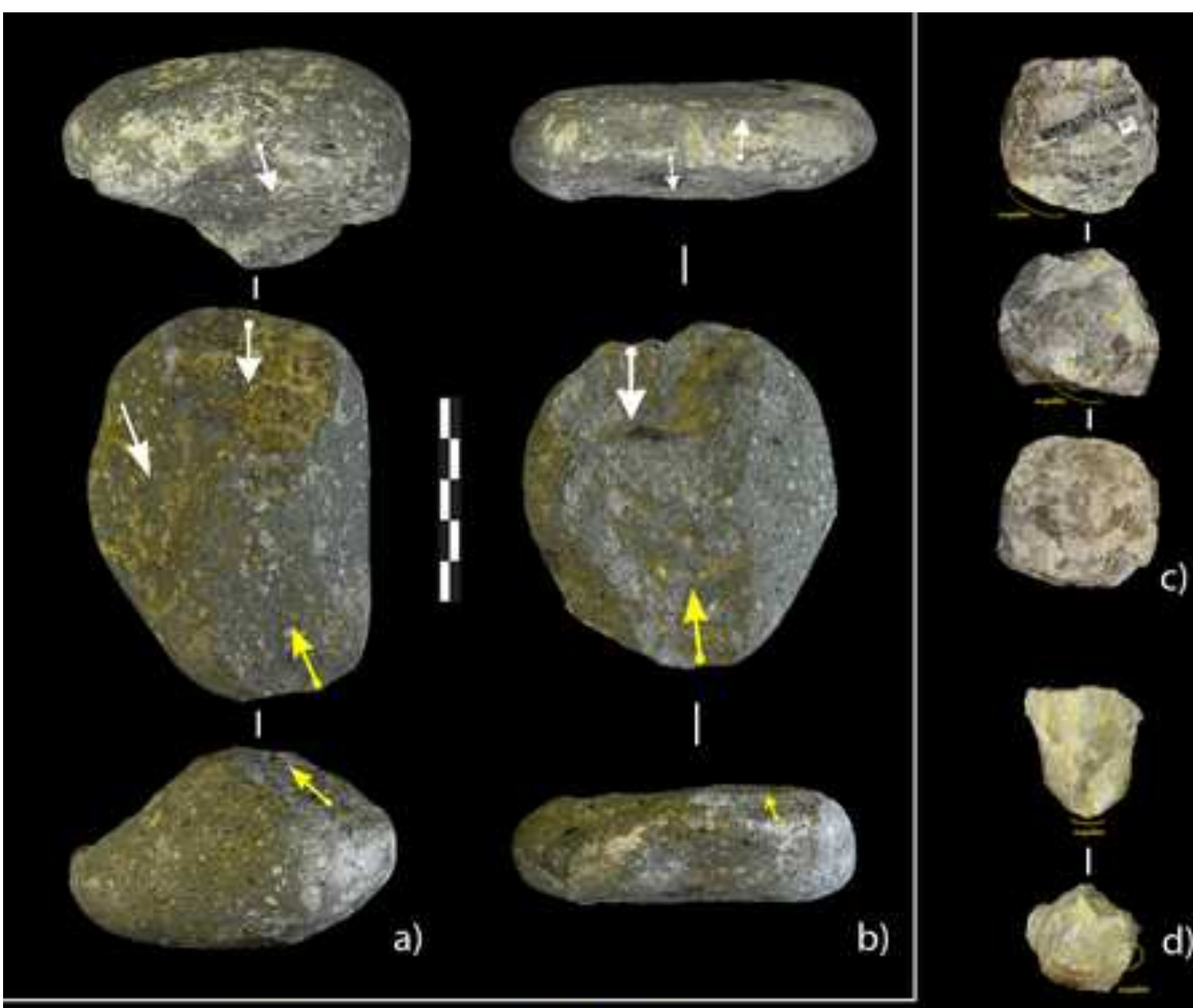

c)

d)

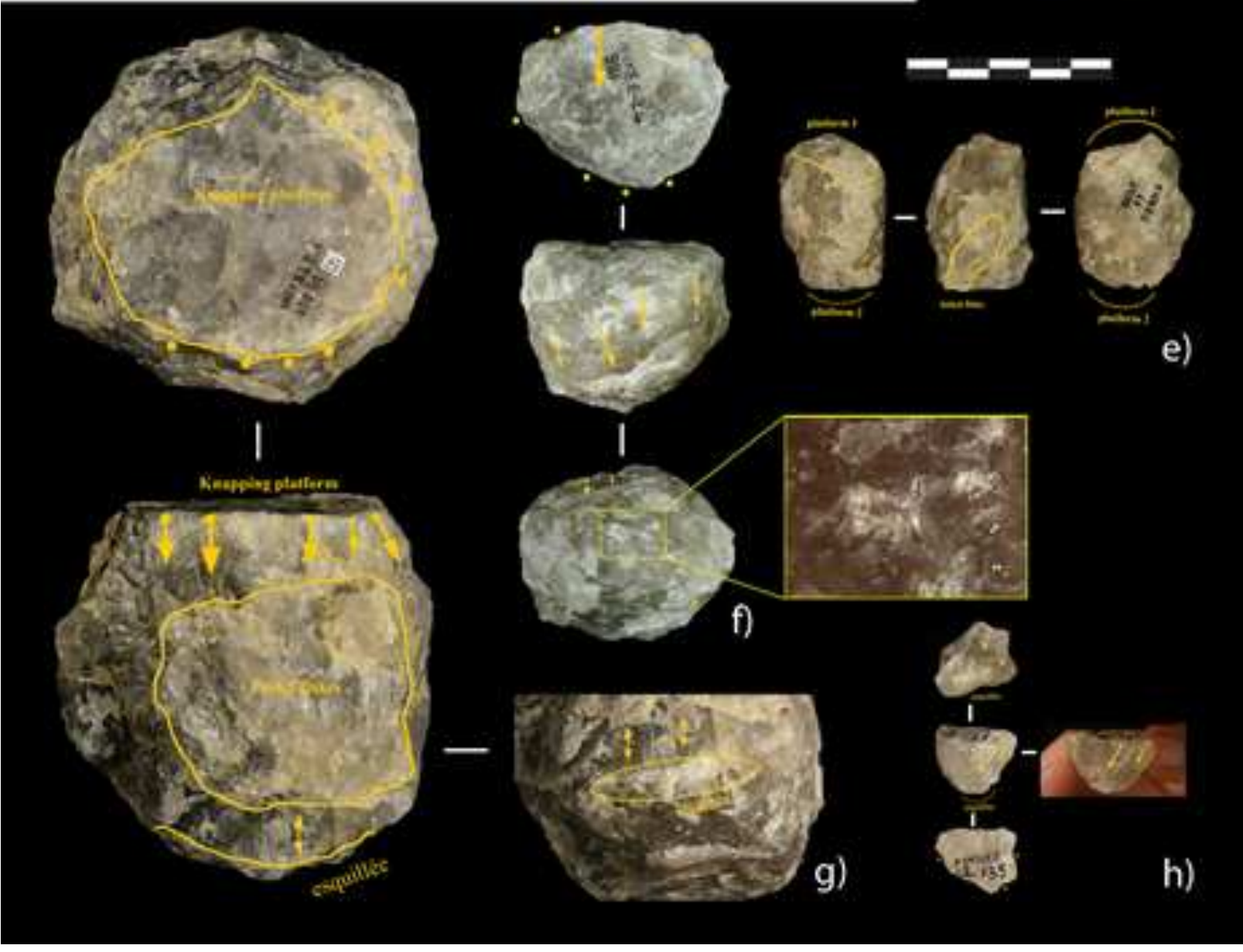


Figure_11

Click here to download high resolution image
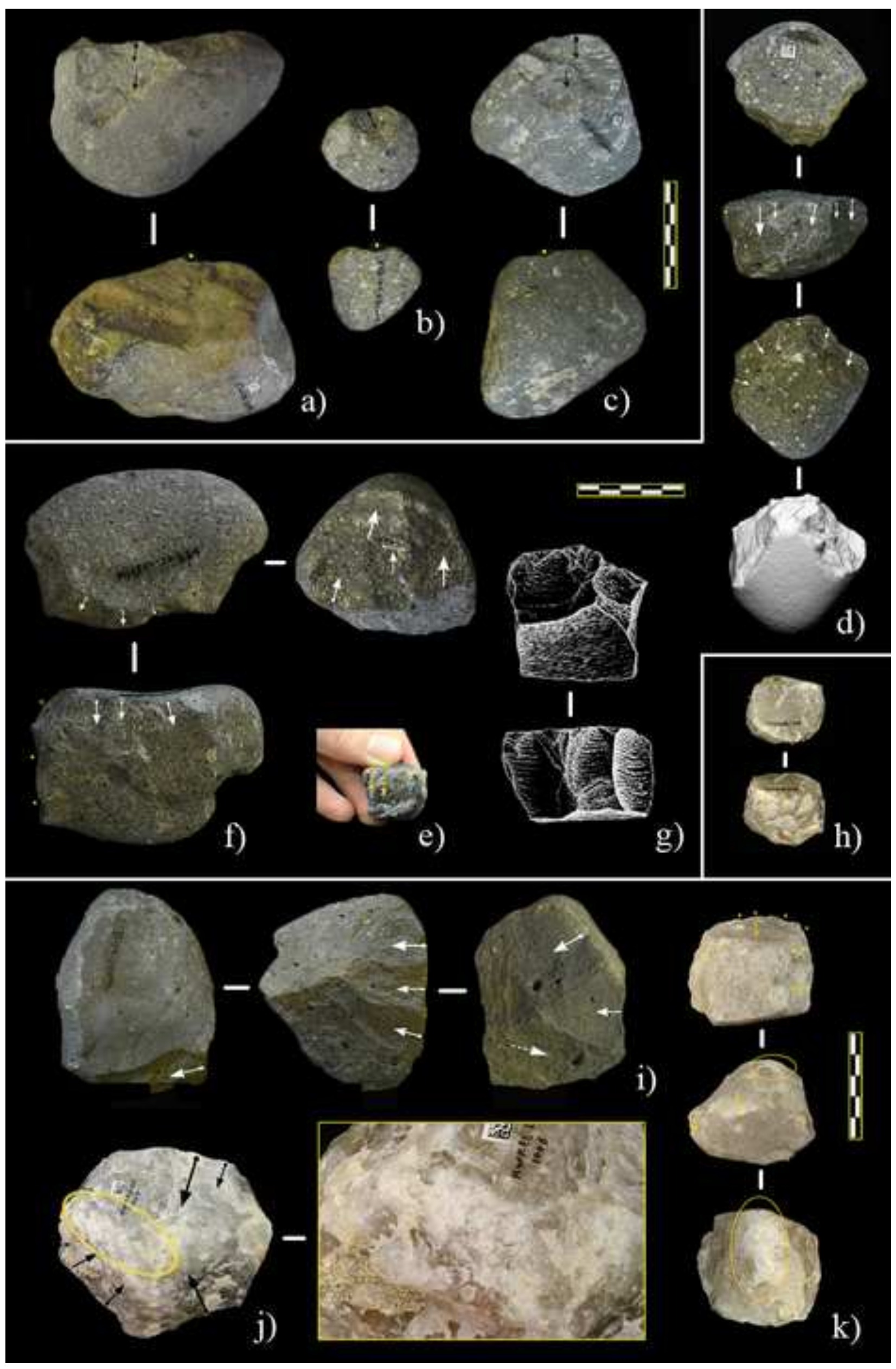

a)

e)

i)

k) 
Figure_12

Click here to download high resolution image
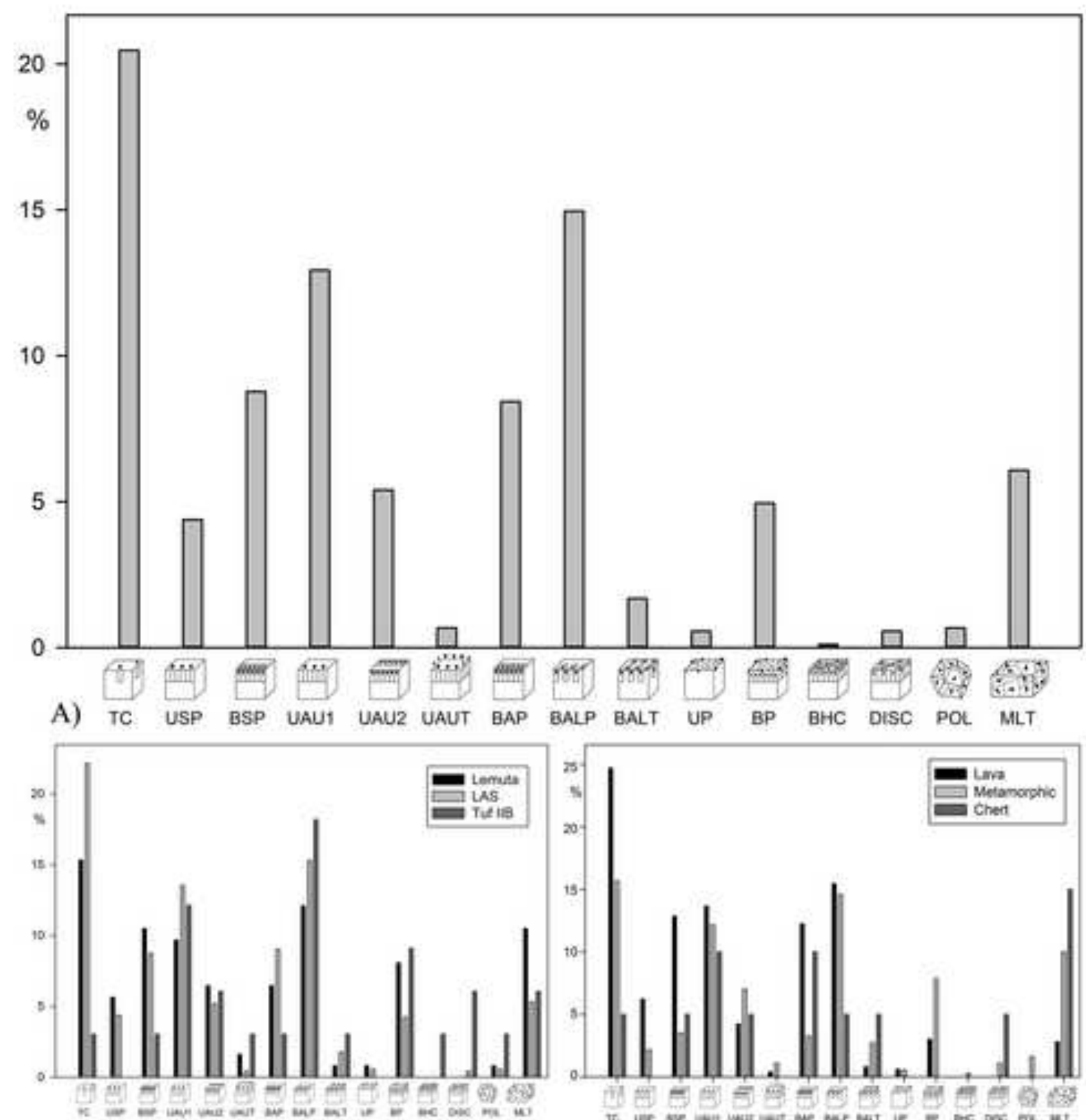

B)

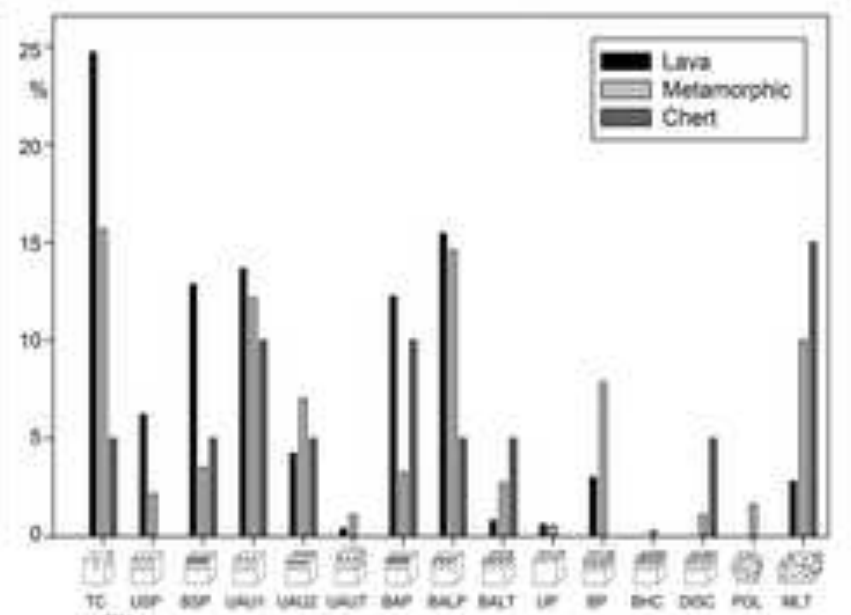

C)

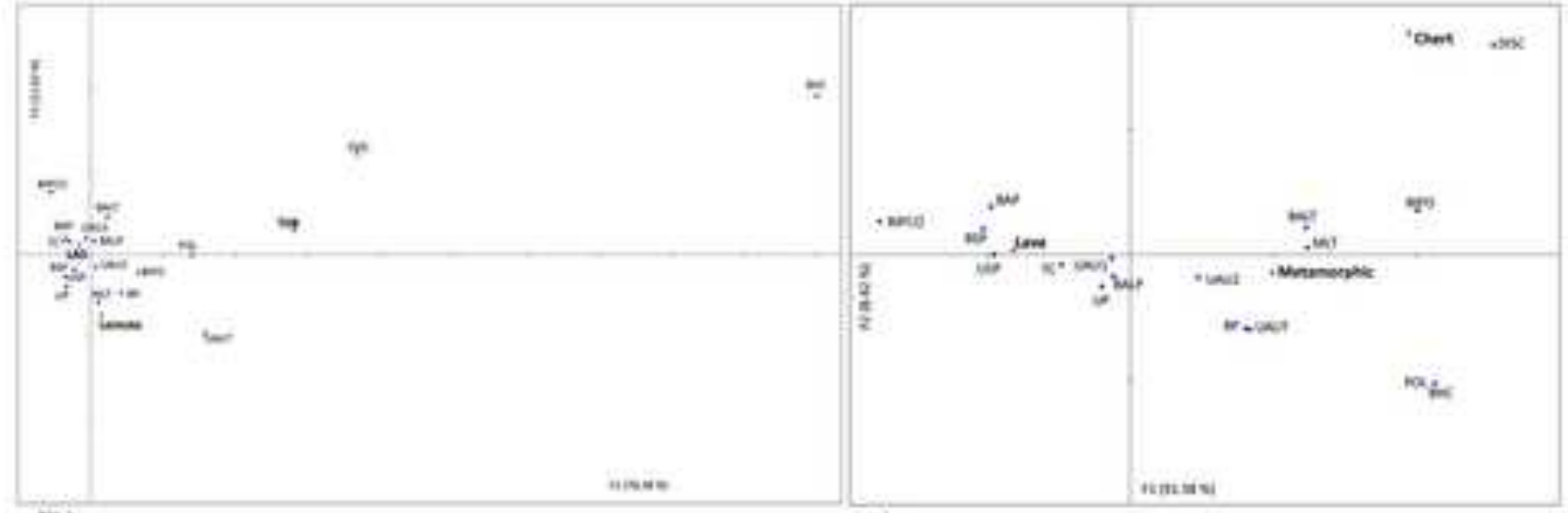

D)

E) 
Figure_13

Click here to download high resolution image

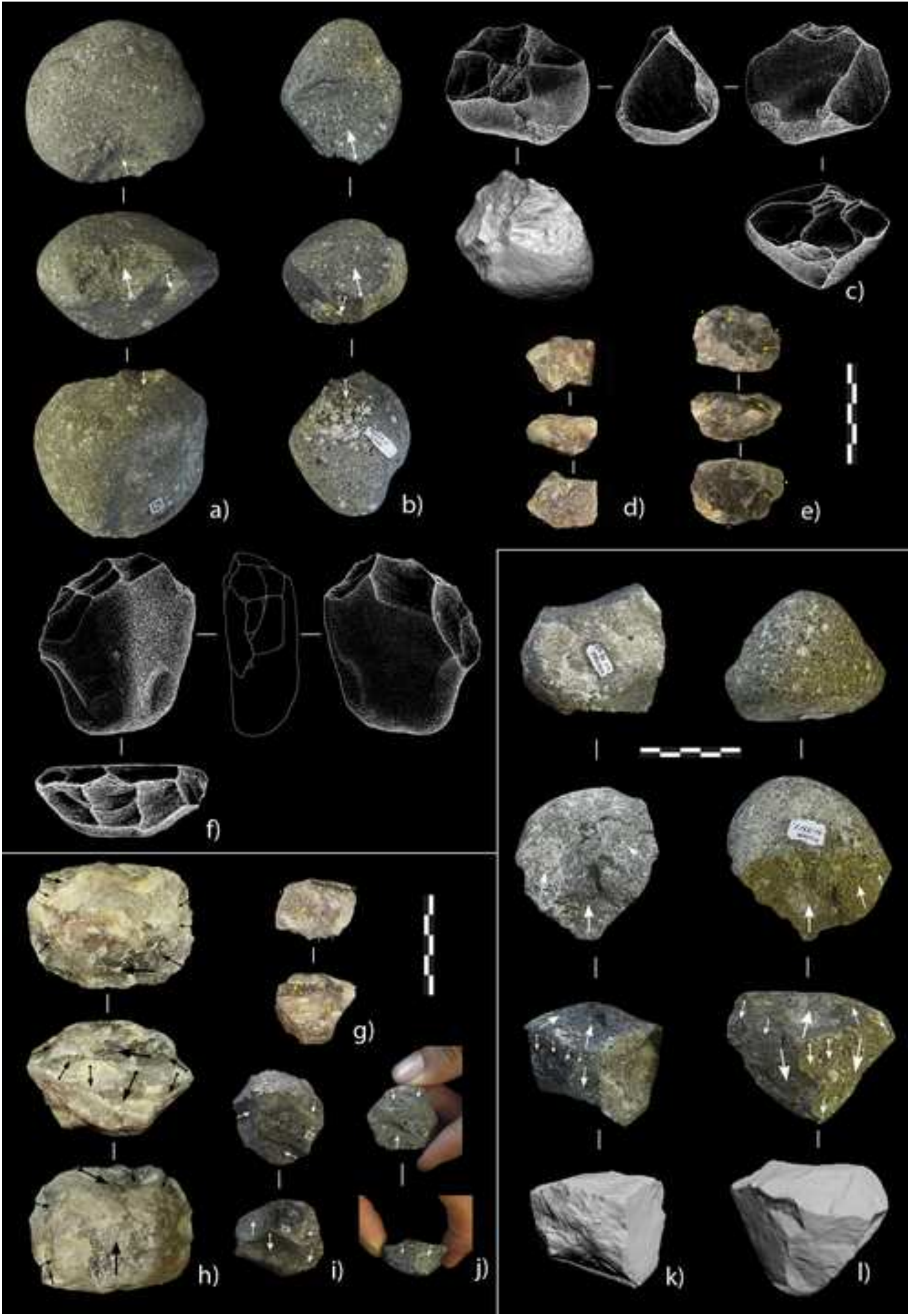


Click here to download high resolution image

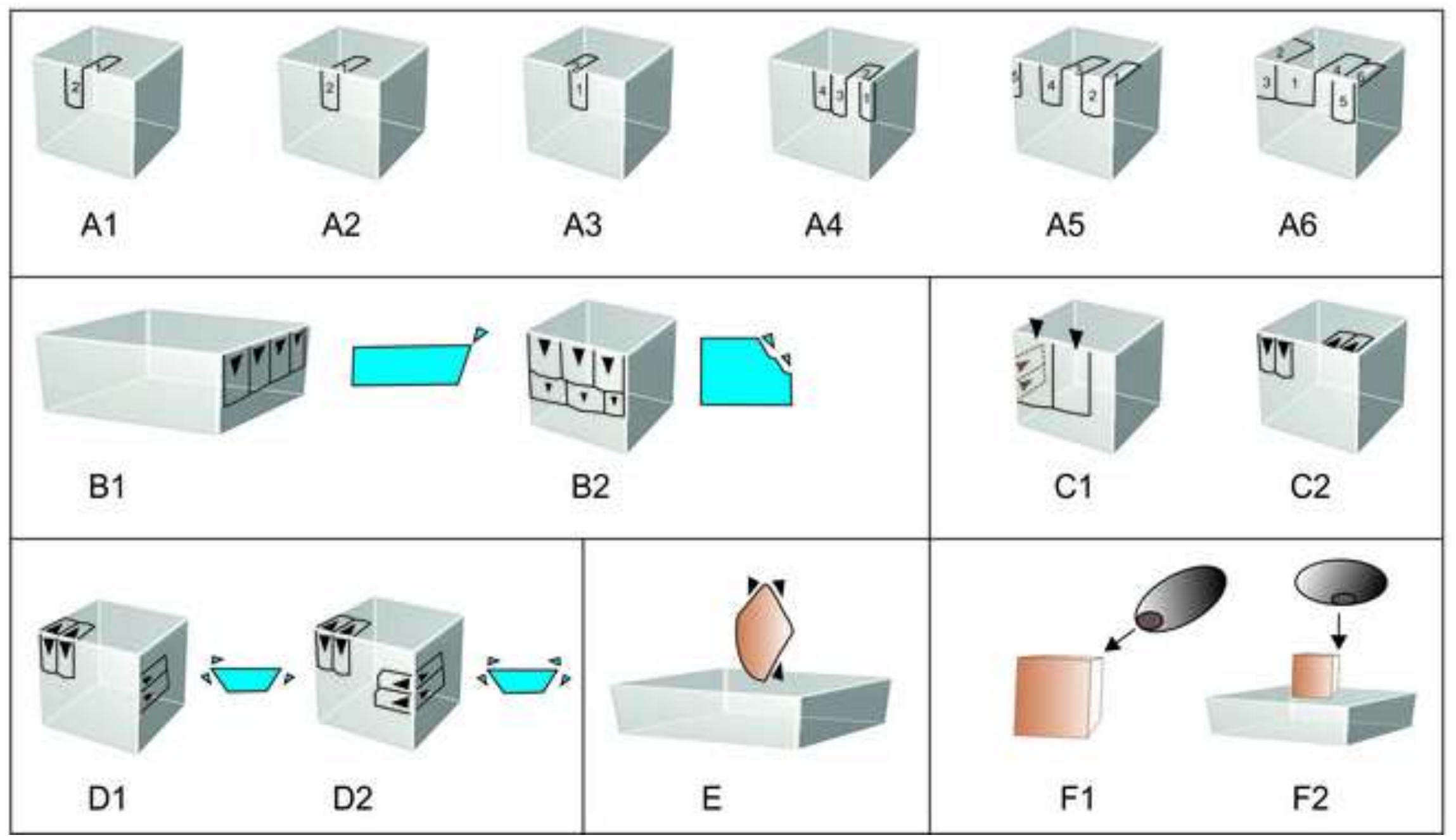


Figure_15

Click here to download high resolution image
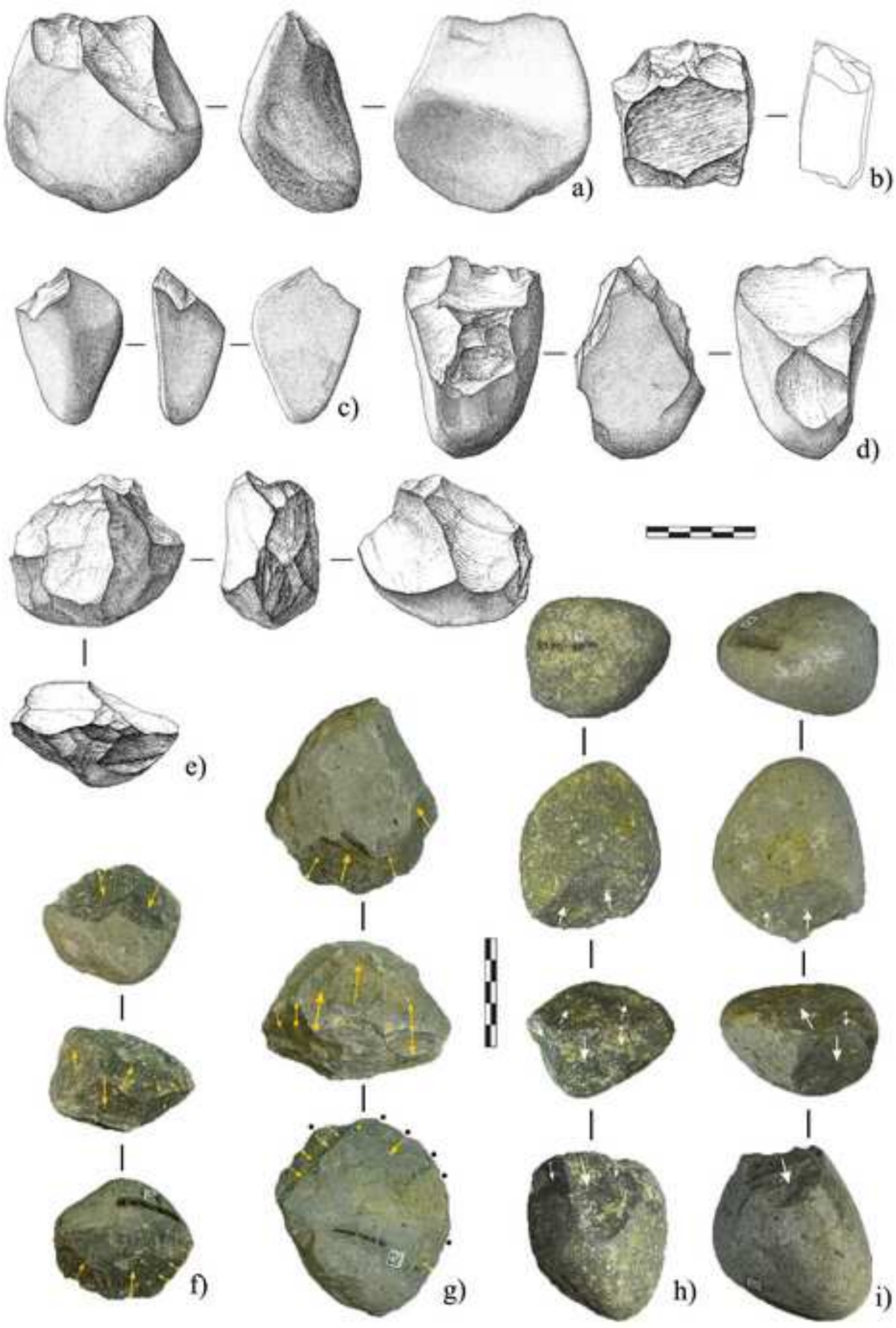


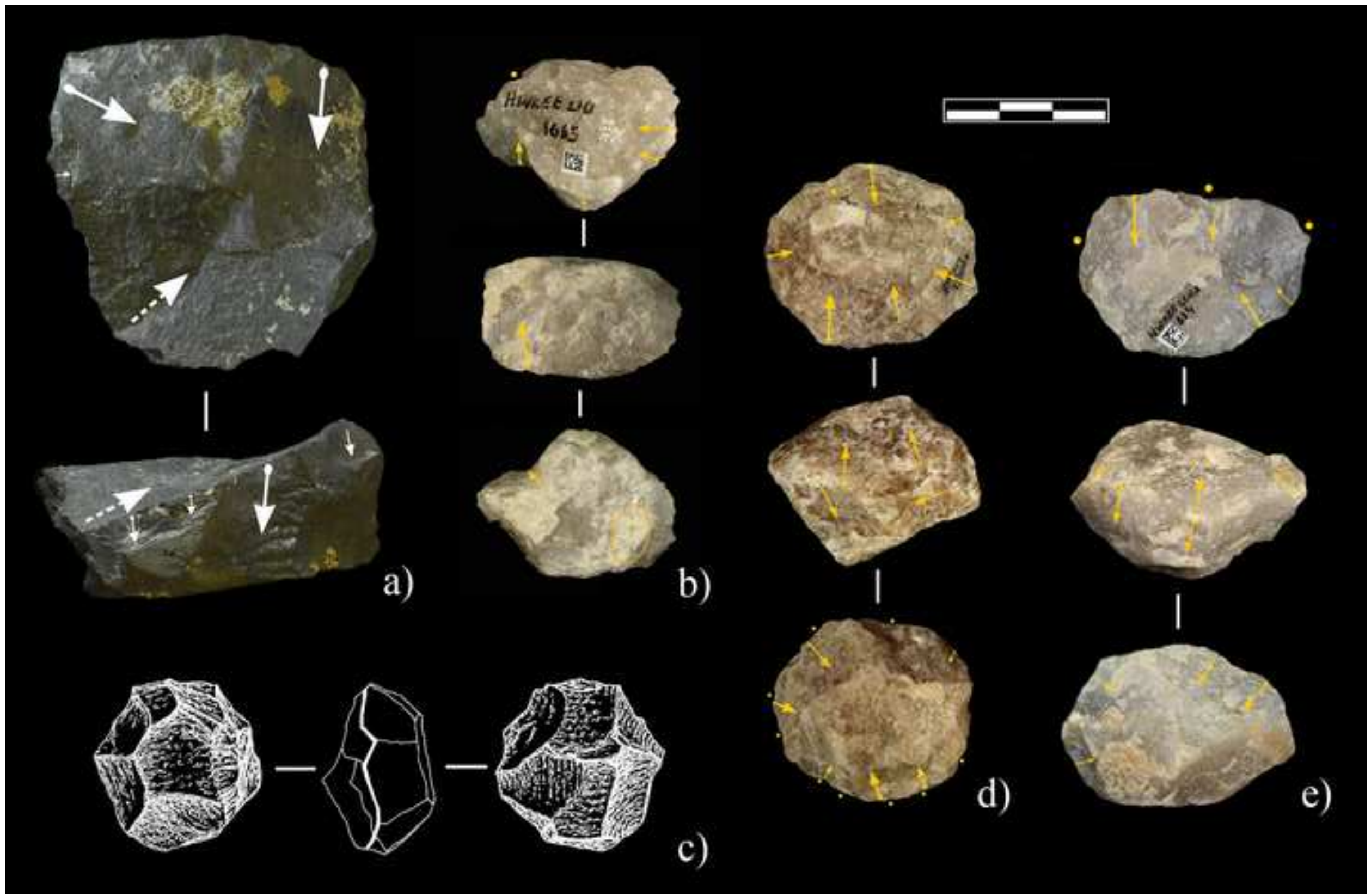

c)

.


Figure_17

Click here to download high resolution image
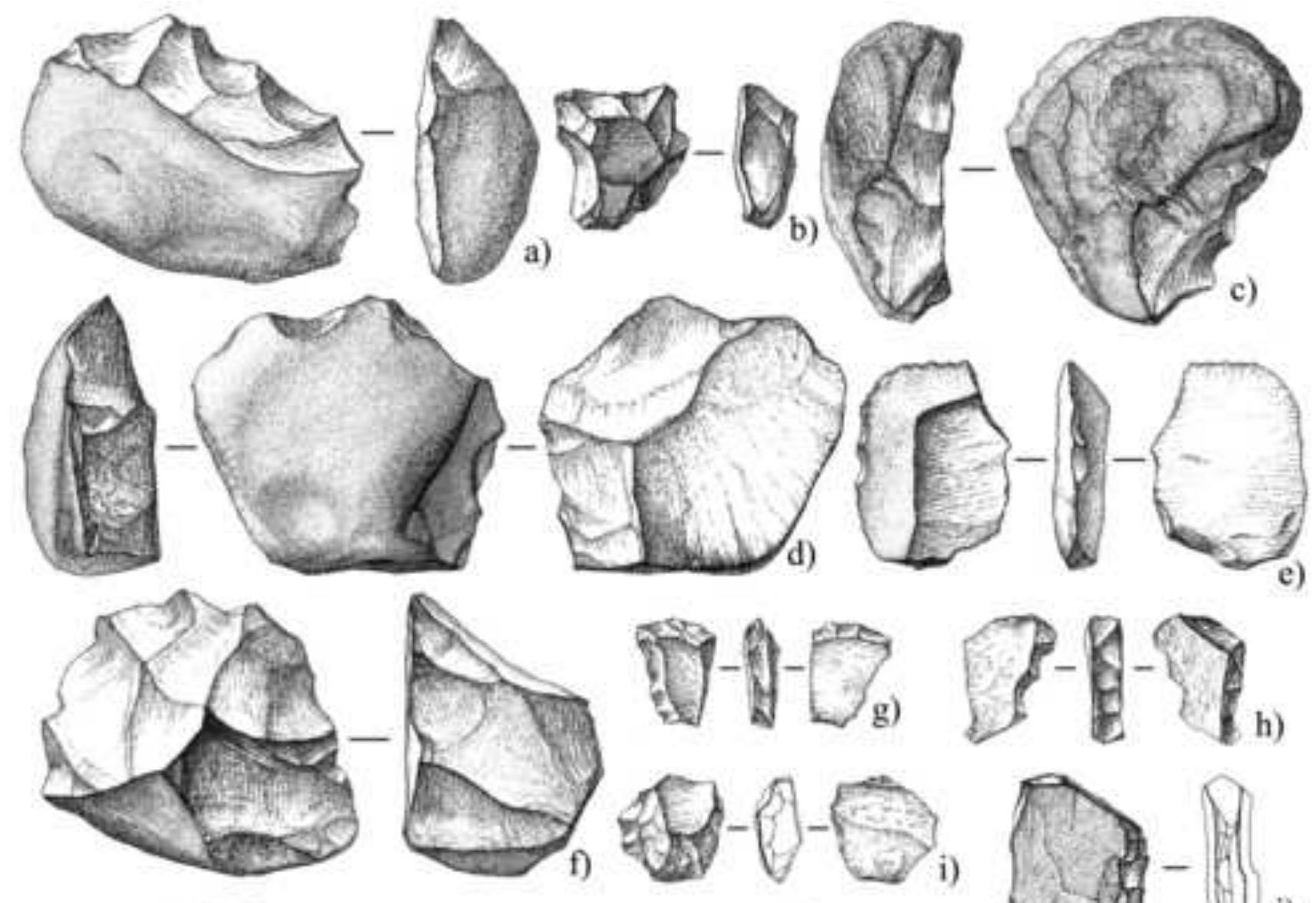

$28-8$
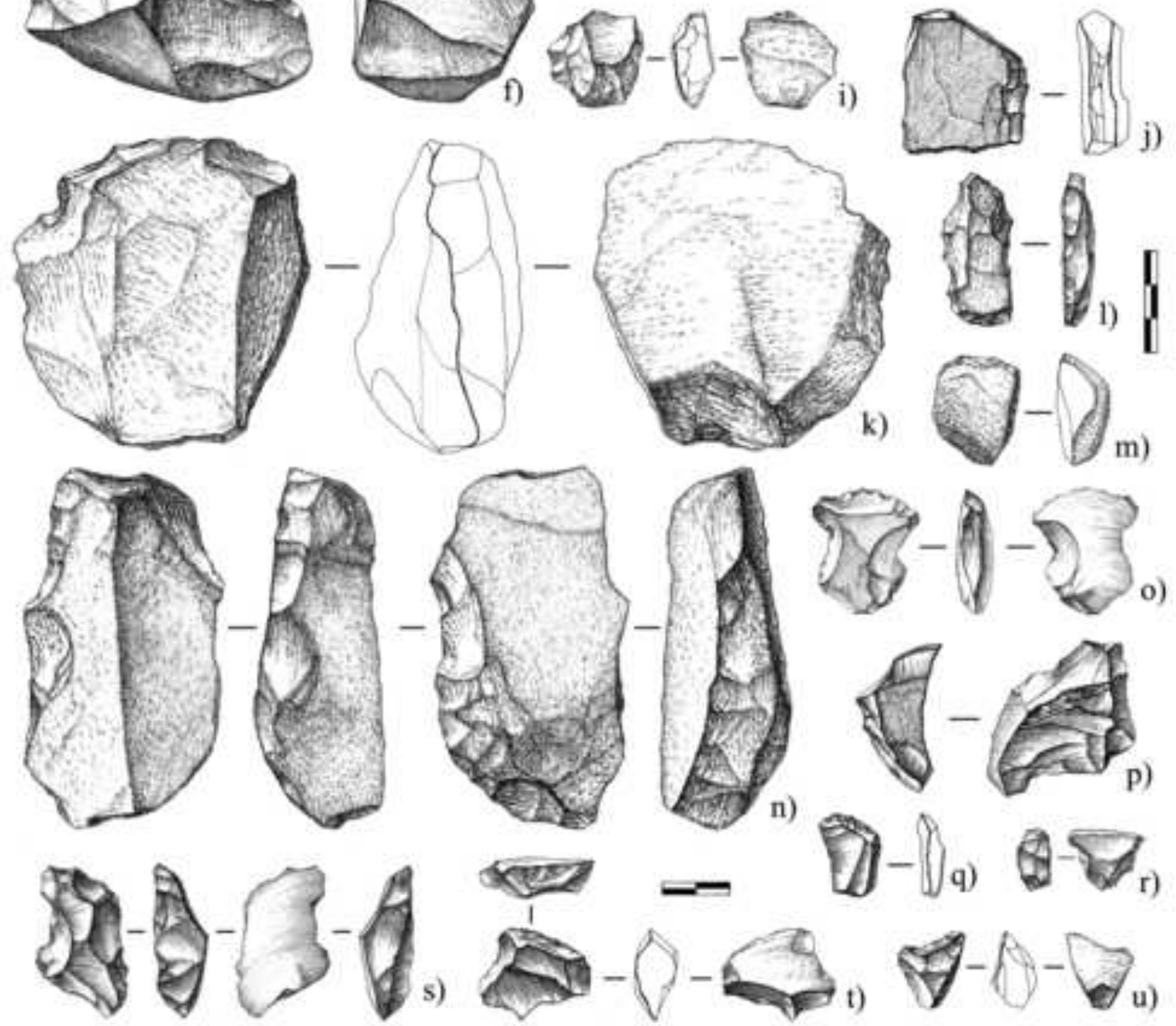

s)

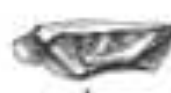

$$
\left.2-\int q\right) \quad 8-q_{r}
$$

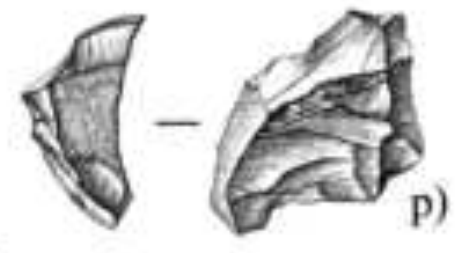



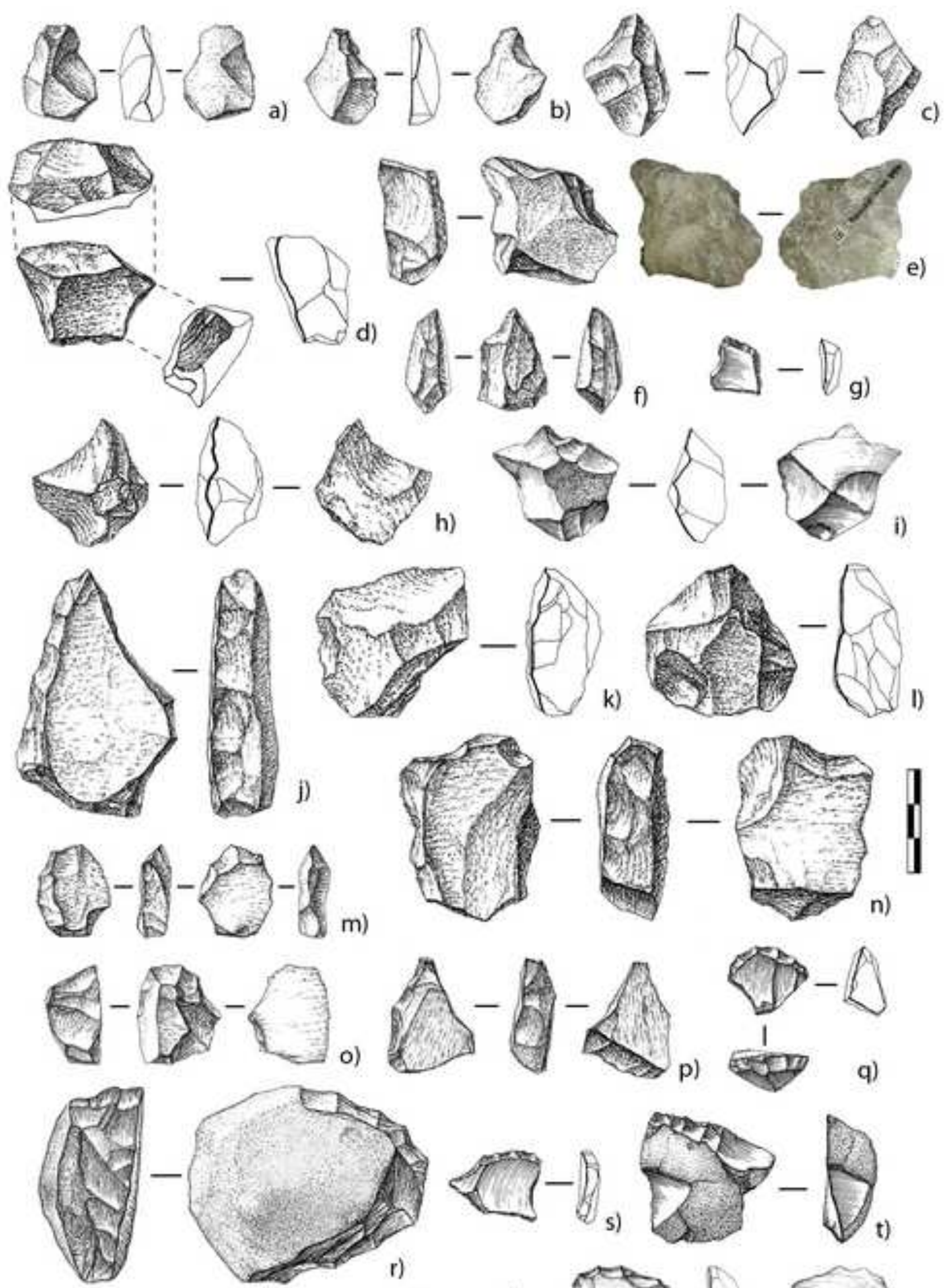

19-8)- -3

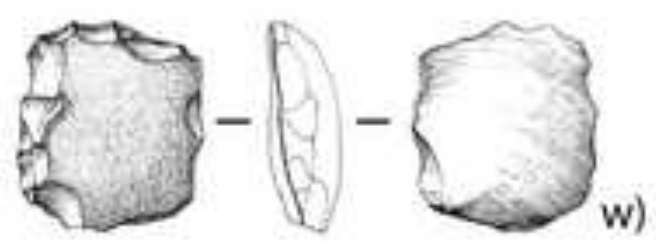


Figure_19
Click here to download high resolution image
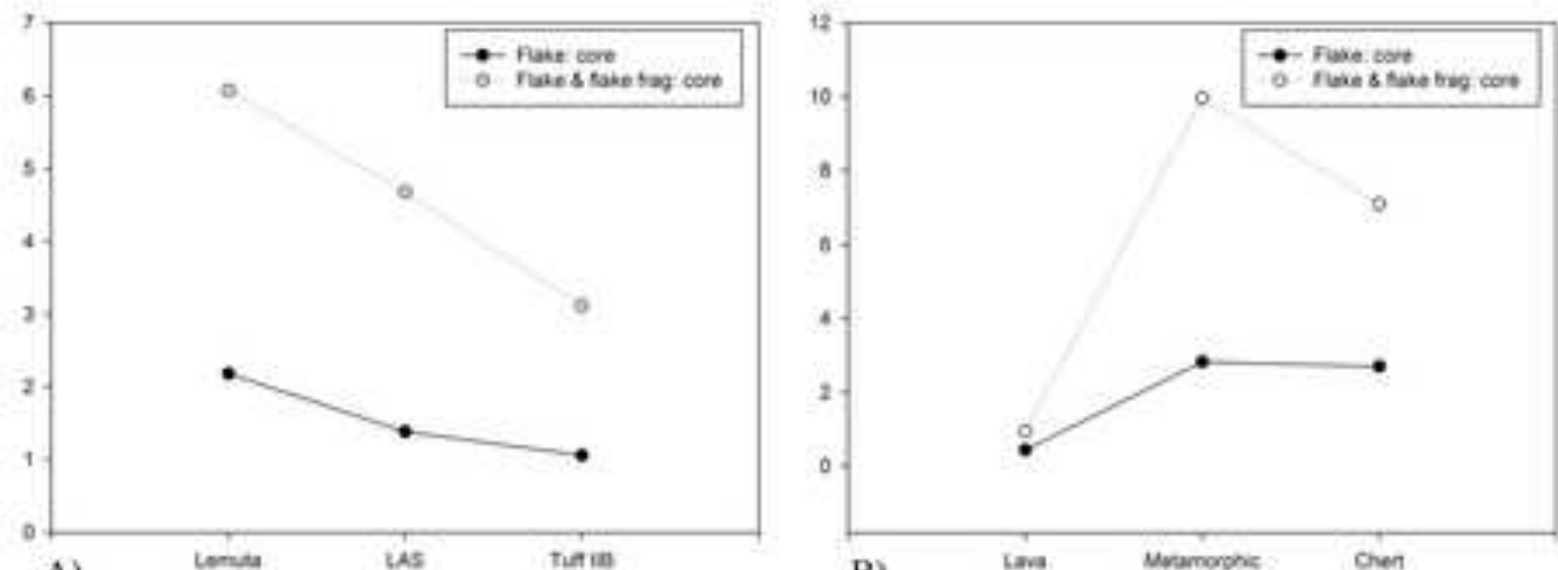

A)
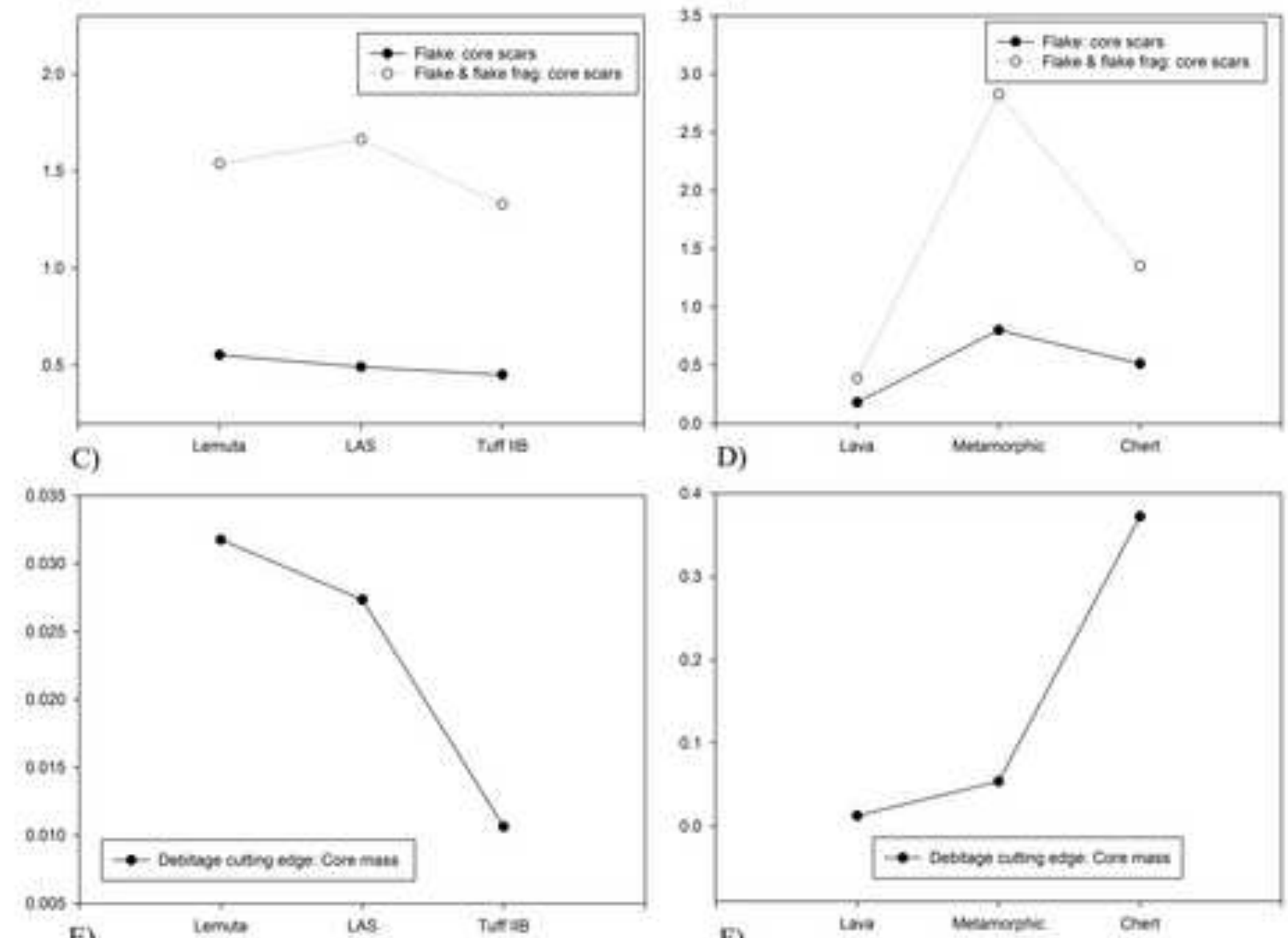

E)

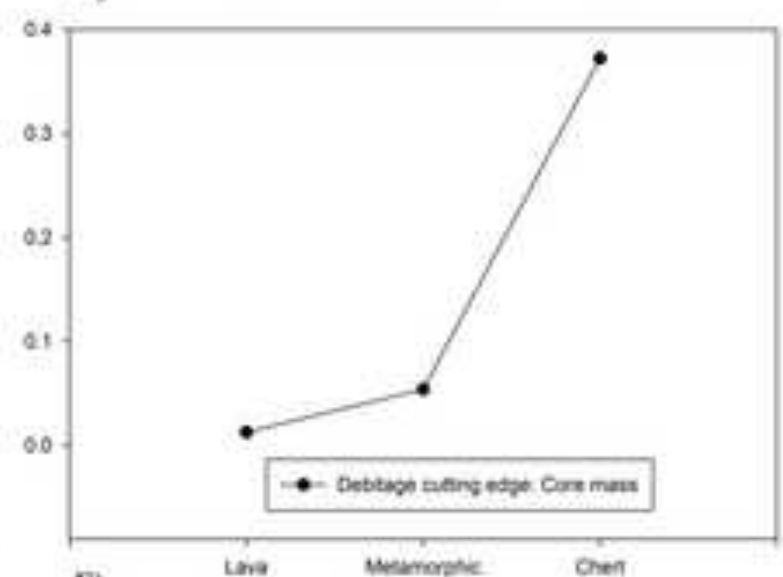

F)
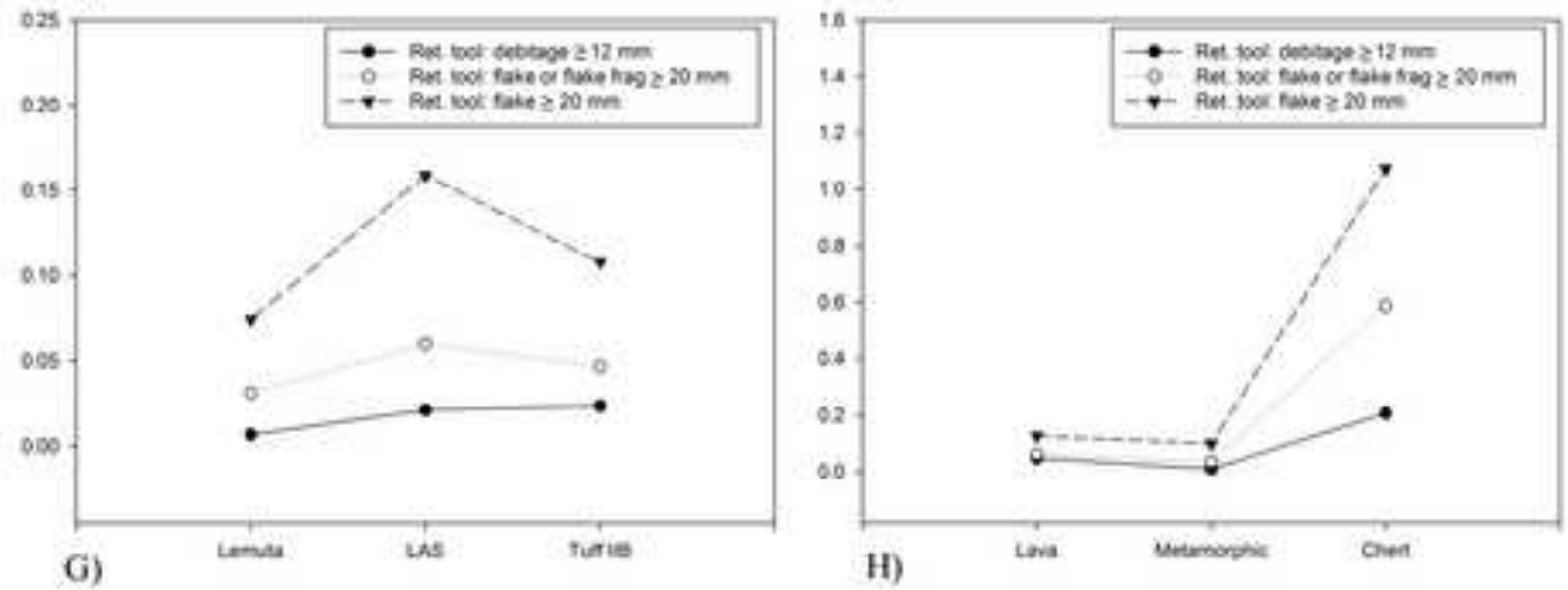
OQAOROAQOGEQ

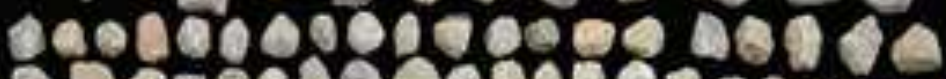

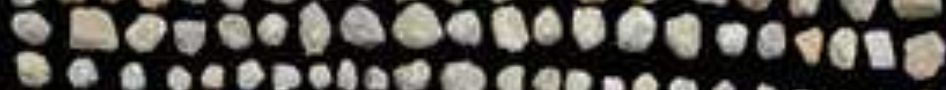

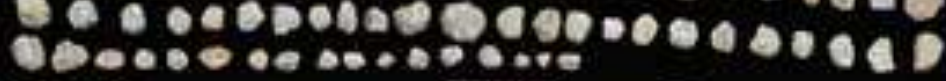

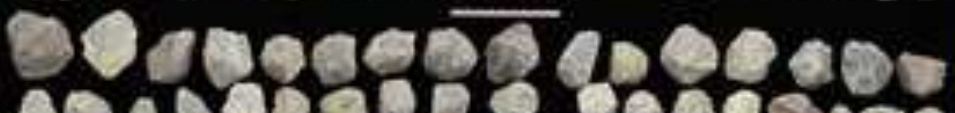

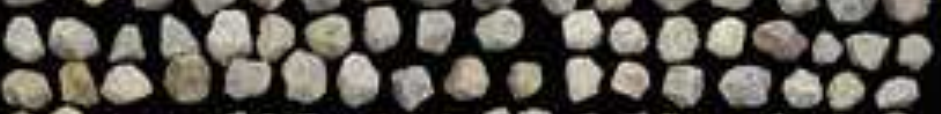

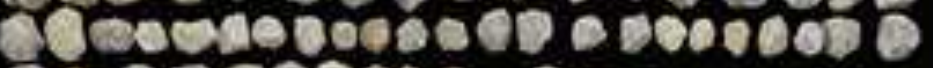

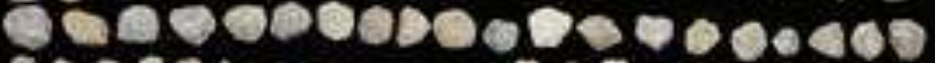

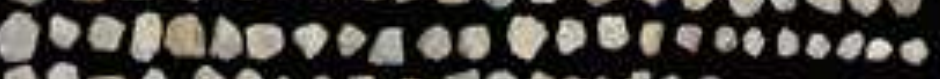

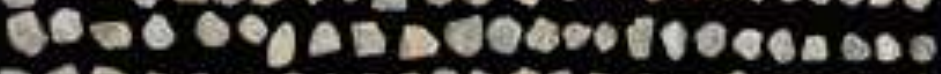

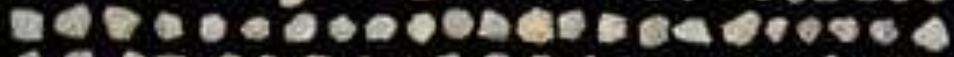

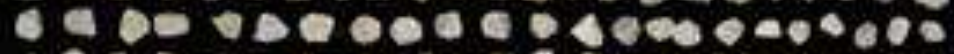

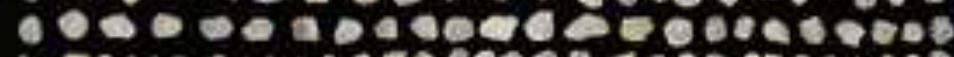

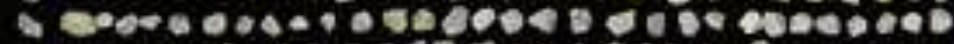

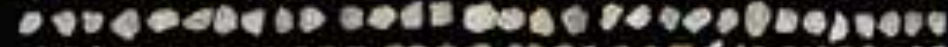

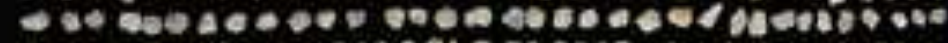

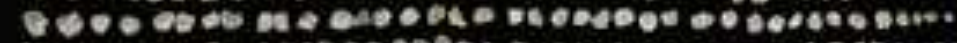

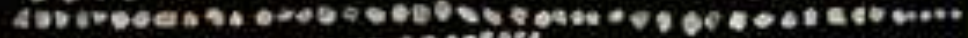

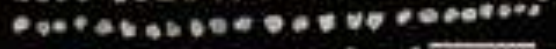

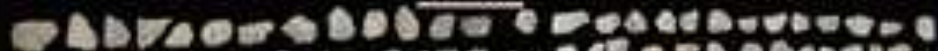

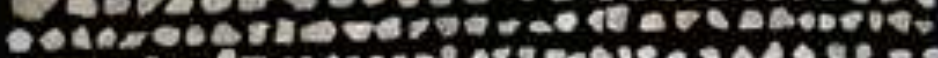

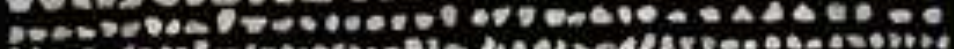

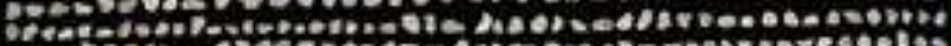

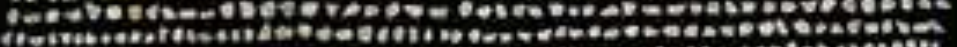

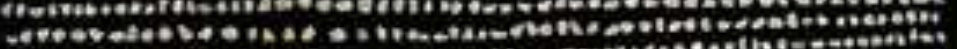

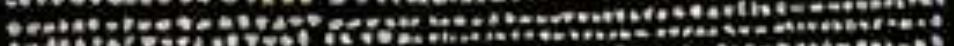


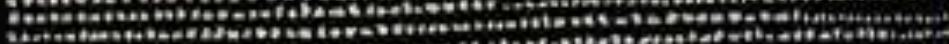

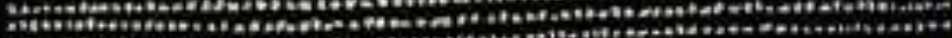
жын

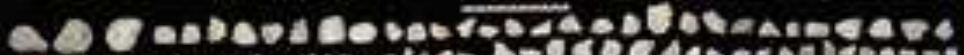

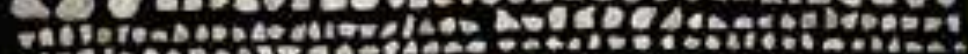

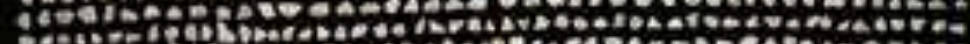

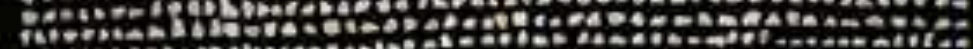
201.

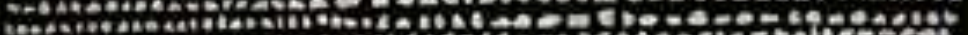

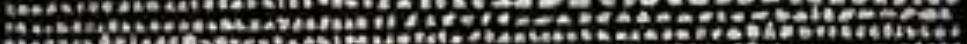
1.4. स.+.

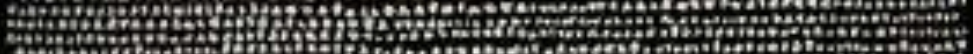
Fin

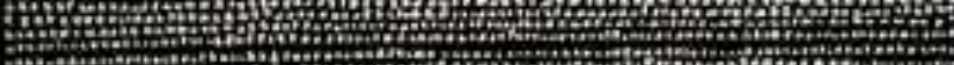

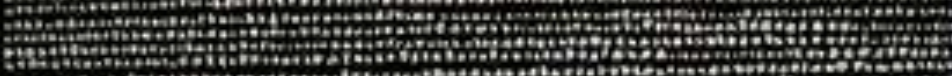

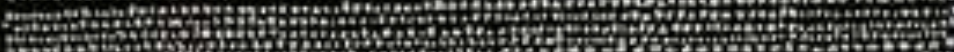
(1)

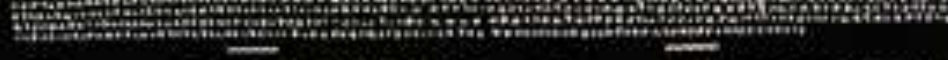

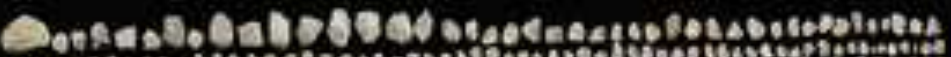

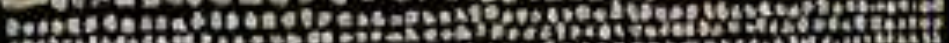

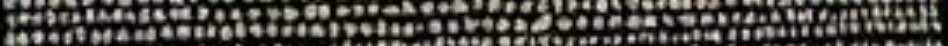

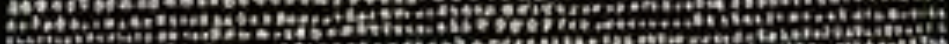
A H

D.

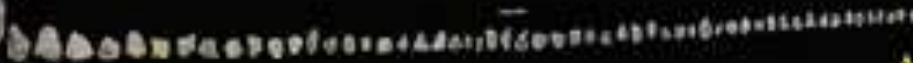

antwan- A)

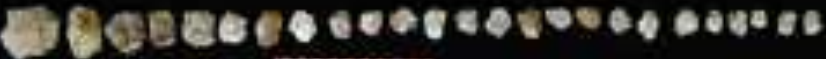

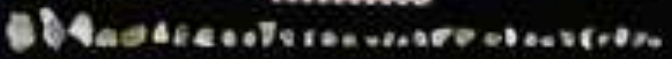

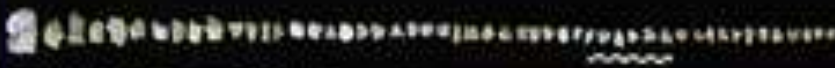

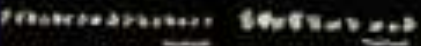

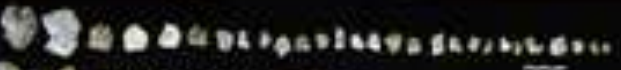

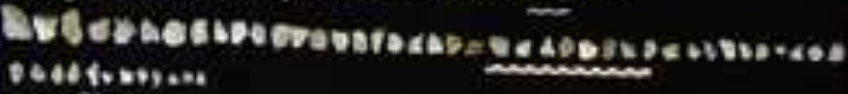

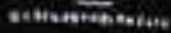

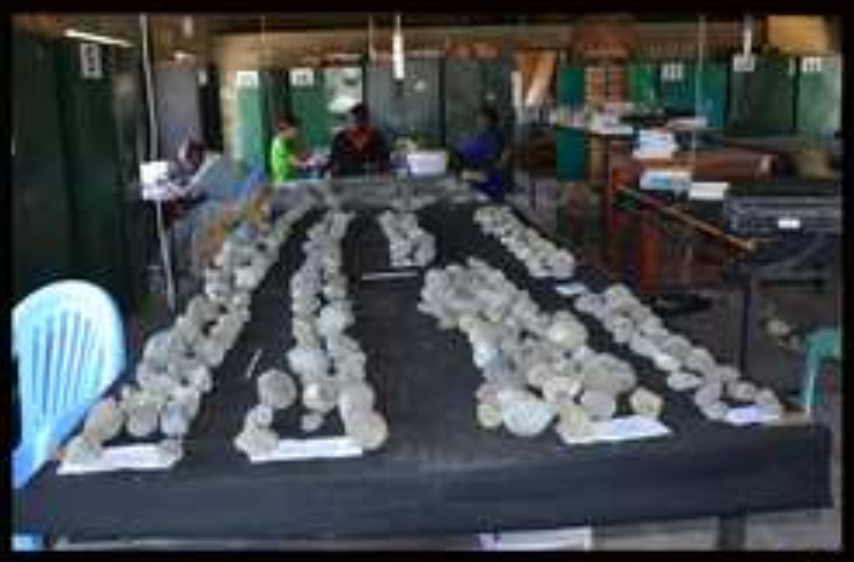

C)

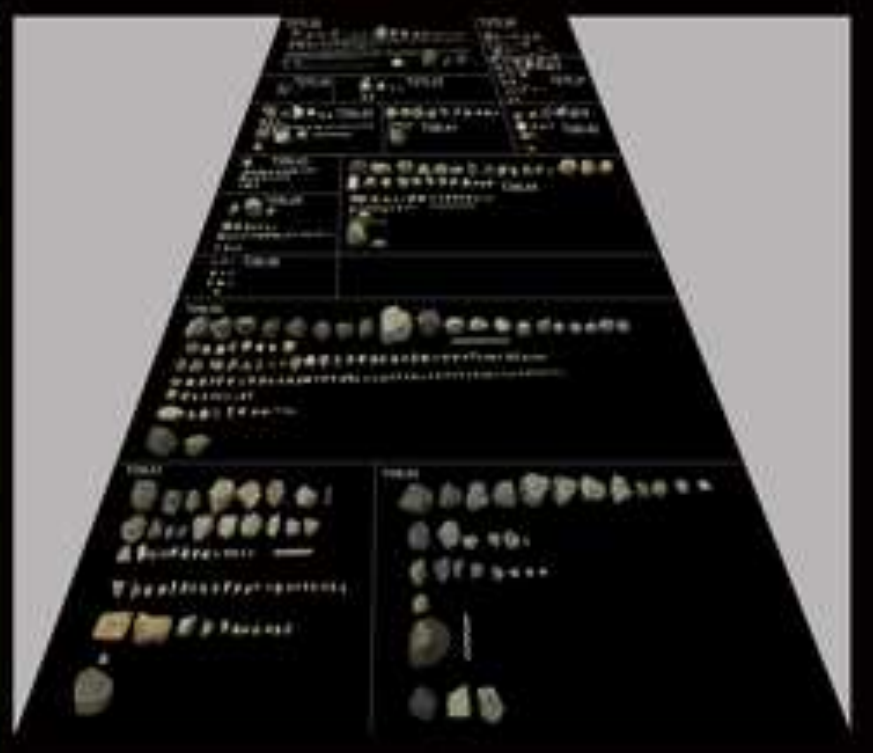




\section{Click here to download Supplementary Material: Suppl_Mat_Online.pdf

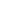




\section{Editorial Use: Not for Production}

Click here to download Editorial Use: Not for Production: Instructions_for_Production.docx 